\title{
Estimating Future Costs for Alaska Public Infrastructure At Risk from Climate Change
}

\author{
Prepared by \\ Peter Larsen and Scott Goldsmith, Institute of Social and Economic Research (ISER), UAA \\ Orson Smith, Civil Engineering Department, UAA \\ Meghan Wilson, ISER, UAA \\ Ken Strzepek, University of Colorado at Boulder \\ Paul Chinowsky, University of Colorado at Boulder \\ Ben Saylor, ISER, UAA \\ Sponsored by \\ University of Alaska Foundation \\ National Commission on Energy Policy, Washington D.C. \\ Alaska Conservation Foundation, Anchorage, Alaska \\ Rural Alaska Community Action Program, Anchorage, Alaska
}

June 2007

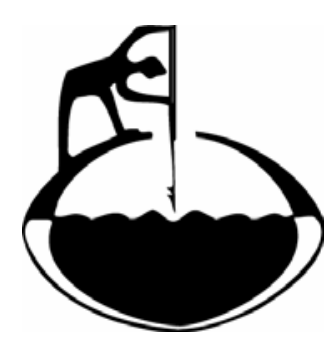

Institute of Social and Economic Research

University of Alaska Anchorage

3211 Providence Drive, Anchorage, Alaska 99508

www.iser.uaa.alaska.edu 

50 years ago I used to swear at my dog team. Today, I swear at my computer. [Climate] change is change and you must adjust to it. My generation survived a lot. It's been all uphill in the North since then. I have great confidence in your generation.

Walt Parker at 2005 Snowchange Conference

The nation behaves well if it treats resources as assets which it must turn over to the next generation increased, and not impaired, in value.

Theodore Roosevelt, 1910 



\section{ACKNOWLEDGMENTS}

We could not have completed this research without help and insight from many people. First, we thank the sponsors of our research, including Sasha Mackler at the National Commission on Energy Policy; Shauna Hegna at the Rural Alaska Community Action Program; Susanne Fleek and Deborah Williams, formerly of the Alaska Conservation Foundation; and the University of Alaska Foundation.

We also thank Professors Benoit Mandlebrot and Robert Repetto of Yale University, who provided constructive feedback during our early modeling efforts. Professors Gary Yohe of Wesleyan University and Dan White of the University of Alaska Fairbanks provided external peer review of our methodological approach. Joel Smith and Carolyn Wagner at Stratus Consulting provided technical advice and suggestions for the climate projections. SAS programming experts from the University of Georgia's SAS-LISTSERV provided invaluable advice for the life-cycle analysis component of this model. Katriina Timm helped us with the mapping output for the project. Bruce Sexauer and Lorraine Cordova of the U.S. Army Corps of Engineers gave us insight into the rates of coastal erosion for many communities most affected by climate change. Janusz Strzepek provided programming support for the University of Colorado team.

Claudia Tebaldi and Seth McGuiness at the Institute for the Study of Society and the Environment at the National Center for Atmospheric Research (NCAR) provided us with 21 regional projections of climate change. Without the collaboration between Joel Smith and researchers at NCAR to attain these climate projections for Alaska, we would not have been able to present our results in a way meaningful to policymakers.

We also gratefully acknowledge the support of faculty and staff at the Institute of Social and Economic Research (ISER). Sharman Haley, Steve Colt, Lance Howe, Gunnar Knapp, and Matt Berman provided valuable feedback throughout the course of our research. Linda Leask and Clemencia Merrill helped edit and prepare graphics for this report. Caroline Schultz, a summer intern at ISER, helped process the climate projections from NCAR. We owe the greatest debt to UAA's interim chancellor, Fran Ulmer, for her patience and trust in us during this challenging project. Her extensive knowledge of Alaska's people and places-and the issues that affect them - was of particular importance to us.

Any errors and omissions are, of course, the authors' responsibility. 



\section{CONTENTS}

Executive Summary

I. Introduction 1

$\begin{array}{ll}\text { II. } & \text { Background }\end{array}$

$\begin{array}{ll}\text { III. Climate Projections } & 17\end{array}$

IV. Public Infrastructure Database 27

$\begin{array}{lll}\text { V. ICICLE Model Description } & 37\end{array}$

VI. Adaptive Climate Response Cost Models 51

$\begin{array}{llr}\text { VII. Model Results } & 69\end{array}$

$\begin{array}{ll}\text { VIII. Future Directions of Research } & 79\end{array}$

$\begin{array}{ll}\text { IX. Conclusions } & 81\end{array}$

X. Appendix: Assumptions for Modeling Scenario 83

$\begin{array}{ll}\text { XI. References } & 85\end{array}$ 



\section{How Much Might Climate Change Add to Future Costs for Public Infrastructure?}

June 2007

UA Research Summary No. 8

By Peter Larsen and Scott Goldsmith

Institute of Social and Economic Research - University of Alaska Anchorage

Scientists expect Alaska's climate to get warmer in the coming years and the changing climate could make it roughly 10\% to 20\% more expensive to build and maintain public infrastructure in Alaska between now and 2030 and 10\% more expensive between now and 2080.

These are the first estimates of how much climate change might add to future costs for public infrastructure in Alaska, and they are preliminary.

"Public infrastructure" means all the federal, state, and local infrastructure that keeps Alaska functioning: roads, bridges, airports, harbors, schools, military bases, post offices, fire stations, sanitation systems, the power grid, and more. Privately owned infrastructure will also be affected by climate change, but this analysis looks only at public infrastructure.

A warming climate will damage Alaska's infrastructure because it was designed for a cold climate. The damage will be concentrated in places where permafrost thaws, flooding increases, and coastal erosion gets worse. But the extra costs will likely diminish over time, as government agencies increasingly adapt infrastructure to changing conditions.

Keep in mind that we're not projecting how much Alaska's climate may change in the future. Scientists from around the world are doing that. We're estimating how much the future costs for public infrastructure in Alaska might increase, based on what scientists expect to happen.

The estimates are from a model we developed with UAA's School of Engineering and the University of Colorado at Boulder. They are in net present value, a method of estimating costs over long periods. (See note in Figure 1.)

- Even without climate change, costs of maintaining and replacing public infrastructure in Alaska are considerable —an estimated \$32 billion between now and 2030 and \$56 billion between now and 2080.
- Damage from climate change could add \$3.6 to \$6.1 billion (10\% to 20\%) to future costs for public infrastructure from now to 2030 and $\$ 5.6$ to $\$ 7.6$ billion (10\% to 12\%) from now to 2080. These estimates take into account different possible levels of climate change and assume agencies adapt infrastructure to changing conditions.

- Extra infrastructure costs from climate change in the next 25 years will mostly be for maintaining or replacing roads, runways, and water and sewer systems. Those types of infrastructure are most vulnerable to thawing permafrost, flooding, and coastal erosion — and they're expensive to replace.

We're publishing these estimates, even though they're preliminary, because they show the magnitude of extra costs agencies could face and the potential value of efforts to mitigate climate change. We also hope they will stimulate more efforts to better understand and measure the problem.

We plan to improve both our modeling techniques and cost estimates in the future. To make those improvements, we need more information about existing infrastructure. We also need to refine our methods for estimating effects of climate change on building conditions and to learn more about techniques for adapting infrastructure. The climate projections we used are among the best available today — but as time goes on scientists will learn more about climate trends and will update their projections.

In the following pages we start by providing background about recent climate change in Alaska, using data from the Geophysical Institute at the University of Alaska Fairbanks. Next we discuss the climate projections that are the basis for our estimates, then describe the steps involved in creating our life-cycle model. Finally, we present our preliminary estimates of future infrastructure costs in more detail.

Figure 1. How Much Might Climate Change Add to Future Costs for Public Infrastructure in Alaska?
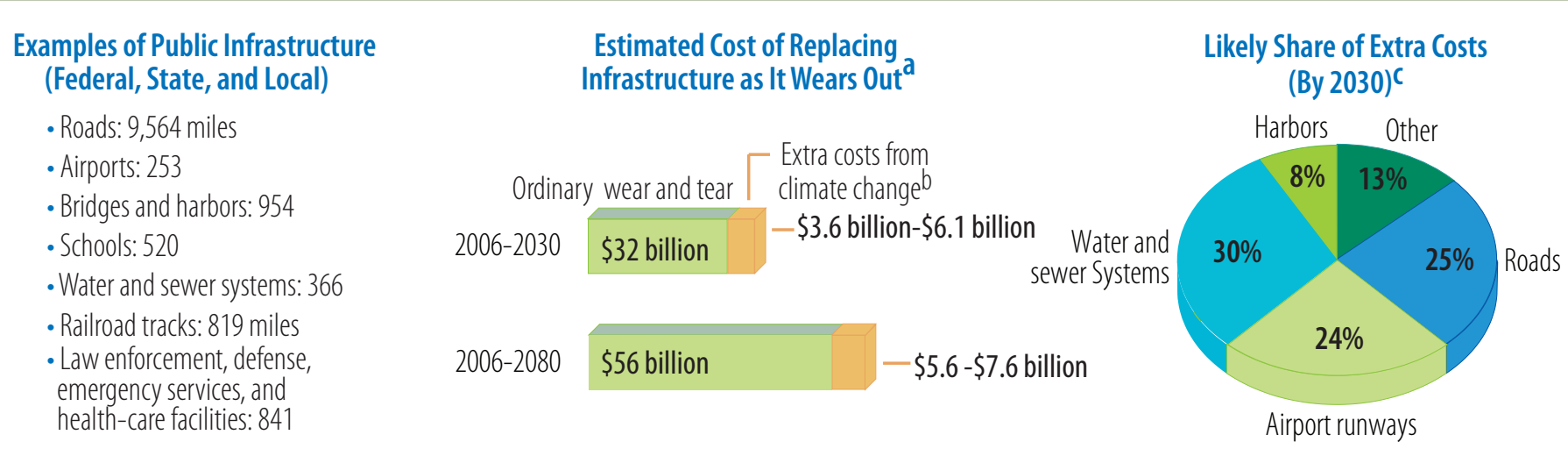

aThese estimates are in net present value, which is a standard way of summarizing potential costs over long periods. Think of it as the amount that would need to be deposited in a bank today, earning interest, to cover all the costs for a project (or some other purpose) over a specified future period. ${ }^{b}$ Depends on the level of climate warming and takes likely design adaptations into account. ${ }^{C}$ Assumes moderate climate warming 


\section{What is Happening?}

Alaska's climate has gotten warmer in recent decades. Map 1 shows that average annual temperatures around Alaska increased from 2 degrees to 5 degrees Fahrenheit from 1949 to 2005. Climate models project that both temperature and precipitation will continue increasing in Alaska. The recent climate change was more pronounced in the Arctic than it was elsewhereand scientists also expect future change to be more substantial in the Arctic.

The Intergovernmental Panel on Climate Change has concluded that people are responsible for much of the warming climate worldwide, by putting $\mathrm{CO}_{2}$ and other greenhouse gases into the atmosphere. But natural climate variability and other factors also contribute. The findings aren't as definite at the scale of Alaska, but scientists believe much of the warming in the Arctic is probably also due to human activities, with natural variability playing a role.

Warmer temperatures will affect both natural and man-made systems in Alaska, with many economic and social consequences. One effect will be to increase building and maintenance costs for public infrastructure, although not all areas or all infrastructure will be equally affected.

\section{About the ISER Model}

With help from engineers at the University of Alaska and researchers at the University of Colorado, we created a model to begin assessing how much climate change could add to the future costs for Alaska's public infrastructure. We didn't attempt to estimate the economic value of mitigating greenhouse gases. We just looked at potential extra costs for infrastructure, given the projected changes in climate. Here are a few important points about our current model.

- The model deals with uncertainty about climate change by incorporating a range of climate projections. It also takes into account the natural variability in temperature and precipitation from year to year.

- The model uses thawing permafrost, increased flooding, and more coastal erosion to gauge damage to infrastructure.

- As a basis for estimating costs, the model uses the life span of infrastructure. We assume warming temperatures mean infrastructure has to be replaced more often. (It's also possible that the changing climate could actually increase the life of some structures, but we haven't so far identified any such exceptions.)

- These preliminary estimates are based on costs of replacing existing infrastructure as it wears out, in existing communities. So far we haven't estimated how the amount and location of public infrastructure might change in the future.

- The model assumes that costs of replacing any given type of infrastructure - say, schools — are the same statewide. We know that costs in remote areas are higher, but in our initial work we weren't able to account for such cost differences.

- Assumptions about future inflation and other factors, as well as characteristics of the model, are summarized in Table 4 on page 8.

\section{Steps in Building the Model}

Building the ISER model required several steps: (1) acquiring climate projections; (2) creating a database of public infrastructure throughout Alaska; and (3) estimating the replacement costs and life spans for existing infrastructure, with and without the effects of climate change.

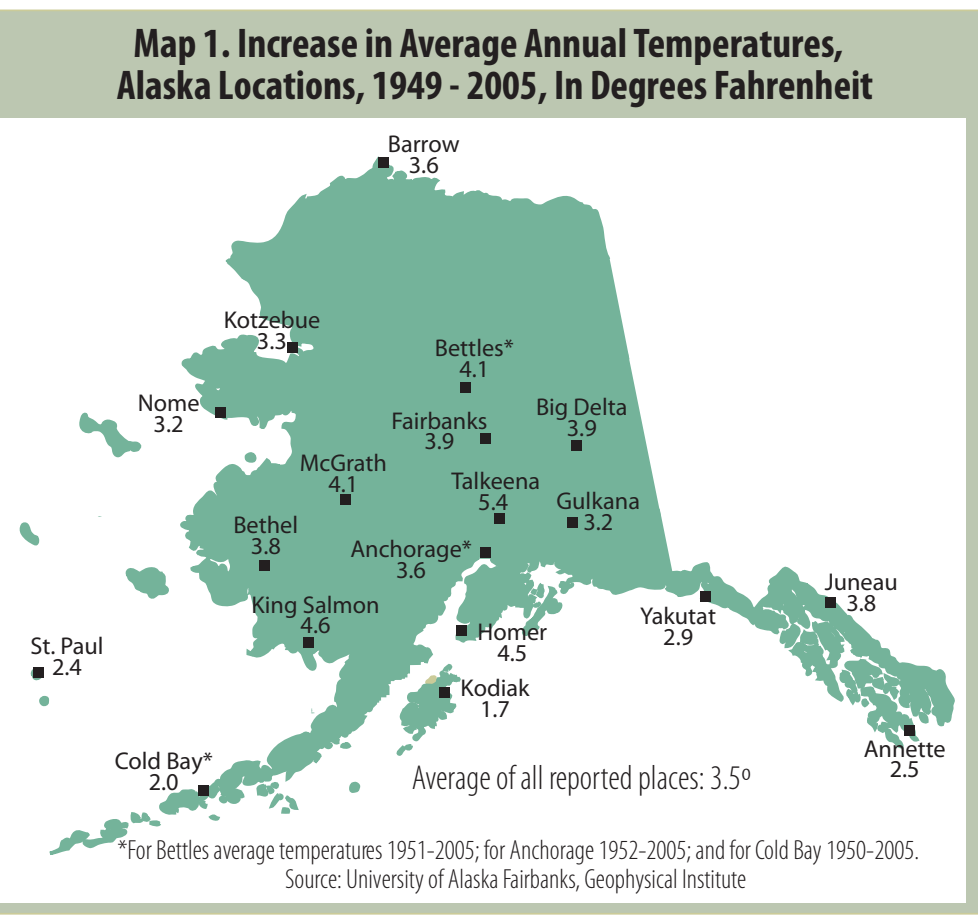

\section{Climate Projections: What's Expected?}

To start our analysis, we needed to know what experts see for the future. In 2000, the Intergovernmental Panel on Climate Change (IPCC) issued a Special Report on Emissions Scenarios, which laid out a range of climate scenarios, each with specific assumptions about future levels of greenhouse gas emissions, population growth, and much more. One of those scenarios is known as the A1B scenario. That scenario is considered middle-of-the-road, and scientists from many countries use it when making climate projections.

Joel Smith, one of the authors of a more recent IPCC report — the 2007 Fourth Assessment Report - asked the Institute for the Study of Society and the Environment at the National Center for Atmospheric Research to provide ISER with projections from 21 climate models based on the A1B scenario. He also recommended three of those projections for use in our analysis.

Figure 2 shows how the three climate projections we used — warm, warmer, and warmest - fit into the pattern of all 21 projections for Barrow in 2080. The warm model projection is from Australia, the warmer model projection is from the U.S. National Oceanic and Atmospheric Administration, and the warmest model projection is from Japan. (See back page for complete citations.) Notice that under any of the projections, temperatures around Barrow are expected to rise enough by 2080 that break-up of ice will come earlier and freeze-up later than today.

For this initial work, the National Center for Atmospheric Research provided us with projections for six representative locations around Alaska. (In later work, we plan to incorporate projections for more locations.) For areas where we didn't have projections, we estimated changes by interpolating from the known locations. Map 2 shows the locations of Alaska for which we had projections and compares projected temperatures with historical averages.

Precipitation is also expected to increase around the state, but not by as much as temperatures. Projected changes are small in the northern areas and larger in southeast Alaska, as Table 1 shows. 
Figure 2. Climate Model Projections of Average Monthly Temperatures, Barrow, 2080

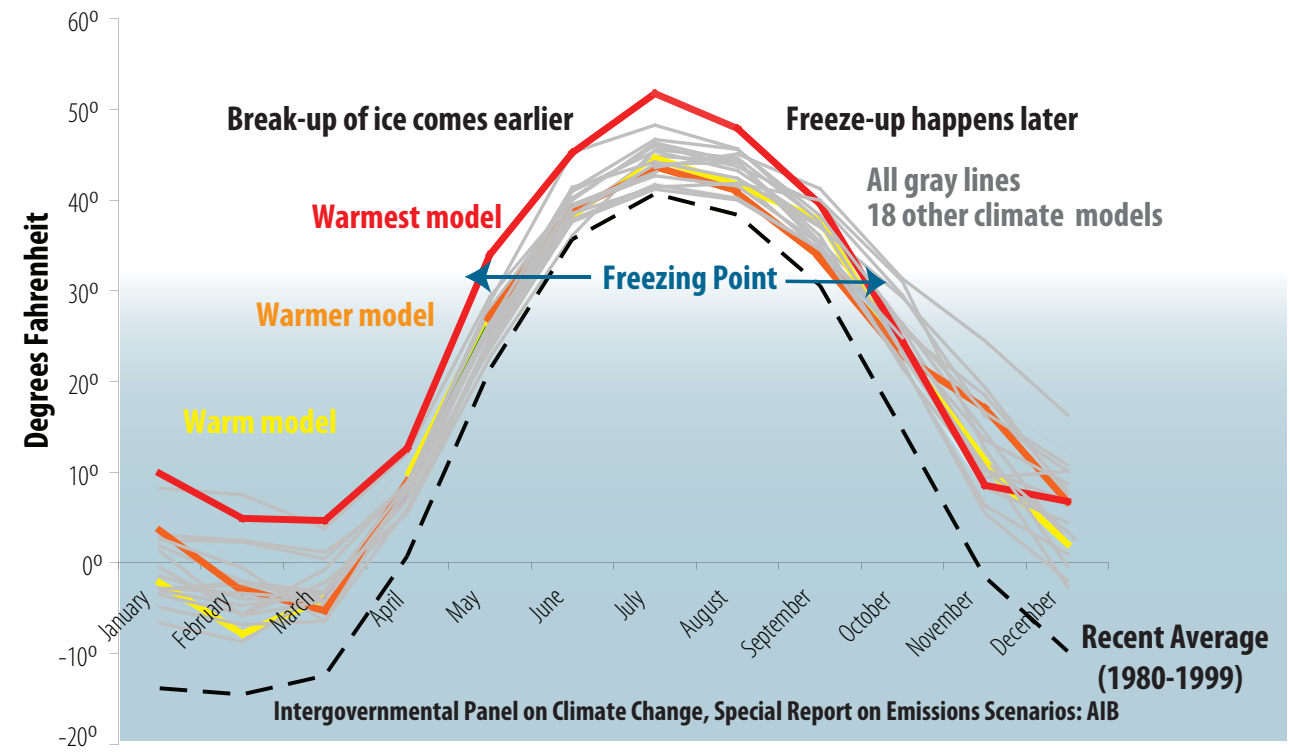

Map 2. Historical Average Annual Temperatures and Projected Temperatures in 2030 For Six Alaska Regions, From Selected Climate Models, In Degrees Fahrenheit

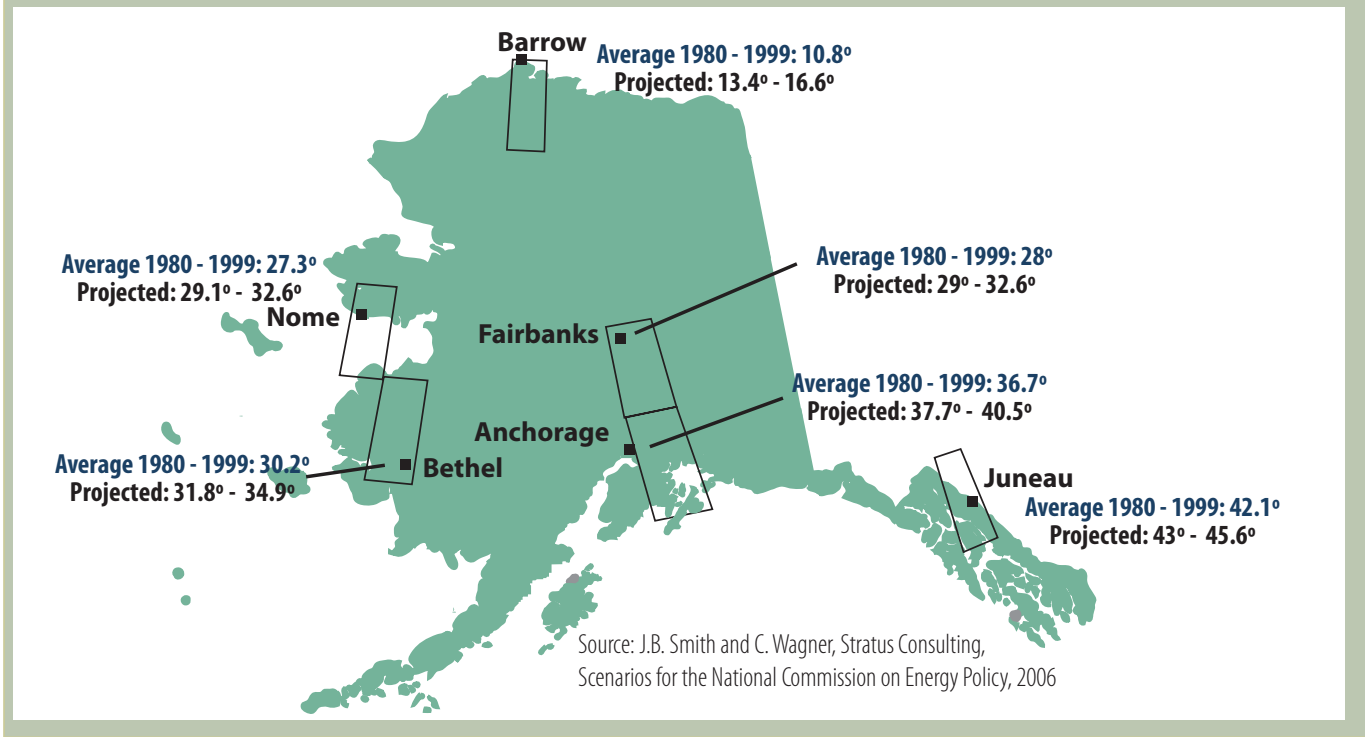

Table 1. Historical and Projected Annual Precipitation, Alaska Locations, From Selected Climate Models, In Inches

\begin{tabular}{|l|c|c|c|c|c|cc|}
\hline Alaska Location & Historical Precip. & \multicolumn{2}{|c|}{ Warm Model Projection } & \multicolumn{3}{|c|}{ Warmer Model Projection } & \multicolumn{3}{|c|}{ Warmest Model Projection } \\
& $\mathbf{( 1 9 8 0 - 1 9 9 9 )}$ & $\mathbf{2 0 3 0}$ & $\mathbf{2 0 8 0}$ & $\mathbf{2 0 3 0}$ & $\mathbf{2 0 8 0}$ & $\mathbf{2 0 3 0}$ & $\mathbf{2 0 8 0}$ \\
\hline Anchorage & 16.8 & 17.7 & 17.4 & 17.5 & 19.4 & 17.5 & 20.2 \\
\hline Barrow & 4.2 & 4.3 & 4.7 & 4.4 & 4.8 & 4.5 & 5.6 \\
\hline Bethel & 16.7 & 18.1 & 18.6 & 17.7 & 18.1 & 17.5 & 20.4 \\
\hline Fairbanks & 10.7 & 11.3 & 11.2 & 11.3 & 12.5 & 11.1 & 13.4 \\
\hline Juneau & 61.0 & 60.3 & 65.2 & 64.9 & 73.1 & 63.3 & 73.3 \\
\hline Nome & 17.4 & 19.2 & 20.2 & 18.2 & 19.3 & 18.8 & 21.8 \\
\hline Sources: Lawrence Livermore National Lab (PCMDI Collection); NCAR/ISSE; ISER-UAA, 2006; UAF Geophysical Institute, 2006 & & \\
\hline
\end{tabular}




\section{Assembling a Database and Estimating Replacement Values}

Our next step toward estimating future public infrastructure costs for Alaska was trying to find out what exists today. We hoped to find out how much infrastructure there is, how long the various types typically last, where it's all located, when it was built, and how much it would cost to replace it.

We collected all the publicly available data about infrastructure around the state. We relied on many sources, including the State Office of Risk Management; the Denali Commission; and the Alaska Departments of Natural Resources, Transportation and Public Facilities, and Education and Early Development.

The available information isn't complete, and in some cases may not be accurate. Getting accurate information about all the public infrastructure in Alaska is difficult, for several reasons - including Alaska's huge size, security concerns in the aftermath of 9/11, and the fact that public agencies didn't necessarily have reasons to collect and maintain that information in the past.

There are about 350 cities, towns, and villages spread across the state's 375 million acres. Some are on road systems or are regularly served by ferries or airlines. But many are far from regular transportation systems and are accessible by water only part of the year and by air taxis or charter airlines year-round, weather permitting. Different federal, state, and local agencies are responsible for the different types of infrastructure in all those diverse places.

Map 3 helps illustrate just how scattered public infrastructure is in Alaska. It shows the general distribution of transportation infrastructure around the state - major roads, bridges, airports, harbors, and the Alaska Railroad. Other kinds of infrastructure are distributed in similar patterns.
A lot of infrastructure is concentrated in the more heavily populated areas of southcentral Alaska, along the major road systems into the interior, and in southeast Alaska. But there is also infrastructure in hundreds of small, isolated communities along river systems in the interior and southwest Alaska, along the coasts, on the North Slope, on the Pribilofs and other islands in the Bering Sea, and along the Aleutian chain.

We weren't able to verify all the information for the hundreds of communities in our database. But we hope that when government agencies see the information we have so far, they will tell us what we're missing or what we have wrong. Table 2 shows information in the database right now.

- Currently the database contains nearly 16,000 individual elements of public infrastructure in 19 categories. We placed each item in a category, identified it by location, and assigned it a useful life and replacement value. We also assigned each a set of values associated with local permafrost conditions, susceptibility to flooding, and proximity to the coast.

- The infrastructure in our database has an estimated price tag of around $\$ 40$ billion today. Much of that is in various types of transportation infrastructureespecially roads — which are expensive to build and maintain in Alaska. Sanitation systems are also expensive to build and very difficult to maintain in remote northern, western, and interior places.

- The database clearly undercounts and undervalues some types of infrastructure, especially defense facilities and power and telephone lines. Information about the extent and value of defense facilities is often suppressed for reasons of national security. The database may also in some cases overcount infrastructure.

- Agencies often don't report replacement costs for infrastructure. Whenever possible, we got replacement costs from public agencies. But when no replacement cost was reported, we estimated, using average insured value or other available information.

\section{Map 3. Transportation Infrastructure in Alaska, 2006}

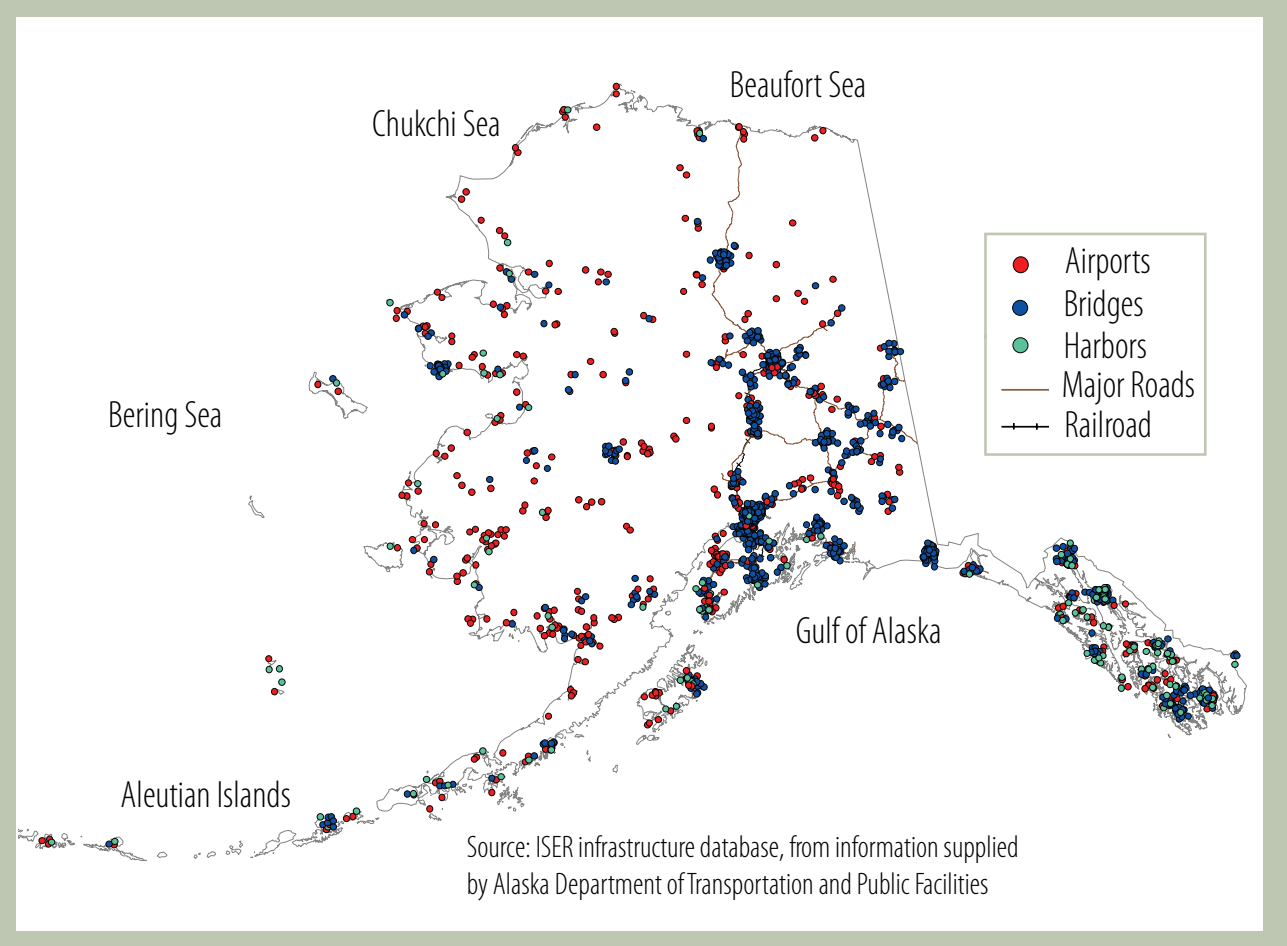

- Information on the expected useful life and the actual age of infrastructure in Alaska is also scarce. For this initial work we made assumptions about the useful life of various types of infrastructure, based on information from the Alaska Division of Finance and personal communications with employees of government agencies and academic researchers. We also assumed, in the absence of specific information, that the various types of existing infrastructure are equally distributed along an age continuum, from new to near the end of useful life. The length of "useful life" varies among different types of infrastructure, as Table 2 shows. 


\begin{tabular}{|c|c|c|c|c|c|}
\hline Type of Infrastructure & Count/Length & $\begin{array}{l}\text { Useful Life } \\
\text { (Years) }\end{array}$ & $\begin{array}{l}\text { Replacement Cost } \\
\text { per Unit (In \$2006) }\end{array}$ & Units & $\begin{array}{l}\text { Total Replacement } \\
\text { Costs Today (In \$2006) }\end{array}$ \\
\hline Airports & 253 & 20 & $\$ 20$ million & Whole & $\$ 5.06$ billion \\
\hline Bridges & $\begin{array}{c}823 \\
31.4 \text { miles }\end{array}$ & 40 & $\$ 10,000$ & Per Foot & \$1.7 billion \\
\hline Court facilities & 42 & 40 & $\$ 16$ million & Whole & $\$ 678$ million \\
\hline Defense facilities ${ }^{b}$ & 178 & 40 & $\$ 305,000$ & Whole & $\$ 54$ million \\
\hline $\begin{array}{l}\text { Emergency Services } \\
\text { (Fire stations, other) }\end{array}$ & 233 & 20 & $\$ 467,000$ & Whole & \$108 million \\
\hline $\begin{array}{l}\text { Energy (Fuel tanks, other structures } \\
\text { off power grid) }\end{array}$ & 234 & 30 & $\$ 32,000$ & Whole & $\$ 7$ million \\
\hline Misc. government buildings & 1,571 & 30 & $\$ 1$ million & Whole & $\$ 1.6$ billion \\
\hline $\begin{array}{l}\text { Power grid (lines, transformers } \\
\text { substations) }\end{array}$ & $\begin{array}{c}68 \\
768 \text { miles of line }\end{array}$ & 15 & $\$ 100,000$ & Per Mile & $\$ 77$ million \\
\hline $\begin{array}{l}\text { Misc. health buildings (clinics, other } \\
\text { non-hospital facilities) }\end{array}$ & 346 & 30 & $\$ 1.6$ million & Whole & $\$ 565$ million \\
\hline Harbors & 131 & 30 & $\$ 10$ million & Whole & \$1.3 billion \\
\hline Public hospitals & 18 & 40 & $\$ 44.7$ million & Whole & $\$ 806$ million \\
\hline $\begin{array}{l}\text { Law enforcement facilities (police } \\
\text { and trooper stations, prisons, other } \\
\text { correctional) }\end{array}$ & 66 & 30 & $\$ 4$ million & Whole & $\$ 259$ million \\
\hline Alaska Railroad & $\begin{array}{l}45 \text { structures } \\
819 \text { miles track }\end{array}$ & 30 & $\$ 2.8$ million & Per Mile & $\$ 2.3$ billion \\
\hline Roads & $\begin{array}{c}\text { 10,476 roads } \\
4,564 \text { miles paved } \\
5,000 \text { miles unpaved }\end{array}$ & 20 & $\begin{array}{l}\$ 1 \text { million (unpaved) } \\
\$ 3 \text { million (paved) }\end{array}$ & Per Mile & \$18.7 billion \\
\hline Schools & 520 & 40 & $\$ 2.5$ million & Whole & $\$ 1.3$ billion \\
\hline Sewer systems & 124 & 20 & $\$ 30$ million & Whole & \$3.7 billion \\
\hline $\begin{array}{l}\text { Telecommunications (towers, } \\
\text { satellites, other) }\end{array}$ & 275 & 10 & $\$ 300,000$ & Whole & $\$ 82$ million \\
\hline Telephone linesb & $\begin{array}{c}20 \\
222 \text { miles }\end{array}$ & 15 & $\$ 50,000$ & Per Mile & \$11.1 million \\
\hline Water systems & 242 & 20 & $\$ 5$ million & Whole & $\$ 1.2$ billion \\
\hline Totals: & 15,665 & & & & \$39.4 billion \\
\hline \multicolumn{6}{|c|}{$\begin{array}{l}\text { apreliminary database, compiled from publicly available information in } 2006 . \\
\text { bThe counts and the replacement costs in these categories are obviously low, especially for defense facilities. In part for security reasons, little public } \\
\text { information is available about the size and value of defense facilities. } \\
\text { Sources: Denali Commission; Alaska Departments of Transportation and Public Facilities, Administration (Risk Management), Commerce, } \\
\text { Community and Economic Development, Natural Resources, Education and Early Development; ISER }\end{array}$} \\
\hline
\end{tabular}




\section{Method of Estimating Additional Costs}

The three climate projections and the infrastructure database gave us the foundation for building our life-cycle cost estimation model, to assess the effects of climate change on future infrastructure costs. We made estimates for the years 2030 and 2080, the years for which we acquired climate projections. (Those projection years are in fact averages for 20-year spans - 2020-2039 for 2030 and 2070-2089 for 2080.)

- Our model assumes that existing infrastructure is replaced as it wears out, that it is replaced in the same community, and that no new infrastructure is added.

- Our model assumes that climate change will damage infrastructure by thawing permafrost, increasing flooding, and creating more coastal erosion. These effects will occur not only because of increasing temperatures and precipitation but also because the lack of shore-fast ice will make coastal places more vulnerable to erosion caused by storms.

- Thawing permafrost and other changes can add to the costs of maintaining and replacing infrastructure in various ways. But in this initial work we used a reduction in the useful life of infrastructure - meaning that it wears out faster and has to be replaced sooner - as a proxy for different ways the costs of infrastructure might increase.

- We first estimated infrastructure replacement costs in the coming years, assuming no climate change. That estimate served as the basis for assessing additional costs that could result from climate change. Infrastructure in Alaska is expensive to build and maintain, even without taking climate change into account.

- We then estimated a range of additional building and maintenance costs resulting from climate change. Most scientists believe Alaska's climate will continue to get warmer, but it's impossible to perfectly predict how much and how fast the climate will change over the next several decades. We took that uncertainty into account by (1) using three different climate projections and (2) applying the historical natural variability in annual temperatures and precipitation to each of the three projections, to assess the range of possible conditions - and therefore the range of possible additional costs. For each of the three climate projections, we did repeated model runs to assess the potential range of costs.

- We first estimated additional costs assuming that agencies simply react as conditions change - the no-adaptation case. They continue to design and construct infrastructure, taking local conditions into account, and finding new methods for dealing with problems as they develop. But in this case, we assume they don't act strategically - that is, they don't anticipate and plan for continuing trends in climate change and future vulnerabilities of infrastructure. We don't believe that in fact agencies would react so passively. Still, this no-adaptation case offers a useful starting point for further analysis. It provides a benchmark for measuring the efficacy of adaptation measures. It also gives agencies an idea of how big a problem they could face, in an environment of continuing change.

- We next estimated costs assuming that agencies act strategically to minimize the ongoing effects of climate change on infrastructure - the adaptation case. For example, they would try to design bridges to take into account projected climate change throughout the life of the bridge. We believe this adaptation case better reflect what agencies will actually do.

\section{How Much Might Climate Change Add to Costs?}

Our estimates of additional infrastructure costs are in net present value, which is a standard way of summarizing potential costs over long periods. Think of it as an amount that would need to be deposited in a bank today, earning interest, to cover all the future costs for something — in this case, the estimated additional costs for replacing public infrastructure through 2030 and through 2080.

Figure 1 on the front page summarizes our estimates of additional costs resulting from climate change, taking likely design adaptations into account. Those are the averages under each of the three climate projections, and it's most probable that costs would be close to those averages.

But there is some chance that the additional costs could be much higher or much lower than the averages. That's because in reality temperatures and precipitation in any given year vary from the averages. The three climate projections we used project trends in temperature and precipitation — but there will inevitably be years when either temperature or precipitation, or both, will be higher or lower than the trend projection.

Our model uses historical observations to project how additional infrastructure costs might vary, when temperature and precipitation differ from the projected average. We did repeated model runs — up to 100 for each climate projection to estimate the range of possible costs.

Figures 3 and 4 show our preliminary estimates of the range of possible additional costs from climate change, taking likely adaptations into account, under each climate projection. Table 3 shows estimates of additional costs both with and without strategic adaptations to climate change. What do the figures and the table show?

- Even without climate change, maintaining and replacing infrastructure in Alaska is an expensive proposition - costing an estimated $\$ 32$ billion between now and 2030 and $\$ 56$ billion by 2080.

- Climate change could add 10\% to 20\% to infrastructure costs by 2030 and 10\% to $12 \%$ by 2080 , under different climate projections and taking design adaptations into account. The additional costs are relatively higher in the short run, because agencies haven't had as much time to adapt infrastructure to changing conditions.

- Strategic design adaptations have much more potential to reduce extra costs in the long run. Between now and 2030, adaptations might reduce costs related to climate change by anywhere from zero to as much as 13\%, depending on the extent of climate warming. But between now and 2080, adaptations could save anywhere from $10 \%$ to $45 \%$ of costs resulting from climate change.

- Transportation infrastructure - especially roads and airport runways - will account for most of the additional costs between now and 2030. That's because transportation infrastructure is expensive to build and maintain in Alaska under any circumstances, and many airports and some roads are in areas that will be most affected by a warming climate. But water and sewer systems - which are very expensive to build and difficult to maintain in areas with a lot of permafrost - will also account for nearly a third of the costs resulting from climate change by 2030 . 
Figure 3. Range of Additional Public Infrastructure Costs, 2006-2030, Adaptation Case

(In Billions of Dollars, Net Present Value)

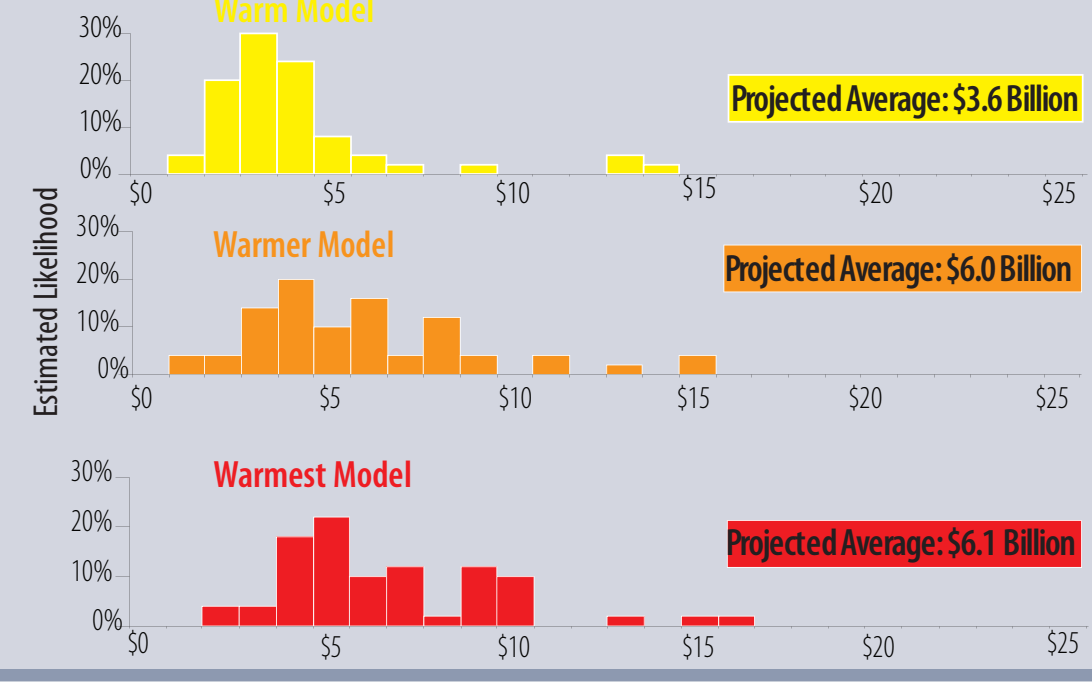

Figure 4. Range of Additional Public Infrastructure Costs, 2006-2080, Adaptation Case

(In Billions of Dollars, Net Present Value)

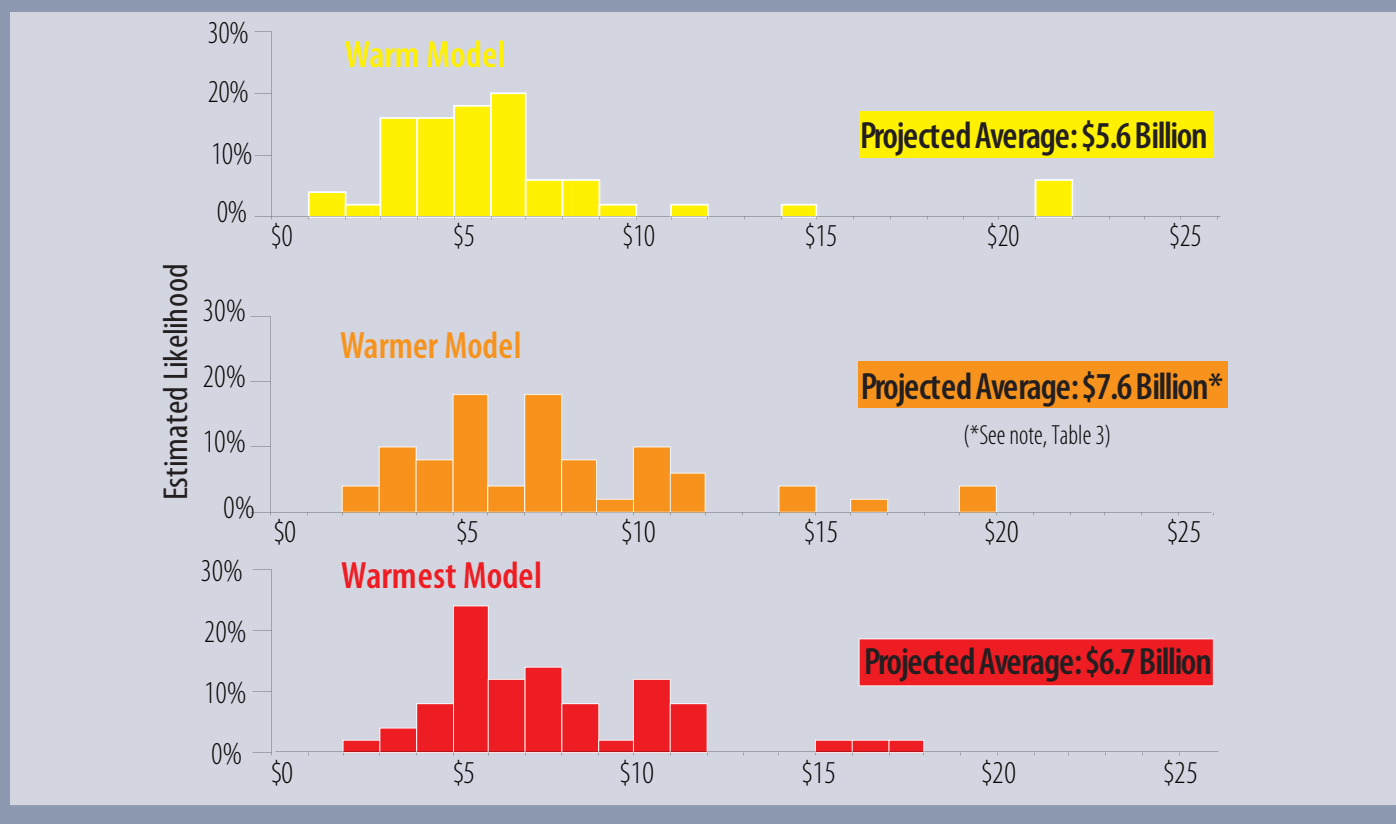

Table 3. Estimating Additional Infrastructure Costs From Climate Change

(In Billions of Dollars, Net Present Value)

\begin{tabular}{|c|c|c|c|c|c|c|c|c|}
\hline & \multirow{3}{*}{$\begin{array}{c}\text { Ordinary wear } \\
\text { and tear } \\
\text { (No climate change) }\end{array}$} & \multicolumn{6}{|c|}{ Extra Costs from Climate Change } & \multirow{3}{*}{$\begin{array}{l}\text { Potential Savings } \\
\text { from Strategic } \\
\text { Adaptations }\end{array}$} \\
\hline & & \multicolumn{2}{|c|}{ Warm Model } & \multicolumn{2}{|c|}{ Warmer Model } & \multicolumn{2}{|c|}{ Warmest Model } & \\
\hline & & $\begin{array}{c}\text { No } \\
\text { Adaptations }\end{array}$ & $\begin{array}{c}\text { With } \\
\text { Adaptations }\end{array}$ & $\begin{array}{c}\text { No } \\
\text { Adaptations }\end{array}$ & $\begin{array}{c}\text { With } \\
\text { Adaptations }\end{array}$ & $\begin{array}{c}\text { No } \\
\text { Adaptations }\end{array}$ & $\begin{array}{c}\text { With } \\
\text { Adaptations }\end{array}$ & \\
\hline 2006-2030 & $\$ 32$ & $\$ 3.6$ & $\$ 3.6$ & $\$ 6.1$ & $\$ 6.0$ & $\$ 7.0$ & $\$ 6.1$ & $0 \%-13 \%$ \\
\hline $2006-2080$ & $\$ 56$ & $\$ 6.2$ & $\$ 5.6$ & $\$ 10.6$ & $\$ 7.6^{*}$ & $\$ 12.3$ & $\$ 6.7$ & $10 \%-45 \%$ \\
\hline
\end{tabular}


Table 4. Characteristics of ISER Life-Cycle Model

\begin{tabular}{|c|c|}
\hline Functional Form & Probabilistic life-cycle analysis \\
\hline Discount Rate & 2.85\%/year (real) \\
\hline Base Year & 2006 \\
\hline Projected Years & 2030,2080 \\
\hline Depreciation Matrix Version & January 31, 2007 \\
\hline Climate Model Base Years & 1980-1999 \\
\hline Observed Climate Variability Data Source & University of Alaska Fairbanks, Geophysical Institute \\
\hline Distribution Shape for Observed Regional Climate & Gaussian \\
\hline Extreme Climate Events Probability & $\begin{array}{l}\text { Less than 1st percentile, greater than 99th percentile } \\
\text { (for observed range of climate) }\end{array}$ \\
\hline Extreme Climate Events Scalar & $+10 \%$ increase in effects on useful life \\
\hline Natural Variability Forward in Time & Static at observed regional annual variances \\
\hline Infrastructure Growth Forward in Time & Static at 2006 count \\
\hline Permafrost State Forward in Time & Static at 1965 location (USGS) \\
\hline Software System & SAS 9.1 TS Level 1M3, XP PRO Platform \\
\hline Hardware System & $\begin{array}{l}\text { Dell Dimension } 8300 \text { (Intel Pentium } 3.06 \text { GHz; } \\
500 \text { GB Hard Drive) }\end{array}$ \\
\hline
\end{tabular}

Climate Models Used in Analysis

Warm Model

Modeling Group: CSIRO Atmospheric Research, Australia

Model Identification: CSIRO-Mk3.0

Modeling Group: U.S. Department ofCommerce, National Oceanic and Atmospheric Administration, Geophysical Fluid Dynamics Laboratory Model Identification: GFDL-CM2.0

\section{Warmest Model}

Modeling Group: Center for Climate System Research (University of Tokyo); National Institute for Environmental Studies; and Frontier Research Center for Global Change (JAMSTEC), Japan

Model Identification: MIROC3.2(hires)

\section{Directions for Future Research}

We anticipate that continuing research in a number of areas will allow us to refine our model and the cost estimates, both for the state as a whole and for regions and particular types of infrastructure.

- Climate projections: Our technical advisors tell us that the climate projections we used in our analysis have a useful life of about two to five years. As time passes, we will need to get new projections. We hope the new generation of climate projections will be available for smaller geographic areas.

- Infrastructure database: We need more complete information about the count, the useful life, the age, and the replacement costs of public infrastructure in Alaska. What we have currently is a good start toward creating the first comprehensive database of federal, state, and local infrastructure in the state. Also, as time goes on and more public infrastructure is built, we need to work with public agencies to make sure new infrastructure is added to our database.

- Changes in building conditions: We need to learn more about how changes in temperature, storm severity, and other anticipated climate changes affect building conditions, including the stability of soils, erosion, and other factors.

- Effects of building conditions on life-cycle costs of infrastructure: We need to learn more about how changing building conditions resulting from climate change affect the life-cycle costs for infrastructure. Also, we need better information about how building on permafrost affects soil temperatures, regardless of climate change.

- Maintenance costs: We need to learn more about how changing building conditions resulting from climate change affect costs of maintaining infrastructure.

- Adaptation techniques: We need more information about the array of techniques that could be used to adaptinfrastructure to changing climate conditions. What would specific adaptations cost? And which would not only ameliorate the effects of climate change on infrastructure but also be cost-effective?

\section{About Shishmaref, Kivalina, and Newtok}

The U.S. Army Corps of Engineers reports that increasing erosion along the Bering Sea coast means the villages of Shishmaref, Kivalina, and Newtok in western Alaska will need to be moved in the next 10 to 15 years, at an estimated cost of up to $\$ 455$ million. We have not included that estimate in our cost projections, because it includes a very wide range of costs associated with relocating entire communities. The corps did not report what share is specifically for public infrastructure.

\section{Acknowledgments}

The authors thank Joel Smith of Stratus Consulting, Dan White of the University of Alaska Fairbanks, and Gary Yohe of Wesleyan University for providing us with valuable suggestions. Several sponsors made this research possible:

\section{University of Alaska Foundation National Commission on Energy Policy Alaska Conservation Foundation Rural Alaska Community Action Program}

This summary is based on Estimating Future Costs for Alaska Public Infrastructure at Risk from Climate Change, by Peter Larsen, Scott Goldsmith, Ben Saylor, and Meghan Wilson of ISER; Orson Smith of UAA's Civil Engineering Department; and Ken Strzepek and Paul Chinowsky of the University of Colorado at Boulder. It is available online at www.iser.uaa.alaska.edu, or from ISER's offices in Anchorage (907-786-7710).

The authors ask that any one with better information about public infrastructure in Alaska, or comments about our research methods, please call or send an e-mail message to Peter Larsen at 907-786-5449 or ANPHL@uad.alaska.edu.

Editor: Linda Leask • Graphics: Clemencia Merrill 


\section{INTRODUCTION}

The Institute of Social and Economic Research (ISER) at the University of Alaska Anchorage created a probabilistic life-cycle model to estimate how much climate change could add to the costs of public infrastructure in Alaska in the coming decades. This report describes how we developed that model and presents our preliminary estimates of additional public infrastructure costs resulting from climate change. Faculty members at UAA's School of Engineering and at the University of Colorado in Boulder helped us in this work.

These are the first estimates of what climate change could add to the future bill for public infrastructure in Alaska. We're presenting the estimates here, even though they are preliminary, because (1) they give a general picture of the magnitude of extra costs public agencies could face and of the potential value of any efforts to mitigate climate change; and (2) we hope they will stimulate more efforts to better understand the problem and measure it. We want to emphasize, however, that we plan to continue improving the model and refining the cost estimates over time, as more information becomes available.

\section{Why Do This Analysis?}

Alaska's climate has gotten warmer in recent decades, and scientists expect both temperature and precipitation to continue increasing in the coming years. Those changes are part of a worldwide warming trend, but the changes have been especially pronounced in the Arcticand climate researchers also expect future changes to be larger in the Arctic than elsewhere.

Warmer temperatures and more precipitation will affect both natural and man-made systems in Alaska, with widespread social and economic consequences. One effect will be to damage public infrastructure and shorten its useful life, although not all areas or all types of infrastructure will be equally affected. It's even possible that a warmer climate may prolong the life of some infrastructure in some areas, but in this initial work we haven't identified any such exceptions.

Maintaining and replacing infrastructure across Alaska is expensive to begin with, and it will become more so as thawing permafrost and other effects of climate change add to ordinary wear and tear. Our preliminary count of individual elements of federal, state, and local infrastructure around Alaska is close to 16,000 . We estimate that this existing public infrastructure has a price tag of about $\$ 40$ billion today, and that maintaining and replacing it as 
needed from now to 2030 could cost $\$ 32$ billion, in today’s value. Damage from climate change could add billions to those costs.

But planning and adapting infrastructure in the face of climate change could substantially reduce future costs. Some agencies - like the Alaska Department of Transportation and Public Facilities - are already taking steps to adapt infrastructure. We hope our initial modeling work and preliminary estimates can be the first step toward providing policymakers with a systematic way to assess the potential risks for the state's infrastructure and to determine the efficacy of various ways of trying to reduce extra costs related to climate change.

\section{Scope of Study and Methods}

This analysis looks only at how climate change may affect future costs for public infrastructure: all the federal, state, and local roads, airports, harbors, sanitation systems, schools, post offices, police stations, health clinics, and other infrastructure that make it possible for Alaska to function. Private infrastructure - the biggest example being the trans-Alaska oil pipeline - will also be affected by climate change. But we did not estimate potential future costs for private infrastructure. Also, we did not attempt to estimate how efforts to control greenhouse gases could influence the future costs for public infrastructure. We just looked at the potential extra costs for maintaining and replacing public infrastructure, given the climate changes projected in current climate models. Building the ISER life-cycle model and developing the preliminary estimates involved a number of steps.

(1) To start our analysis, we compiled a database of all the publicly available information about the number, location, and replacement costs of public infrastructure in Alaska's 350 communities. We relied on a number of sources, including the Denali Commission and several state agencies. The available information isn't complete, but it serves as a good beginning for the first comprehensive database of public infrastructure throughout Alaska.

(2) Next we acquired projections from 21 of the best available climate models, developed by scientists around the world. All those models project rising temperatures and increased precipitation for Alaska, but some project less and some more warming. Joel Smith, one of our advisors and an author of the 2007 Fourth Assessment Report from the Intergovernmental Panel on Climate Change, recommended three projections for use in our analysis. All three project warming, but they project different levels of warming. These projections are for the years 2030 
and 2080. We recognize, of course, that projections decades in the future are subject to a lot of uncertainty.

(3) We then used rules of thumb to estimate how thawing permafrost, increased flooding, and more coastal erosion affect building conditions, and how those changing conditions affect infrastructure costs. Those rules are, by necessity, based on limited historical experience with thawing permafrost and other anticipated changes.

(4) We estimated future costs of maintaining and replacing Alaska's existing infrastructure, assuming no climate change. This serves as the base case against which to estimate potential additional costs resulting from climate change.

(5) We estimated additional costs resulting from climate change, under three different climate projections. Given the uncertainty about the level and rate of future climate change, we developed a range of cost estimates, with different probabilities of occurring. We also took into account the natural variability of Alaska's climate from year to year, independent of climatechange trends.

(6) We estimated additional costs with and without likely adaptations to infrastructure in the face of climate change. We believe agencies will develop adaptations to changing conditions - some are already doing so — but the estimates assuming no adaptations are still useful. They provide a benchmark that could be used to measure the efficacy of specific adaptation measures, and they illustrate the magnitude of the problem agencies face in an environment of continuing change.

\section{Structure of Report}

Chapter II sets the stage for the analysis by describing climate changes that have already occurred in Alaska in recent decades and discussing what studies have been done in other places of the potential effects of climate change.

Chapter III then discusses the 21 Atmosphere-Ocean General Circulation Model (AOGCM) climate projections provided ISER by the Institute for the Study of Society and the Environment at the National Center for Atmospheric Research. It cites the three projections we used in our analysis and what they project for different areas of Alaska. 
Chapter IV talks about how we created the preliminary database of public infrastructure around Alaska and how we estimated replacement costs and useful life of that infrastructure. The chapter includes estimates of the current value of 19 types of infrastructure, as well as maps of the location of transportation and other types of infrastructure.

Chapter V describes the development of the life-cycle cost estimator model. It discusses major assumptions, including assumptions about the susceptibility of infrastructure to permafrost thawing, flooding, and coastal erosion. It explains how the model accounts for uncertainty and how it estimates costs. Chapter VI then turns to a discussion of how researchers developed three cases - the base case, assuming no climate change; the no-adaptation case; and the event-driven case - to estimate potential additional costs resulting from climate change, under three climate projections. Chapter VII presents the model results.

Chapter VIII broadly discusses additional information we hope to acquire and how over time we hope to refine both our life-cycle model and estimates of future costs. Chapter IX offers brief conclusions. An appendix summarizes major model assumptions and other important model elements.

\section{Interpreting the Findings}

Estimating the effects of climate change on infrastructure costs decades in the future involves a lot of uncertainty to begin with, and in this initial work we weren't able to get all the information we hoped for. So before turning to the next chapters, we want to emphasize several important caveats.

- ISER is not projecting climate change. We made preliminary estimates of one type of economic cost of climate change - costs to public infrastructure - using three of the latest climate projections from climate research institutes around the world.

- Our cost estimates are a range rather than a single value. All computer models, whether they are climate change models or economic models, involve uncertainty. This paper attempts to capture some of that uncertainty by presenting cost estimates as a distribution of outcomes that have different probabilities of occurring. We also intend to ask the atmospheric research community to help us refine our model assumptions. 
- We had to estimate average infrastructure replacement costs, depreciation rates, and useful life for much of Alaska's public infrastructure. There is little information on the actual, location-specific replacement costs for most infrastructure. When it was available, we used information provided by the Alaska Division of Risk Management. In most cases, we estimated rough statewide averages of replacement costs for each type of infrastructure, using a variety of sources - including personal communication with researchers at many of the state and federal agencies. These initial rough estimates will be continuously revised and disaggregated to improve accuracy.

- Given time and budget constraints, we did not attempt to estimate the effects on infrastructure from projected increases in sea levels. Estimates of global sea-level rise from the Intergovernmental Panel on Climate Change show increases ranging from $5 \mathrm{~cm}$ to $15 \mathrm{~cm}$ for 2030, relative to 1990 levels, and increases of $15 \mathrm{~cm}$ to $65 \mathrm{~cm}$ by 2080 . It is not easy to assess which Alaska communities will be affected by a general increase in sea levels. Researchers have shown that vertical movements of the land, ocean currents, and other local conditions can all affect the local sea-level rise (Douglas and Peltier, 2002).

- The climate models project climate change for a limited number of locations and future dates. We generalized the climate projections to more than 350 Alaska locations and to the years between 2030 and 2080. These methods smooth out some of the spatial and temporal variability in climate that are certain to occur in the future.

- The climate models summarize climate change using two variables-annual average temperature and precipitation-that do not capture all the dimensions of change that are likely to occur. As the climate models become more refined, we'll be able to incorporate a more complete picture of how natural systems are likely to evolve.

- We summarized the links between climate change and the costs of infrastructure replacement using the useful life of buildings and other public facilities. Over time, more study should give us the ability to better model these complex relationships. In addition, we need better information about how building on permafrost changes soil temperatures, regardless of climate change. 
- In this initial work, we assumed a static economy - that is, we assumed no change in the economy or the population that would change the level or mix of public infrastructure.

- Our analysis of the potential for adaptations to reduce costs associated with climate change is very preliminary. More work is necessary to investigate the policies in place, as well as the potential for adaptation measures in the short and long run.

- Potential damage to public infrastructure from climate change is only one measure of the potential cost to Alaskans. We pointed out earlier that our estimates don't include private infrastructure. There are also many other potential social, economic, and cultural costs. Some of those can be quantified in dollars - like potential reductions in commercial fish harvests — and some can't_-like the potential loss of, or changes in, traditional subsistence resources Alaska Natives rely on. 


\section{BACKGROUND}

Alaska has been called the "canary down the mine" because it is already seeing the early effects of global climate change, and climate researchers also expect future climate change in Alaska and other Arctic places to be more pronounced than it is elsewhere. The Intergovernmental Panel on Climate Change has concluded that people are responsible for much of the climate warming worldwide, because they are putting $\mathrm{CO}_{2}$ and other greenhouse gases into the atmosphere. But natural variability in climate and other factors also contribute. Alaska and other Arctic places in particular are known to experience a lot of natural climate variability.

Measurements from all corners of the state show that annual average temperatures have risen substantially over the past 50 years. The Geophysical Institute at the University of Alaska Fairbanks reports that from 1949 to 2005 , annual temperatures increased 3.6 $6^{\circ}$ Fahrenheit in Barrow, $3.8^{\circ}$ in Juneau, and $3.6^{\circ}$ in Anchorage. According to climate scientists, this warming has been accompanied by extensive melting of glaciers, thawing of permanently frozen ground (permafrost), retreat and overall thinning of sea ice, and coastal erosion from increased storm activity. Ice core samples indicate that the Arctic today is the warmest it has been in at least 400 years. Precipitation levels are expected to continue increasing, but warmer summer temperatures will more than offset that increase, causing soil moisture levels to drop noticeably in some areas.

Some climate-change models forecast that Anchorage's annual precipitation will increase approximately $6 \%$ to $9 \%$ above recent historical levels by 2030 and $15 \%$ to $19 \%$ by 2080 . Anchorage's average temperature could increase by $1^{\circ}$ to $4^{\circ} \mathrm{F}$ by 2030 and $4^{\circ}$ to $9^{\circ}$ by 2080 (Smith and Wagner, 2006). Actual change could be less or more under different conditions. Other Alaska communities are likely to experience even larger climate changes in the coming years. Speakers at recent major conferences-including the Alaska Forum on the Environment, the Alaska Federation of Natives, and the Snowchange workshop - reported that many species of plants and animals are changing their migratory and growth patterns in response to changing ocean currents, thawing permafrost, coastal erosion from severe storms, and flooding from a general rise in sea level. The effects of arctic climate trends as reported in a number of sources (ACIA, 2005; Romanovsky et al., 2002; Osterkamp et al., 1998; Chapman and Walsh, 2003; Weller et al., 1999) include:

- Rising temperatures, particularly in the winter

- Rising river flows, with earlier peak spring flows

- Increased precipitation, mostly as rain in the autumn and winter 
- Thawing permafrost, with a northern shift in the southern limit

- Declining snow cover, particularly in the spring

- Diminished lake and river ice, with later freeze-up and earlier breakup

- Melting glaciers

- Retreating summer sea ice

- Rising sea level

- Reduction in ocean salinity and density

The figures below illustrate one aspect of those trends - rising temperatures. Figure II-1 documents increasing surface air temperatures since 1943, showing a "hot spot" in Alaska. Figure II-2 shows increases in mean annual temperatures in Alaska communities since 1949, showing that change has occurred throughout the state, although not in equal amounts.

Figure II-1. Change in Annual Surface Air Temperature, 1943-2002

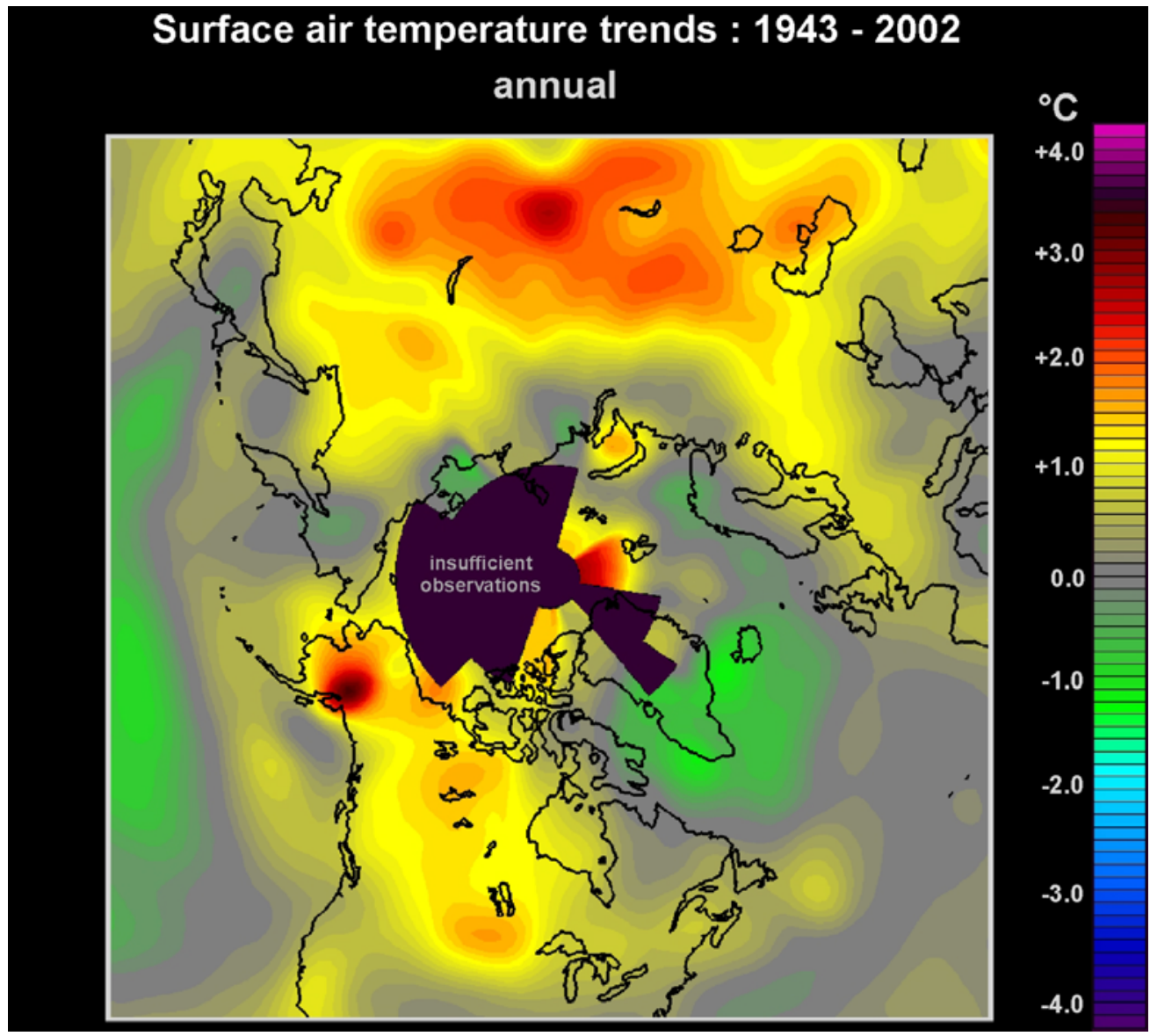

(Image created by Chapman and Walsh, 2003) 


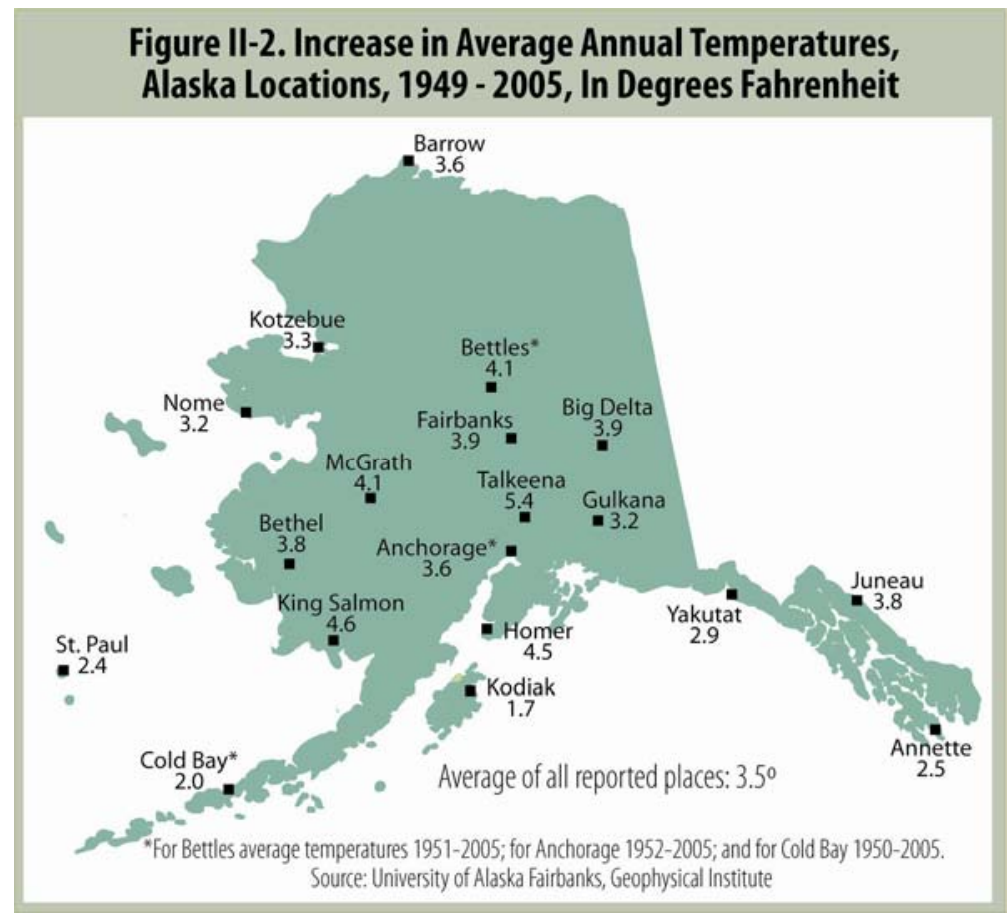

\section{What Are the Human Effects of Climate Change?}

The effects of climate change are widespread throughout Alaska and are difficult to quantify. In addition to directly affecting natural systems, climate change will directly affect the people of Alaska. A number of sources (ANTHC, 2005; USARC, 2003; ACIA, 2005; Weller et al., 1999) cite possible effects, some of which may be beneficial—but many of which won't.

- Difficulty maintaining subsistence hunting cultures

- Expanded marine shipping

- Declining food security

- Human health concerns (increased incidences of vector-borne diseases and asthma)

- Effects on wildlife migratory patterns

- Increased access to offshore resources, including minerals and petroleum

- Changes in marine fisheries

- Decline in freshwater fisheries such as arctic char and salmon

- Enhanced agriculture growing seasons

- Increased forest fire and insect infestation activity

- Disrupted land transportation from thawing permafrost and melting ice roads

- Increased damage to community infrastructure from coastal erosion and thawing permafrost

Problems associated with thawing permafrost, including effects on the foundations of buildings and roads, are well documented and often dramatic, as shown in Figure II-3. See, for 
example: ACIA (2005), Nelson et al (2003), USARC (2003), and Robinson et al. (in prep). Utilities have reported that telecommunication towers are settling due to warming permafrost. United Utilities, for example, has said "warm permafrost is a result of global warming" and is seeking funds for cost overruns in the Yukon-Kuskokwim Delta (Hamlen, 2004).

Figure II-4 shows projected changes in permafrost coverage from the early $21^{\text {st }}$ century to the late $21^{\text {st }}$ century. These are estimates made by experts at the International Arctic Research Center at the University of Alaska Fairbanks and the Cooperative Institute for Research and Environmental Science at the University of Colorado at Boulder, based on the GFDL-CM2.0 climate model from the U.S. Department of Commerce, NOAA, Geophysical Fluid Dynamics Laboratory. ${ }^{1}$ (This is the "warmer" model projection used in this analysis; see Chapter III.) Note that we did not use such high-resolution images in this analysis. We're including them here to illustrate the extent of possible permafrost thawing resulting from climate change.

\section{Figure II-3. Sinkhole Created by Thawing Permafrost}

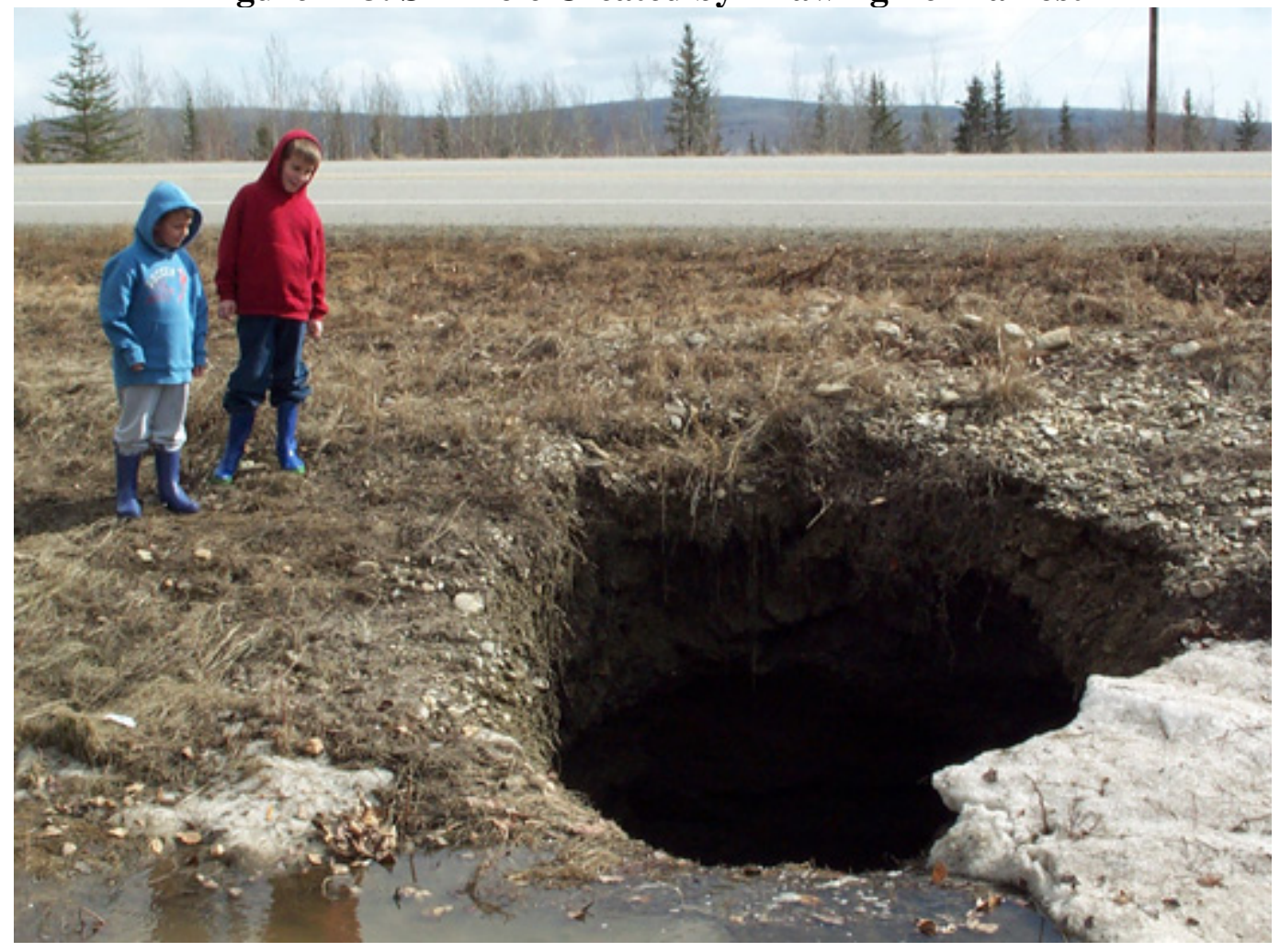

(Source: Vladimir Romanovsky, University of Alaska Fairbanks; UCAR, 2007)

\footnotetext{
${ }^{1}$ These high-resolution images have not yet been formally published, but they will be included in a future paper by IARC and CIRES.
} 
Figure II-4. Projected Permafrost Distribution, Seward Peninsula, Alaska Early $21^{\text {st }}$ Century and Late $21^{\text {st }}$ Century

(Yellow=Continuous; Blue=Discontinuous; Red=Thawing Permafrost/Permafrost Free)
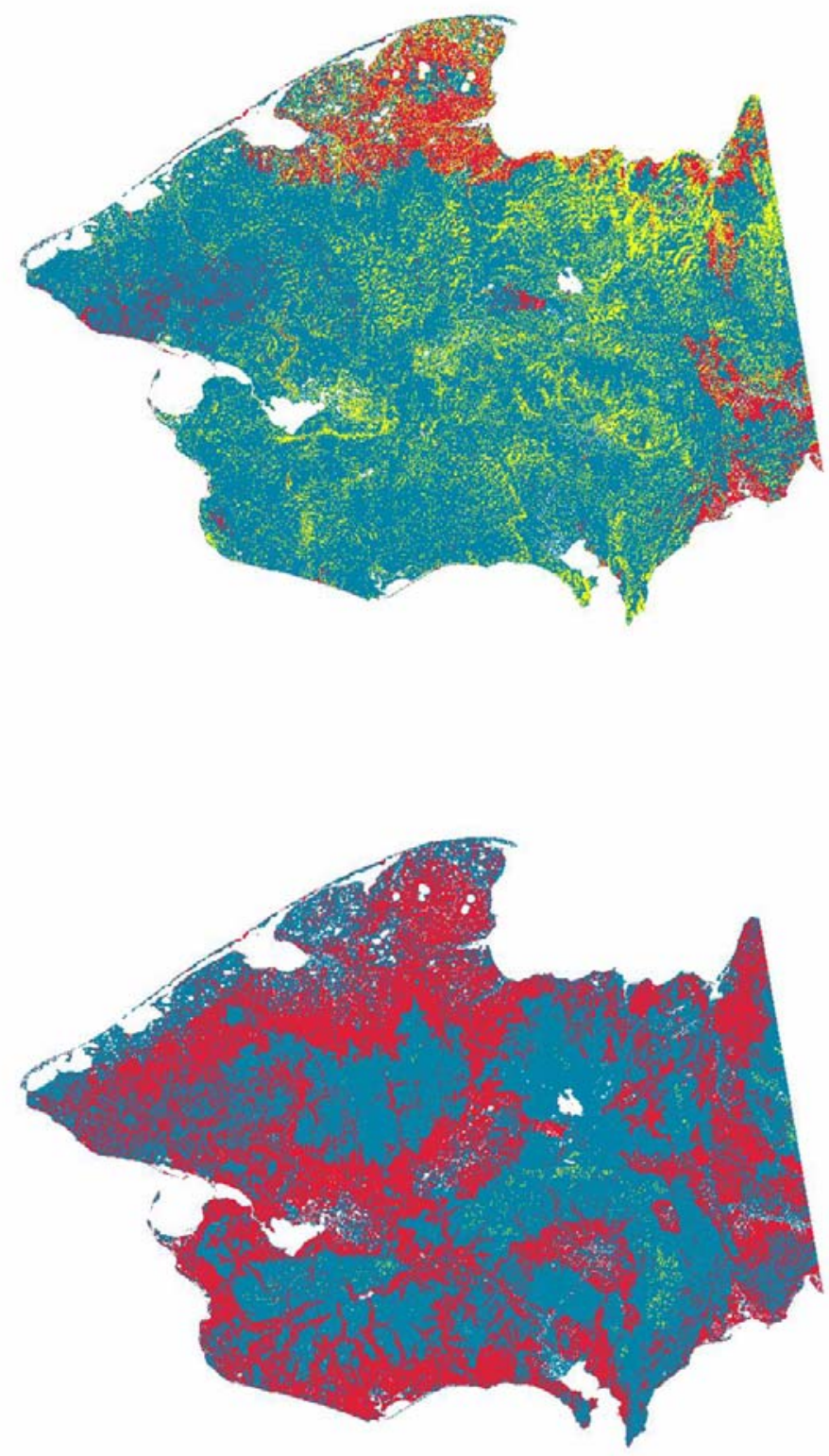

Images from Hinzman, L., R. Busey, and J. Cassano (2007) International Arctic Research Center, University of Alaska Fairbanks and Cooperative Institute for Research in Environmental Science, University of Colorado at Boulder. Images based on IPCC SRES Scenario AIB, and climate model output from U.S. Department of Commerce, NOAA, Geophysical Fluid Dynamics Laboratory, GFDL-CM2.0. 
Problems associated with increased rates of coastal erosion are the result of storm activity and wave action eroding shorelines once protected by shore-fast sea ice. The photo below (Figure II-5) shows how coastal storms have eroded the foundations of structures in western Alaska. This problem is expected to become chronic as the climate warms, sea ice retreats, and coastal storms become more frequent.

\section{Figure II-5. Coastal Storm Activity Undermines Foundations in Western Alaska}

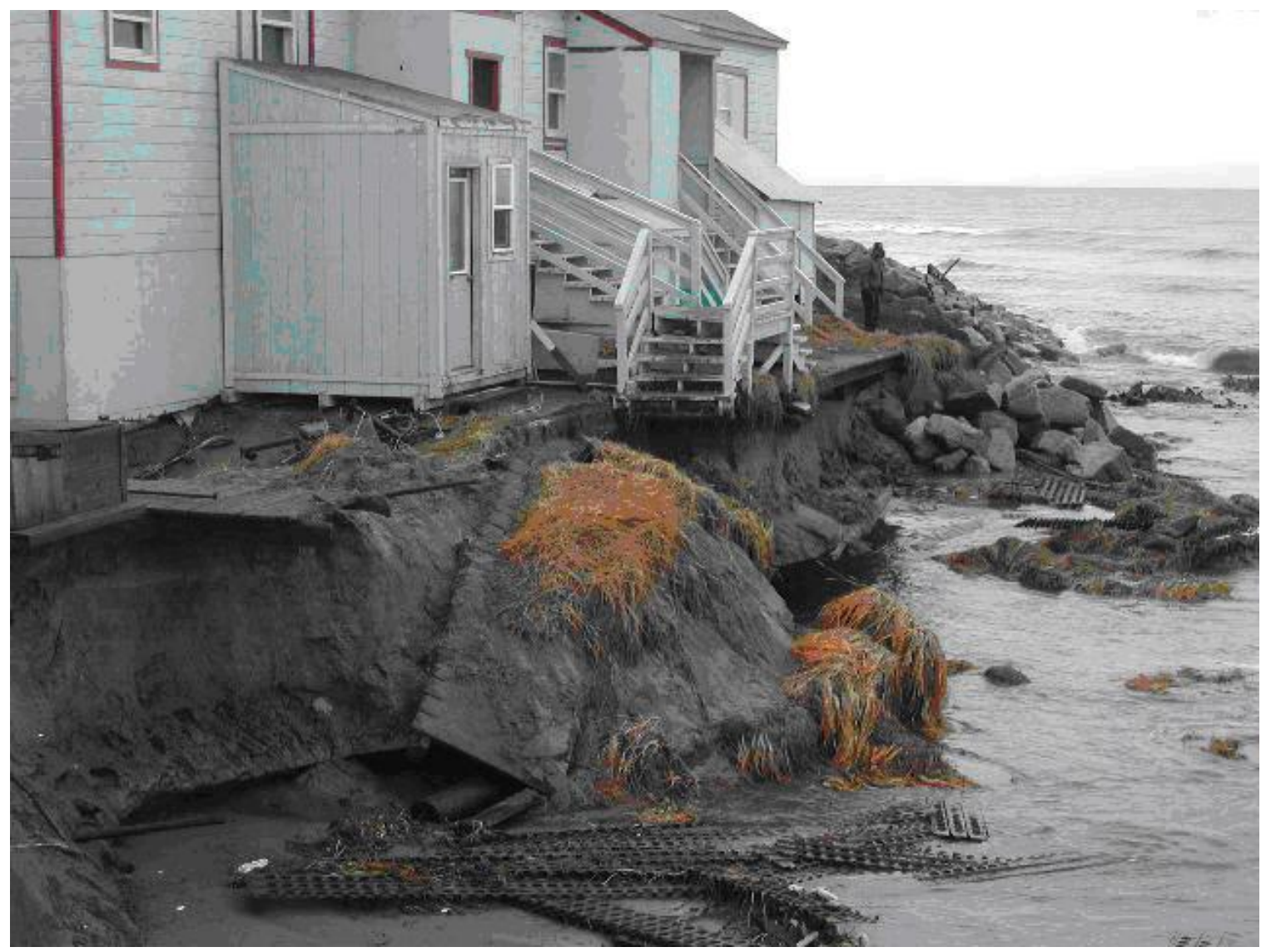

Photo courtesy U.S. Army Corps of Engineers, Alaska

A recent report by the Alaska branch of the U.S. Army Corp of Engineers estimated relocation costs for villages affected by flooding and coastal erosion in western Alaska. Most notably, the corps reports that the communities of Shishmaref, Kivalina, and Newtok must be moved in the next 10 to 15 years to avoid catastrophic losses. Figure II-6 shows projected shoreline erosion affecting community structures at Newtok. The corps estimates that relocating those villages could cost as much as $\$ 455$ million (see Table II-1). These special cases are not 
representative of all rural communities, and the cost estimates include a wide range of costs associated with moving entire communities. ${ }^{2}$ Costs for public infrastructure are just a part of the overall cost, and the corps report does not specify how much. Therefore, in later chapters, when we estimate future infrastructure costs, we do not include the corps' estimate of hundreds of millions of dollars for total community relocation costs. However, these communities underscore the magnitude of the potential effects of climate change.

\section{Figure II-6. Projected Coastal Erosion at Newtok, Alaska Through $2027^{3}$}

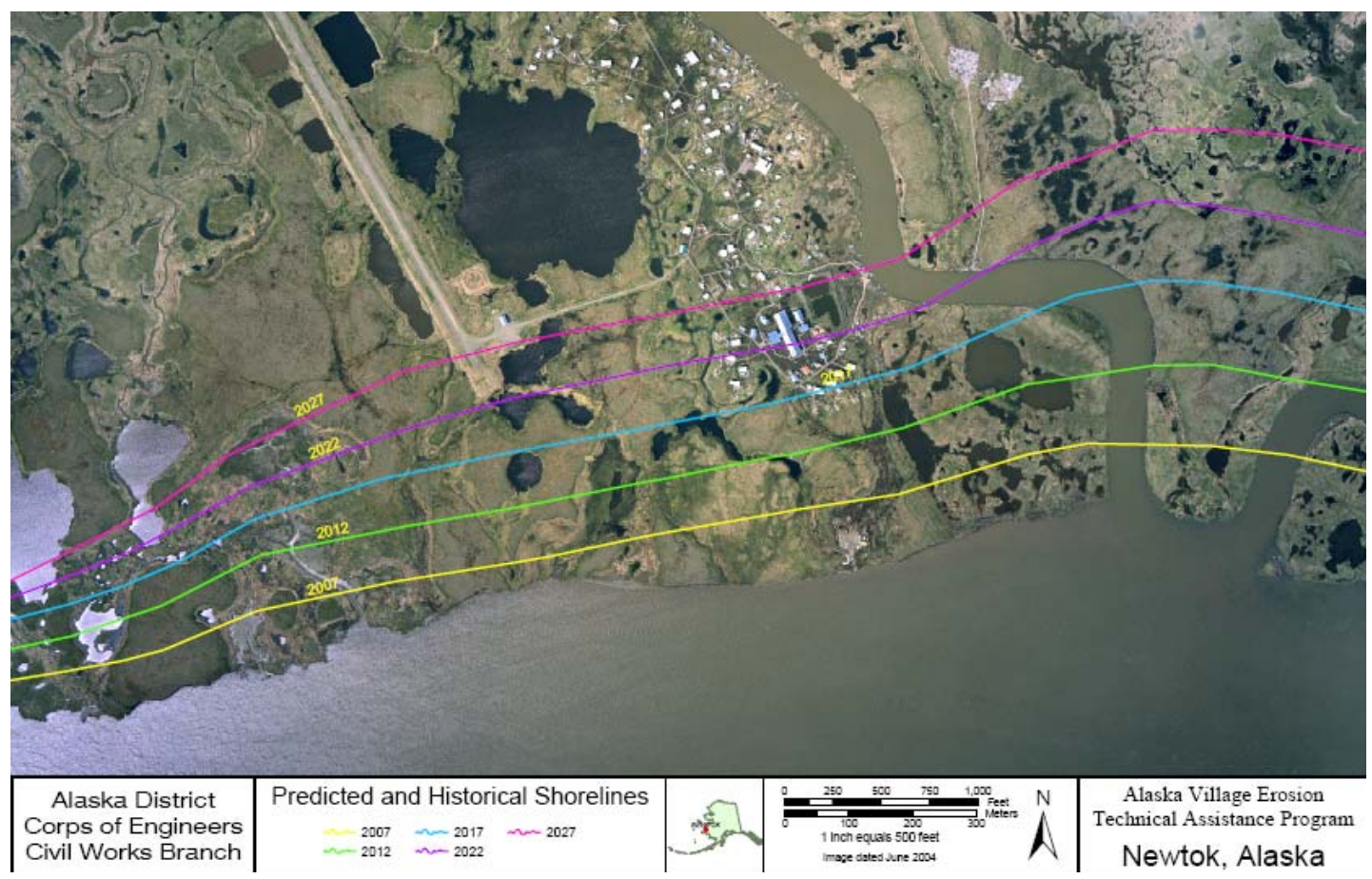

Image Source: Bruce Sexauer, U.S. Army Corps of Engineers, Alaska 2006

\footnotetext{
${ }^{2}$ The U.S. General Accountability Office has reported that "flooding and erosion affect 184 out of 213, or 84 percent, of Alaska Native villages to some extent. While many of the problems are longstanding, various studies indicate that coastal villages are becoming more susceptible to flooding and erosion caused in part by rising temperatures. Small and remote Alaska Native villages have generally not received assistance under federal flooding and erosion programs largely because they do not meet program eligibility criteria. Even villages that do meet the eligibility criteria may still not receive assistance if they cannot meet the cost-share requirements for the project (GAO, 2004).

${ }^{3}$ In the AVETA report, the U.S. Army Corps of Engineers states that coastal erosion was projected "by using a combination of aerial photography and ground measurements to track the rate of erosion over time, then assuming that rate continues, [we] determined the erosion line in the future."
} 
Table II-1. Estimated Protection and Relocation Costs for Three Alaska Communities ${ }^{4}$

\begin{tabular}{|c|c|c|c|}
\hline Community & $\begin{array}{c}\text { Costs of Future } \\
\text { Erosion Protection }\end{array}$ & $\begin{array}{c}\text { Costs to Relocate } \\
\text { Relocation Needed? }\end{array}$ \\
\hline Kivalina & $\$ 15 \mathrm{M}$ & $\$ 95-125 \mathrm{M}$ & $10-15$ years \\
\hline Newtok & $\$ 90 \mathrm{M}$ & $\$ 80-130 \mathrm{M}$ & $10-15$ years \\
\hline Shishmaref & $\$ 16 \mathrm{M}$ & $\$ 100-200 \mathrm{M}$ & $10-15$ years \\
\hline Totals & $\$ \mathbf{1 2 1 M}$ & $\$ \mathbf{2 7 5}-\mathbf{4 5 5 M}$ & $\mathbf{1 0 - 1 5}$ years \\
\hline
\end{tabular}

Source: U.S. Army Corps of Engineers, 2006

\section{What is Known About Potential Costs of Climate Change?}

The British government recently released what has become known as the "Stern Report" (or "Stern Review"). It found that climate change could cost the world's economy nearly 5\% of global gross domestic product, if nations do not take action to mitigate the effects of greenhouse gases and adapt to projected changes in temperature and precipitation (Stern, 2006). However, a number of critics have disagreed with that report's conclusions. Nordhaus (2006) believes the authors chose an exceptionally low social discount rate for their analysis (e.g., 0.1\%/year). The lower the discount rate used in such an analysis, the higher the present value of future costs. Tol and Yohe (2006) also detailed what they see as the shortcomings of the Stern analysis. Tol (2006) concluded that the Stern Review estimates are "well outside the usual range" and that the British government was "out of step with the economic literature on climate change" (Tol, 2006).

There have been a handful of papers on the costs of climate change for specific industries in the United States. For examples of how other academics have attempted to quantify, adapt to, or frame how to address the effects of climate change, see Nordhaus and Yang (1996); Nordhaus and Boyer (2000); Smith et al (2001); Yohe et al (1996); Mendelsohn et al. (2000); Tol and Fankhauser (1998); Jorgenson et al. (2004); Yohe and Tol (2002); Mastrandrea and Schneider (2004); and Toman (1998).

In addition, there have been local efforts to study the effects of climate change on communities. For example, the city of Boston conducted a study on the dollar costs of climate change (Kirshen et al, 2004). Seattle and London also conducted their own analyses and

\footnotetext{
${ }^{4}$ The Army Corps of Engineers report was specifically addressing "rapid coastal erosion of rural Alaska villages," which is often attributed to the increased storm activity and retreat of sea ice from abrupt climate change. The U.S. Arctic Research Commission also mentions in its report that increased storminess and higher waves are eroding Arctic coasts faster than in the past.
} 
concluded that inaction might have extremely high costs (London, 2002) (Cohen et al, 2005). Columbia University did a study for the "Metro-East Coast," indicating the potential economic effects of climate change on that region (Rosenzweig et al, eds, 2001). Hamilton City in New Zealand recently conducted a study indicating that "energy infrastructure systems" and "transport systems" face the largest number of effects induced by climate change, cutting across all sectors of the city's economy (Jollands et al., 2005).

Internationally, Canadian researchers have studied effects of climate change in the Mackenzie River Basin area of northern Canada and estimated some economic effects on business sectors. In one study, researchers developed an integrated impact assessment to study the overall economic effects of climate change on the Mackenzie River Basin (Cohen et al., eds., 1997). An earlier Canadian study, by Lonergan et al. (1993), used econometric analysis, stochastic (i.e., random) modeling, and input/output modeling to calculate the economic effects of climate warming in the Mackenzie River Valley and Northwest Territories.

There is very little information on the potential costs from damage to infrastructure resulting from climate change in Alaska. A recent report of the United States Arctic Research Commission (USARC) says:

Expected values of relocation and rehabilitation can be developed, given estimates of per-mile design and construction costs. A master plan of climate-change-induced major relocation and rehabilitation projects can be formed with this information. (USARC, 2003)

Some Alaska civil engineering and planning experts estimated in 1999 that the costs of dealing with infrastructure at risk from climate change would exceed the budgets of many of the agencies responsible for their upkeep and maintenance. Specifically they wrote: 
Based on these limited examples, the yearly cost for damages due to global climate change for the State of Alaska could be as high as $\$ 35 \mathrm{M}$, or $1.4 \%$ of the total state budget. This is a significant cost. It is very similar to the state and federal costs for fire fighting each year; it represents a sizeable fraction of the state's capital projects budgets of around $\$ 70 \mathrm{M}$; it is about equal to the budgets of the Department of Fish and Game at \$34M and the Department of Natural Resources at $\$ 40 \mathrm{M} . .$. . If the costs due to global climate change grow in future years, and if the state acknowledges cost for climate change in its budgetary balance sheets, these costs, which cannot be avoided, will seriously cut into other standard state programs with serious consequences for state fiscal policy. (Cole et al, 1999)

That rough, incomplete cost estimate of $\$ 35$ million per year, made in 1999, would be more than $\$ 40$ million per year now. If we then aggregate and discount from the year 2030 (using a $2.85 \%$ annual discount rate), we get a net present value of nearly $\$ 1$ billion needed to cover costs of climate change from now to 2030. And the most recent projections of climate variation are higher than projections in the late 1990s, when Cole et al. made that estimate. This simple estimate demonstrates that the potential cost of climate change for Alaska's public infrastructure is large and that more attention needs to be devoted to better understanding its magnitude. 


\section{Climate Projections}

To start our analysis, we needed to know how experts believe Alaska's climate will change in the coming years. The Institute for the Study of Society and the Environment at the National Center for Atmospheric Research provided ISER with 21 Atmosphere-Ocean General Circulation Model (AOGCM) climate projections for the years 2030 and 2080, developed by scientists in a number of countries. AOGCMs couple atmosphere general circulation models with ocean general circulation models to provide detailed projections of future climate conditions on a regional basis. That combination allows for the complex feedbacks between the atmosphere and oceans. The models also include societal inputs, including projected greenhouse gas emissions. Consequently, their output depends on assumptions about future industrial growth, technology, and carbon emissions. They are considered the most sophisticated ones currently available.

\section{Model Projections Used in This Analysis}

The 21 sets of projections we obtained include projected mean monthly temperatures and annual mean precipitation for six Alaska locations for the years 2030 and $2080 .^{5}$ All the projections show Alaska temperatures rising, but they vary in how much and how fast they project temperatures to rise. Joel Smith of Stratus Consulting, who is also an author of a recent report from the Intergovernmental Panel on Climate Change, recommended projections from three of the climate models - projecting less, mid-range, and more warming - to use as inputs in our analysis (Smith and Wagner, 2006). The choice was based on the dual criteria of model bias and uncertainty (Tebaldi et al, 2005; Tebaldi et al, 2004; Smith and Wagner, 2006). ${ }^{6}$

1. Warm Model: CSIRO Atmospheric Research, Australia, CSIRO-Mk3.0

2. Warmer Model: U.S. Department of Commerce, NOAA, Geophysical Fluid Dynamics Laboratory, GFDL-CM2.0

3. Warmest Model: Center for Climate System Research (University of Tokyo); National Institute for Environmental Studies; and Frontier Research Center for Global Change, Japan, MIROC3.2(hires)

\footnotetext{
${ }^{5}$ Unfortunately, the AOGCM outputs were not downscaled for this analysis. The course spatial resolution coming from the AOGCMs provided to us is represented by a grid approximately $5.6^{\circ}$ in latitude and longitude (or about 300 miles across). In this initial run of the model, we simply mapped community infrastructure to the regional projection which is geographically closest to that specific piece of infrastructure. Future iterations of the model will include statistically downscaled AOGCM output with high resolution spatial detail to the community level.

${ }^{6}$ When Smith and Wagner (2006) made their choices on the three representative models used in our analysis, they considered recent research by Tebaldi et al $(2004,2005)$ that involved ranking the AOGCMs based on their skill and performance at replicating past climate observations.
} 
All the models were calibrated and run as part of the Intergovernmental Panel on Climate Change (IPCC)'s coordinated AOGCM model inter-comparison project at Lawrence Livermore National Laboratory: PCMDI. The underlying model assumptions are based on a middle-of-theroad "A1B" emissions and growth scenario defined by the IPCC. The A1 scenario assumes strong economic growth and liberal globalization, low population growth, very high GDP growth, high-to-very high energy use, low-to-medium changes in land use, medium-to-high resource availability (of conventional and unconventional oil and gas), and rapid technological advances. The A1B scenario represents a "balanced" development of energy technologies. It assumes that no one energy source is relied on too heavily and that similar improvement rates apply to all energy supply and end use technologies (Nakićenović and Swart, 2000). ${ }^{7,8}$

Figures III-1 and III-2 show, as examples, how the projections we used fit into the pattern of all 21 projections for Anchorage and Barrow temperatures in 2080, compared with average monthly temperatures from 1980 to 1999. Notice that the projected temperature increases for Barrow are larger, and that they could be enough to make break-up of ice earlier, and freeze-up later, than today.

\footnotetext{
${ }^{7}$ The National Center for Atmospheric Research (NCAR) is a research institution in Boulder, Colorado. The climate projections data provided specifically came from the Institute for Study of Society and the Environment (ISSE) within NCAR, via the PCMDI collection at Lawrence Livermore National Laboratory.

${ }^{8}$ The Program for Climate Model Diagnosis and Intercomparison (PCMDI) collected and archived the model output and the JSC/CLIVAR Working Group on Coupled Modeling (WGCM) organized the model data analysis activity. The multi-model data archive is supported by the Office of Science, U.S. Department of Energy.
} 


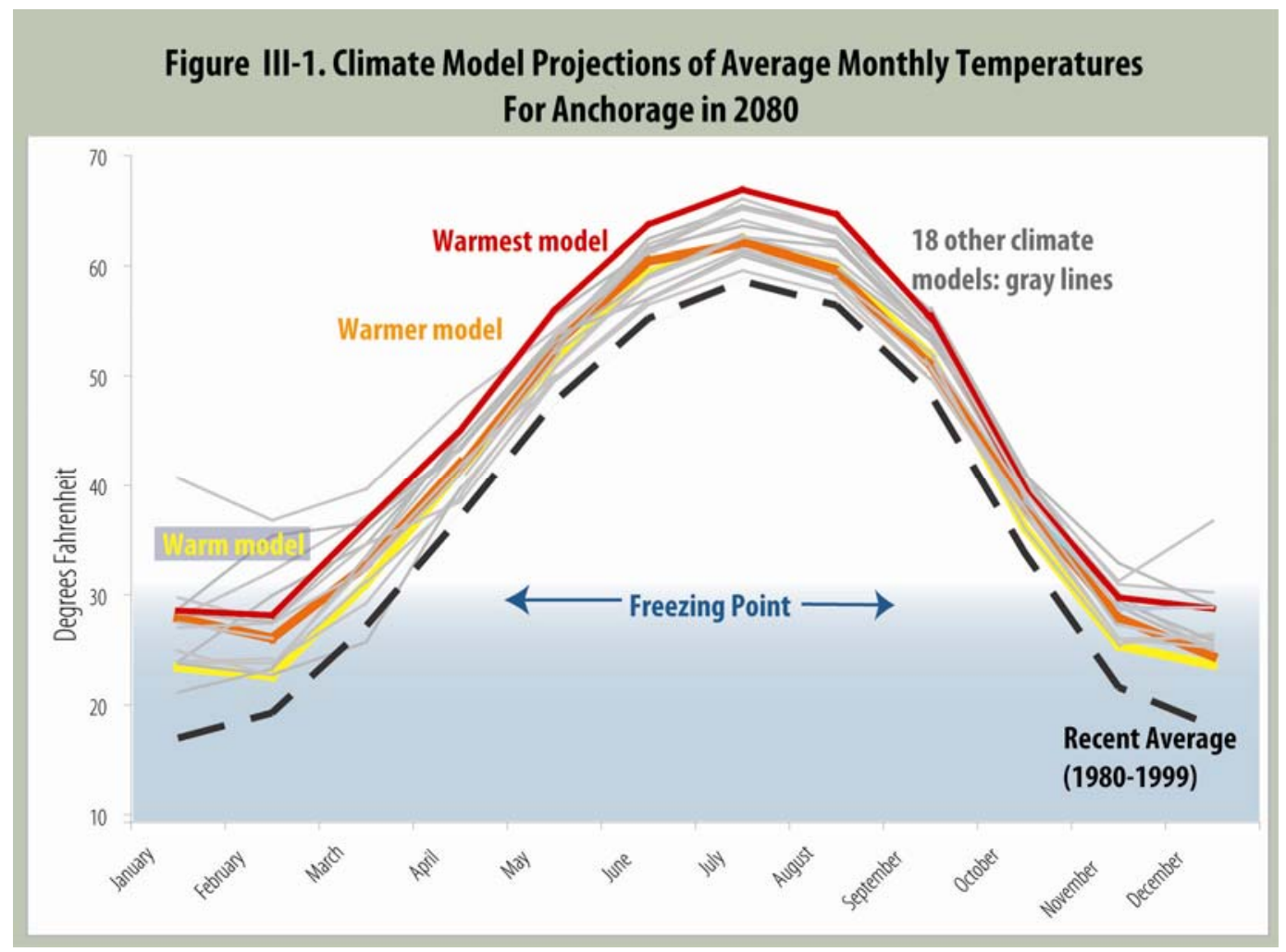

Figure III-2. Climate Model Projections of Average Monthly Temperatures, Barrow, 2080

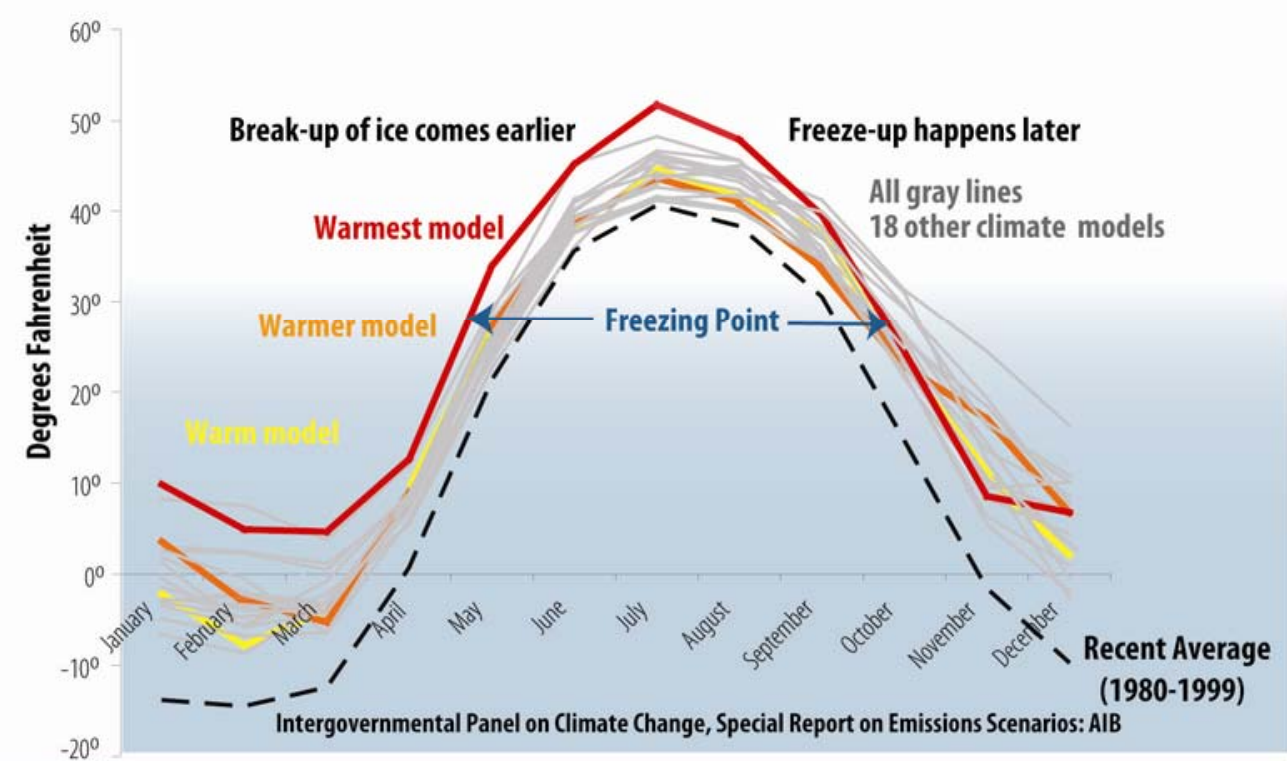


Anchorage and Barrow are two of the six Alaska locations for which we obtained projections. Figure III-3 shows all six Alaska locations, and for each also shows historical average annual temperatures and the projected temperatures for 2030 , under the three projections used in our analysis.

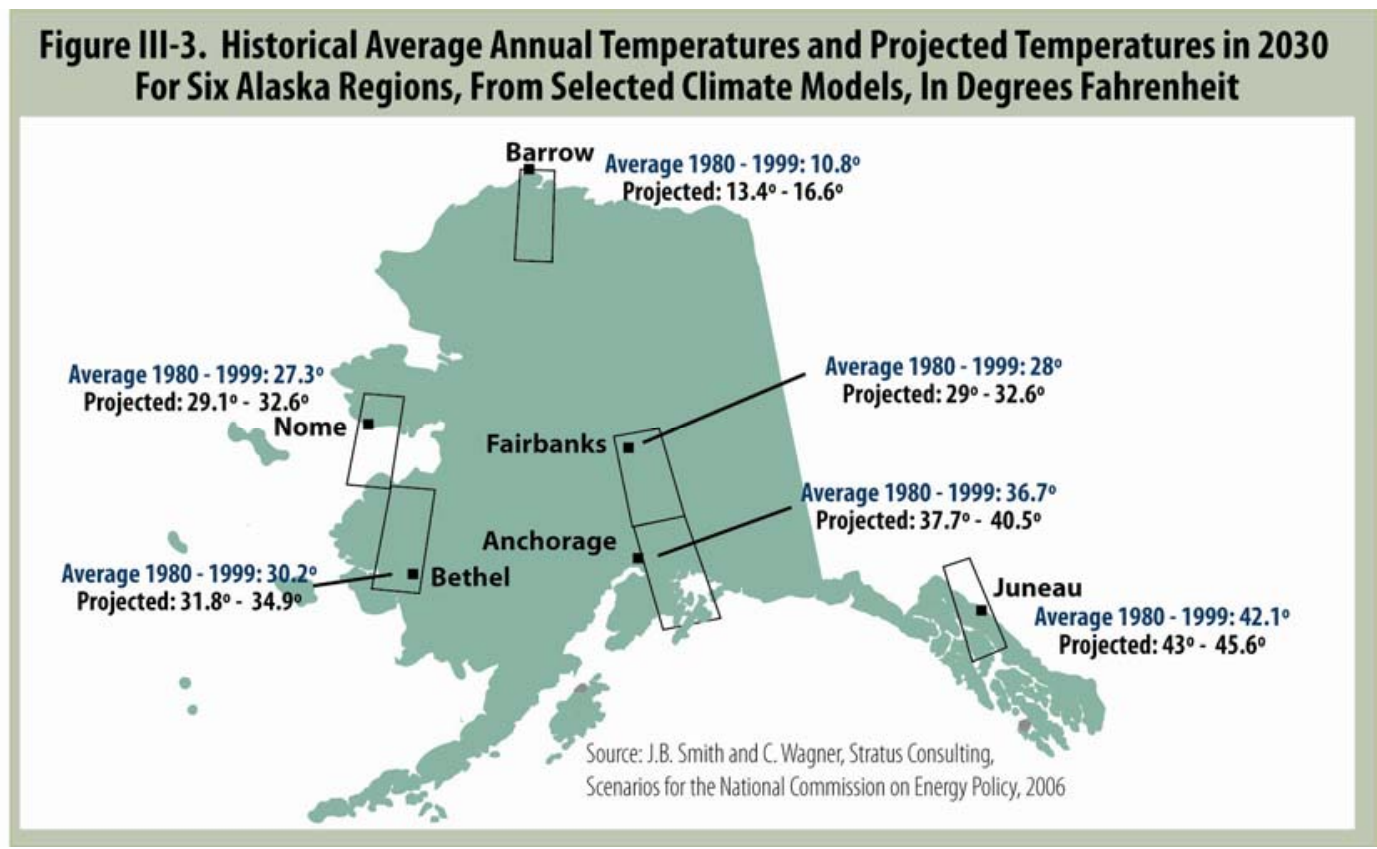

Table III-1 provides more information about the projected changes in temperature in the six Alaska locations shown in Figure III-3. It includes projections for both 2030 and 2080, illustrating the expected changes during that half century, as well as the historical averages. But we know that temperatures naturally vary from the averages in any given year, and Table III-1 also shows the standard deviations from the historical average temperatures.

Table III-2 shows the projected annual average precipitation amounts under the three sets of projections used in our analysis, as well as the historical averages and standard deviations. 


\begin{tabular}{|c|c|c|c|c|c|c|c|c|}
\hline \multirow[b]{3}{*}{ Region } & \multirow{2}{*}{\multicolumn{2}{|c|}{ Warm Model }} & \multirow{2}{*}{\multicolumn{2}{|c|}{ Warmer Model }} & \multirow{2}{*}{\multicolumn{2}{|c|}{ Warmest Model }} & \multirow{3}{*}{$\begin{array}{c}\text { Historical } \\
(1980-1999)\end{array}$} & \multirow{3}{*}{$\begin{array}{c}\text { Historical } \\
\text { Standard } \\
\text { Deviations }\end{array}$} \\
\hline & & & & & & & & \\
\hline & 2030 & 2080 & 2030 & 2080 & 2030 & 2080 & & \\
\hline Anchorage & 37.7 & 40.7 & 38.8 & 42.1 & 40.5 & 45.2 & \begin{tabular}{|l|}
36.7 \\
\end{tabular} & 2.2 \\
\hline Barrow & 13.4 & 18.4 & 14.5 & 19.5 & 16.6 & 24.2 & 10.8 & 2.2 \\
\hline Bethel & 31.8 & 35.9 & 33.8 & 37.2 & 34.9 & 39.7 & 30.2 & 2.4 \\
\hline Fairbanks & 29.0 & 32.2 & 30.6 & 34.1 & 32.6 & 38.4 & 28.0 & 2.3 \\
\hline Juneau & 43.0 & 45.7 & 43.8 & 47.1 & 45.6 & 51.0 & 42.1 & 1.8 \\
\hline Nome & 29.1 & 34.2 & 30.9 & 34.9 & 32.6 & 38.6 & 27.3 & 2.4 \\
\hline
\end{tabular}

\section{Table III-2. Historical and Projected Annual Precipitation, In Inches, Alaska Regions, 2030 and 2080, Selected Climate Models}

\begin{tabular}{|c|c|c|c|c|c|c|c|c|}
\hline \multirow[b]{2}{*}{ Region } & \multicolumn{2}{|c|}{ Warm Model } & \multicolumn{2}{|c|}{ Warmer Model } & \multicolumn{2}{|c|}{ Warmest Model } & \multirow{2}{*}{$\begin{array}{r}\text { Historical } \\
(1980-1999) \\
\end{array}$} & \multirow{2}{*}{$\begin{array}{c}\text { Historical } \\
\text { Standard } \\
\text { Deviations }\end{array}$} \\
\hline & 2030 & 2080 & 2030 & 2080 & 2030 & 2080 & & \\
\hline Anchorage & 17.7 & 17.4 & 17.5 & 19.4 & 17.5 & 20.2 & 16.8 & 3.3 \\
\hline Barrow & 4.3 & 4.7 & 4.4 & 4.8 & 4.5 & 5.6 & 4.2 & 1.9 \\
\hline Bethel & 18.1 & 18.6 & 17.7 & 18.1 & 17.5 & 20.4 & 16.7 & 4.9 \\
\hline Fairbanks & 11.3 & 11.2 & 11.3 & 12.5 & 11.1 & 13.4 & 10.7 & 2.9 \\
\hline Juneau & 60.3 & 65.2 & 64.9 & 73.1 & 63.3 & 73.3 & 61.0 & 10.9 \\
\hline Nome & 19.2 & 20.2 & 18.2 & 19.3 & 18.8 & 21.8 & 17.4 & 4.3 \\
\hline
\end{tabular}

Source: Lawrence Livermore National Lab (PCMDI Collection); NCAR/ISSE; ISER -UAA, 2006; UAF GI, 2006

\section{Developing Annual and Location-Specific Climate Projections}

Using the climate projections shown in the previous figures and tables, we developed annual projections for 350 Alaska locations, by year, in two steps. First, we interpolated mean temperature and precipitation values for all intervening years, using the available data for the three years 2006, 2030, and 2080.

Next, we identified the geographical center of each of the six climate regions and then spatially joined the 350 communities in which public infrastructure exists to those regions. The spatial join involved selecting the community layer in our mapping program and joining the centers of the regions to it. This is known as a "points to points" join. In this type of join, each community is given the attributes of the region center closest to it, 
as well as a distance field to show how close that line is (ESRI, 2006). All layers were projected in Albers NAD1927, Datum, North American 1927.

\section{Accounting for Uncertainty}

Recognizing the uncertainty surrounding point estimates of future temperature and precipitation, ${ }^{9}$ we next generated probability distributions around these annual mean projected values, using historical information on mean temperature and precipitation for roughly the past 75 years, provided by the University of Alaska Fairbanks' Geophysical Institute (UAF GI).

We used a Gaussian multivariate Monte-Carlo simulation to proxy 50 to 75 year observed natural variability around the projected means. ${ }^{10}$ Greene discusses a technique to estimate multivariate normal probabilities given a specified mean $(\mu)$ and $K$-variate covariance matrix $(\Sigma)$ (Greene, 2003). Similarly, the SAS programming language has a command (i.e., VNORMAL) that generates a multivariate normal random series. This command allows us to use the projected means $(\mu)$ from the AOGCMs, along with the co-variances of the historical regional temperature and precipitation $(\Sigma)$ measures, to generate preliminary likelihood probabilities around the climate projections (SAS, 2007).

This method does not take into account historical climate variability before the observed historical record. Forest et al. used natural variability to compute the noise covariance matrix that was obtained for several AOGCMs. The authors point out that they "implicitly neglected the dependence of natural variability on climate sensitivity or ocean heat uptake" (Forest et al., 2002). This "dependence" will clearly influence the uncertainty of the AOGCM projections and the final likelihood estimation that policymakers need for robust analysis.

As examples, Figures III-4 and III-5 show the results of our Gaussian MonteCarlo numerical simulation, using the projected means and observed historical variances

\footnotetext{
9 If the atmospheric scientists provide expertise on model uncertainty as noted by Tebaldi et al (2005), Tebaldi et al (2005), and Forest et al (2002), it would be possible to develop extremely accurate joint probability density functions relating natural variability and related effects on the mean climate projections.

${ }^{10}$ Another uncertainty inherent in this model, but difficult to correct for, is the fact that there may be hidden biases in the observational record of regional temperature and precipitation. For example, fundamental changes in the location and setup of a weather monitoring station in Bethel or Nome over time could have a significant impact on the credibility of the observed results.
} 
for two of the six locations - Juneau and Barrow-for which we had climate projections. The simulations in Figure III-4 are based on the warmer-model projections. Those in Figure III-5 are based on the warmest-model projections.

Figure III-4. Estimated Likelihood of Juneau's Annual Precipitation Variability (Warmer Model)

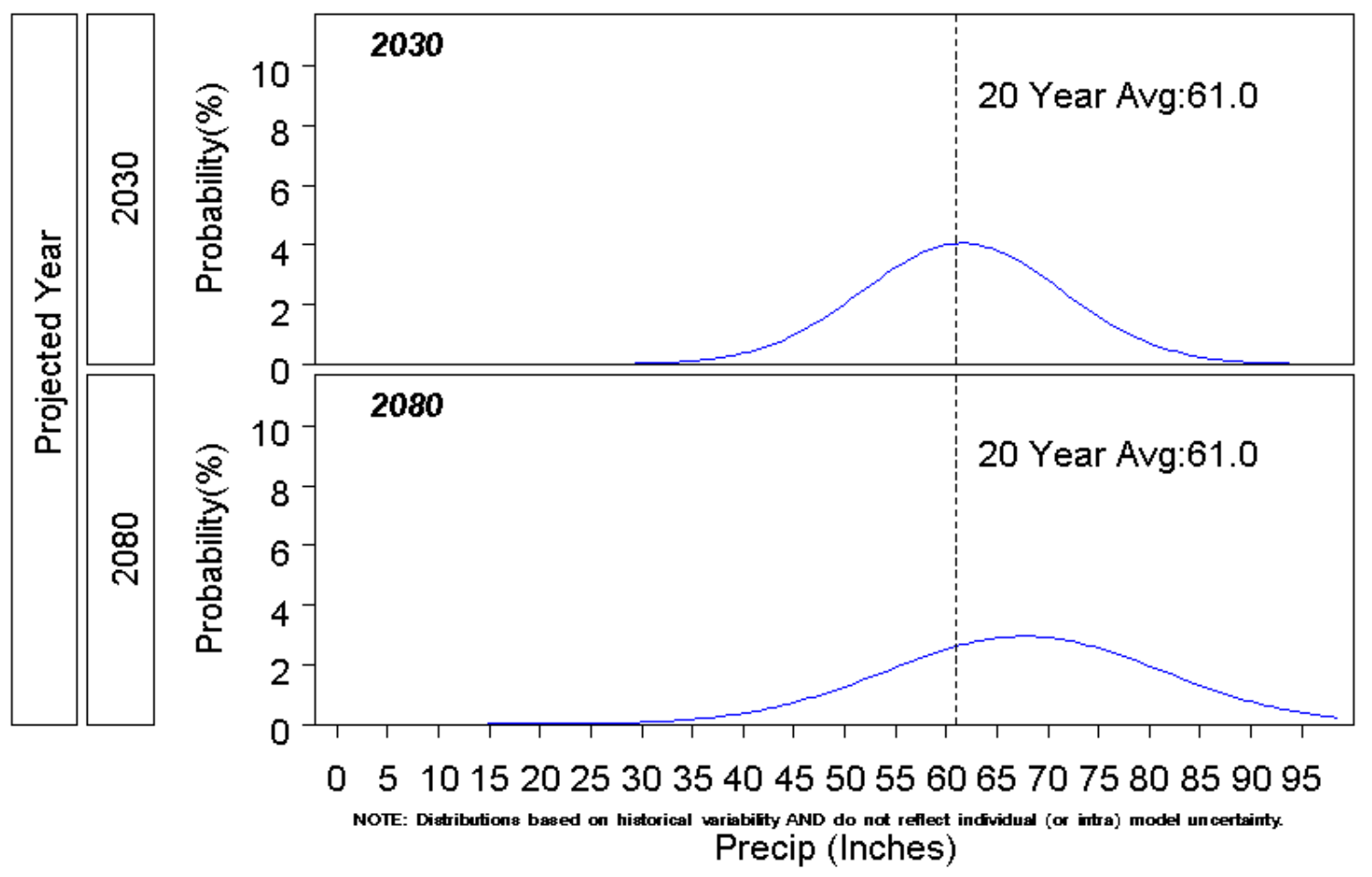


Figure III-5. Estimated Likelihood of Barrow’s Annual Temperature Variability (Warmest Model)

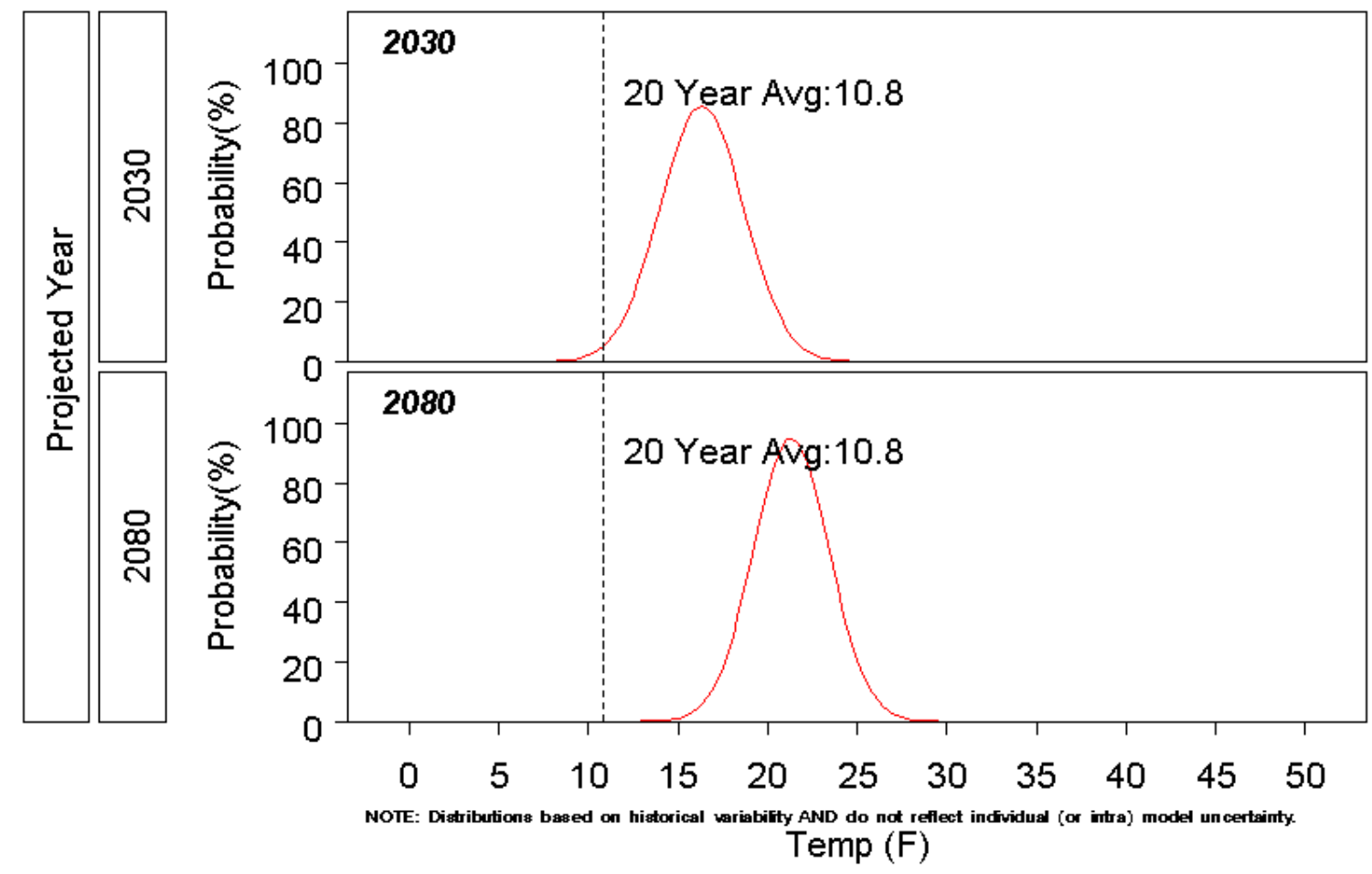

Climate change may include not only changes in the annual average temperature and precipitation, but also changes in the frequency or intensity of periodic events like storms (Brown et al, 2003) (USARC, 2003). Mathematicians-including Mandelbrot $(2006,2004)$ and Baillie (1996) — argue that climatological processes have "long memories" spanning centuries, and that these long memories may explain important natural variation in many systems. Personal and science-based observational records allow us to hypothesize that rather than using normal distributions, there may be more suitable "fat-tailed" distributions that could be used for our multivariate Monte-Carlo simulation, including the Cauchy distribution or mixed-normal distribution (Mount, 2006; Lavallee and Betrami, 2004). We have not yet examined the sensitivity of model results to variation in these distributions.

Recent literature (e.g., Schar et al, 2004) has statistically tested the hypothesis that temperature variability may be increasing over time, using the increased mean temperatures being observed in Europe. We could not find conclusive academic literature describing similar long-run increases (i.e., 50 years or more) in natural variability for Alaska or other Arctic 
regions. Curtis et al (1998) report that long-run precipitation frequency and intensity actually decreased for Barrow (and Barter Island) in northern Alaska. In addition, it was noted that variability of atmospheric pressure actually decreased over time. Therefore, we did not incorporate accelerating time trends in our distributions.

In their critique of the Stern Review, Carter et al. indicate that there is not enough empirical evidence to conclude whether extreme events are increasing in frequency or intensity (Carter et al., 2006). The authors point to the last IPCC report, implying through a selected quote that there is no evidence of a change in the frequency or severity of extreme events. However, the same IPCC report also concludes that:

New analyses show that in regions where total precipitation has increased, it is very likely that there have been even more pronounced increases in heavy and extreme precipitation events. . . . Overall, it is likely that for many mid and high latitude areas, primarily in the Northern Hemisphere, statistically significant increases have occurred in the proportion of total annual precipitation derived from heavy and extreme precipitation events; it is likely that there has been a $2 \%$ to $4 \%$ increase in the frequency of heavy precipitation events over the latter half of the 20th century (IPCC, 2001). 


\section{Public Infrastructure Database}

The second step in our analysis was assembling a database of public infrastructure in Alaska. According to researchers at the Congressional Research Service, critical infrastructure is a term used to describe the "material assets" that are essential for society and the economy to function. In line with that definition, the cost calculations in this analysis are based on public infrastructure - assets owned by local, state, and federal governments that are critical for delivering goods and services communities depend on (Moteff et al, 2003).

\section{Alaska Public Infrastructure Database}

There is limited publicly available information on the amount, type, location, age, and replacement cost of public infrastructure in Alaska, for a variety of reasons. Those include Alaska's huge size, ${ }^{11}$ security concerns in the aftermath of $9 / 11$, and the fact that in the past public agencies have not necessarily felt the need to collect and maintain that information.

Our Alaska Public Infrastructure Database (APID) is the first attempt to develop a comprehensive inventory of community-level information detailing the location of different classes of infrastructure, using secondary data sources. As additional information on the public infrastructure in the state becomes available, we will further refine the database. ${ }^{12}$

We compiled information from many sources, including the State Office of Risk Management; the Denali Commission; and the Alaska Department of Natural Resources, Transportation and Public Facilities, and Education and Early Development.

Table IV-1 shows our preliminary count of public infrastructure statewide, as well as estimated useful life and replacement costs.

\footnotetext{
11 Alaska is more than twice as large as Texas, with only about $10 \%$ accessible by road.

${ }^{12}$ Although we were not able to confirm that all information for the thousands of pieces of infrastructure in the database is accurate, we did randomly sample database information for some communities and compare that with confirmed information about infrastructure in given communities.
} 
Table IV-1. Preliminary Public Infrastructure Database ${ }^{a}$

\begin{tabular}{|c|c|c|c|c|c|}
\hline Type of Infrastructure & Count/Length & $\begin{array}{l}\text { Useful } \\
\text { Life } \\
\text { (Years) }\end{array}$ & $\begin{array}{l}\text { Replacement Cost } \\
\text { per Unit (In \$2006) }\end{array}$ & Units & $\begin{array}{l}\text { Replacement } \\
\text { Costs Total } \\
(\text { In } \$ 2006)\end{array}$ \\
\hline Airports & 253 & 20 & \$20 million & Whole & $\$ 5.06$ billion \\
\hline Bridges & $\begin{array}{l}823 \\
31.4 \text { miles }\end{array}$ & 40 & $\$ 10,000$ & Per Foot & $\$ 1.7$ billion \\
\hline Court facilities & 42 & 40 & $\$ 16$ million & Whole & $\$ 678$ million \\
\hline Defense facilities ${ }^{b}$ & 178 & 40 & $\$ 305,000$ & Whole & \$54 million \\
\hline $\begin{array}{l}\text { Emergency Services } \\
\text { (Fire stations, other) }\end{array}$ & 233 & 20 & $\$ 467,000$ & Whole & \$108 million \\
\hline $\begin{array}{l}\text { Energy (Fuel tanks, other } \\
\text { structures off power grid) }\end{array}$ & 234 & 30 & $\$ 32,000$ & Whole & $\$ 7$ million \\
\hline Misc. gvt. buildings & 1,571 & 30 & $\$ 1$ million & Whole & $\$ 1.6$ billion \\
\hline $\begin{array}{l}\text { Power grid (lines, } \\
\text { transformers substations) }^{b}\end{array}$ & $\begin{array}{l}68 \\
768 \text { miles of line }\end{array}$ & 15 & $\$ 100,000$ & Per Mile & \$77 million \\
\hline $\begin{array}{l}\text { Health buildings (clinics, } \\
\text { non-hospital facilities) }\end{array}$ & 346 & 30 & $\$ 1.6$ million & Whole & $\$ 565$ million \\
\hline Harbors & 131 & 30 & $\$ 10$ million & Whole & $\$ 1.3$ billion \\
\hline Public hospitals & 18 & 40 & $\$ 44.7$ million & Whole & \$806 million \\
\hline $\begin{array}{l}\text { Law enforcement (police } \\
\text { stations, prisons, other ) }\end{array}$ & 66 & 30 & $\$ 4$ million & Whole & \$259 million \\
\hline Alaska Railroad & $\begin{array}{l}45 \text { structures } \\
819 \text { miles track }\end{array}$ & 30 & $\$ 2.8$ million & Per Mile & $\$ 2.3$ billion \\
\hline Roads & $\begin{array}{l}10,476 \text { roads } \\
4,564 \text { miles paved } \\
5,000 \text { miles unpaved }\end{array}$ & 20 & $\begin{array}{l}\text { \$1 million (unpaved) } \\
\$ 3 \text { million (paved) }\end{array}$ & Per Mile & $\$ 18.7$ billion \\
\hline Schools & 520 & 40 & $\$ 2.5$ million & Whole & $\$ 1.3$ billion \\
\hline Sewer systems & 124 & 20 & $\$ 30$ million & Whole & $\$ 3.7$ billion \\
\hline $\begin{array}{l}\text { Telecommunications } \\
\text { (towers, satellites, other) }\end{array}$ & 275 & 10 & $\$ 300,000$ & Whole & $\$ 82$ million \\
\hline Telephone lines ${ }^{b}$ & $\begin{array}{l}20 \\
222 \text { miles }\end{array}$ & 15 & $\$ 50,000$ & Per Mile & $\$ 11.1$ million \\
\hline Water systems & 242 & 20 & $\$ 5$ million & Whole & $\$ 1.2$ billion \\
\hline Totals: & 15,665 & & & & \$39.4 billion \\
\hline \multicolumn{6}{|c|}{$\begin{array}{l}\text { a Compiled from publicly available information in } 2006 .{ }^{b} \text { The counts and the replacement costs in these categories are obviously low, especially } \\
\text { for defense facilities. In part for security reasons, little public information is available about the size and value of defense facilities. } \\
\text { Sources: Denali Commission; Alaska Departments of Transportation and Public Facilities, Administration (Risk Management), Commerce, } \\
\text { Community and Economic Development, Natural Resources, Education and Early Development; ISER }\end{array}$} \\
\hline
\end{tabular}


The database contains nearly 16,000 individual pieces of public infrastructure. Each item is placed in one of 19 infrastructure categories, identified by one of 350 locations (community), assigned a replacement cost and useful life, and further described by susceptibility to climate change. But lack of information meant we had to make a number of assumptions in compiling our initial database.

\section{Assumptions for Building Database}

Replacement costs for the nearly 16,000 pieces of infrastructure in the APID were difficult to collect and estimate for a number of reasons. First, there is very little easily accessible public information indicating the actual costs of the 19 subclasses of infrastructure by Alaska community. For this initial analysis, we used average costs computed across the state as rough proxies for each subclass, with different sources and techniques for the various categories of public infrastructure. Future iterations of this model will include more site-specific estimates of replacement costs. For example, in the future we hope to make distinctions between average costs for high- and low-rated voltage power lines.

We estimate the current total replacement cost of public infrastructure included in the database at nearly $\$ 40$ billion. Roads constitute almost $50 \%$ of that total, and airports and sanitation systems also make up substantial shares.

Roads make up so much of the total replacement cost of existing infrastructure because they are expensive to build and maintain, with the highest costs being in the placement of the roadbed, pavement, culverts, drainage, and roadside slope stability. Those components of roadways are also vulnerable to extraordinary deterioration from changes in average annual temperatures and in total precipitation. Normal use and the typical climate of Alaska make the useful life of roads significantly less than that of most buildings. The major repair of a road at the end of its useful life approaches the original cost of its construction.

In the database, the susceptibility of a given type of infrastructure to climate change at each location is defined by the presence of permafrost and the general local topography-proximity to the coast or a floodplain (USACE, 2006; USGS 2006).

Figures IV-1 and IV-2 show how the extent of permafrost (and therefore the vulnerability of infrastructure) varies around Alaska. The first figure shows the general distribution of four categories of permafrost in Alaska: continuous $(90-100 \%$ of area); discontinuous $(50-90 \%)$; 
sporadic $(10-50 \%)$; and isolated patches (less than 10\%). The second permafrost figure shows general susceptibility of highways and communities to permafrost. The database does not include soil classification related to frost susceptibility. Future refinements may better define soil characteristics, to allow for more accurate estimates of thaw settlement probability.

Alaska communities are exposed to varying degrees of permafrost. But a significant share of public infrastructure value (in the range of $40 \%$ ) is distributed in places underlain by different categories of permafrost coverage, as the estimates in Table IV-2 show.

\section{Figure IV-1. U.S. Geological Survey Illustration of Permafrost Spatial Variability with Regard to Frost-Susceptibility, 1997}

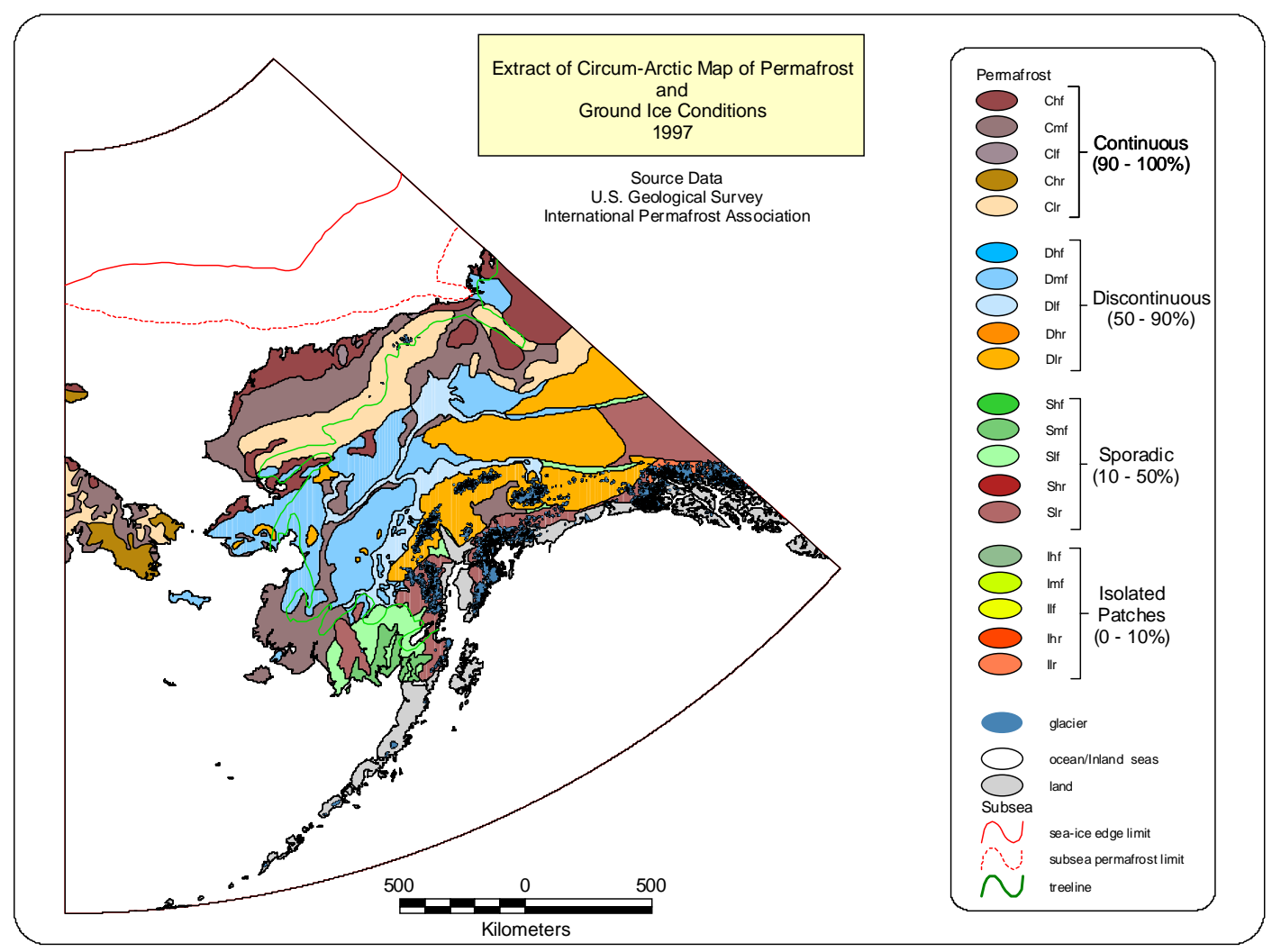

(Color scales descend from most to least frost susceptibility, i.e., tendency for dramatic settlement on thawing.) 


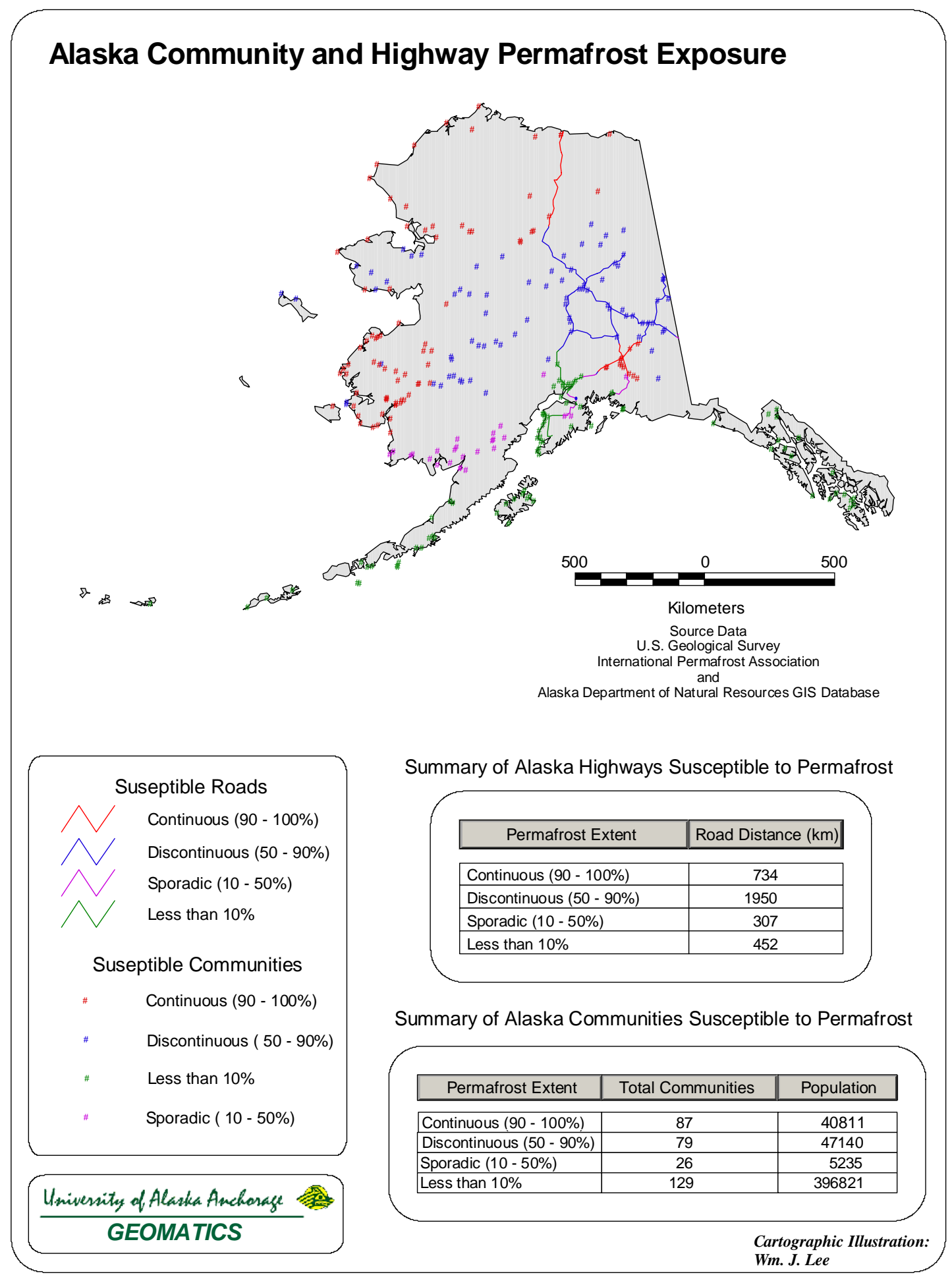

Note: The permafrost information in this map is older than that in Figure IV-1. 


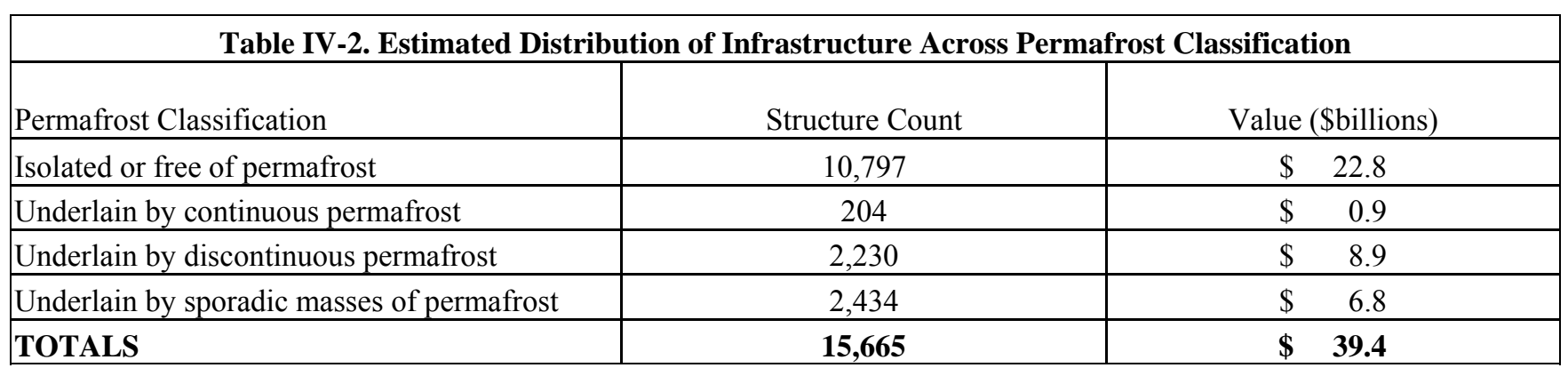

To identify communities in proximity to coastal and interior floodplains, we used information from the U.S. Army Corps of Engineers' Floodplain Hazard Database. The database records flood hazard potential by community. It also notes whether the flood hazards are coastal or from river runoff.

\section{Geographic Distribution of Infrastructure}

The infrastructure database is linked to a software program that allowed us to map the specific location of each class of infrastructure across Alaska. Figures IV-3 through IV-8 are maps depicting the locations of specific types of infrastructure throughout Alaska. 
Figure IV-3. Location of Emergency Services Infrastructure in Alaska

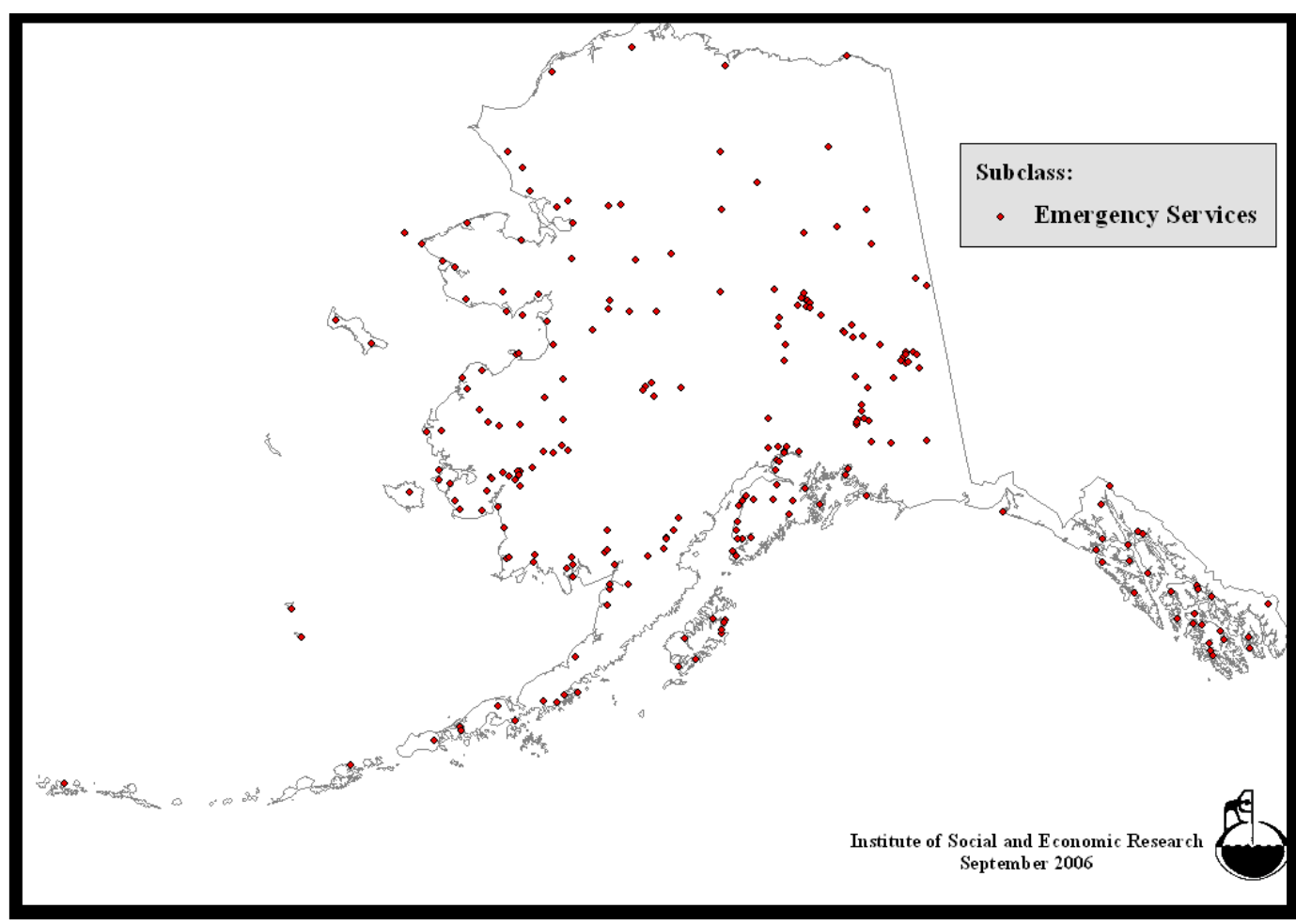

Figure IV-4. Location of Government Building Infrastructure in Alaska

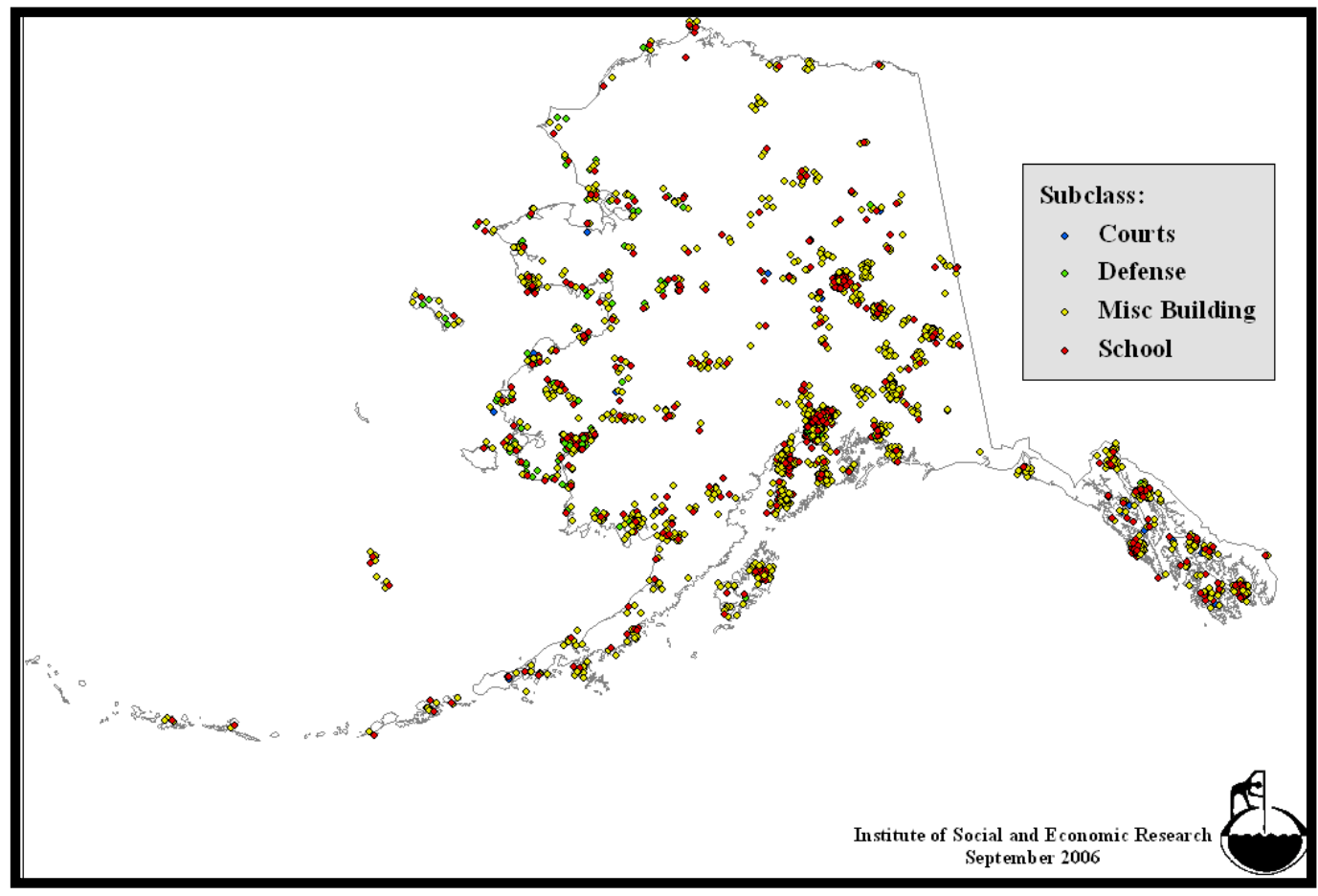


Figure IV-5. Location of Law Enforcement Infrastructure in Alaska

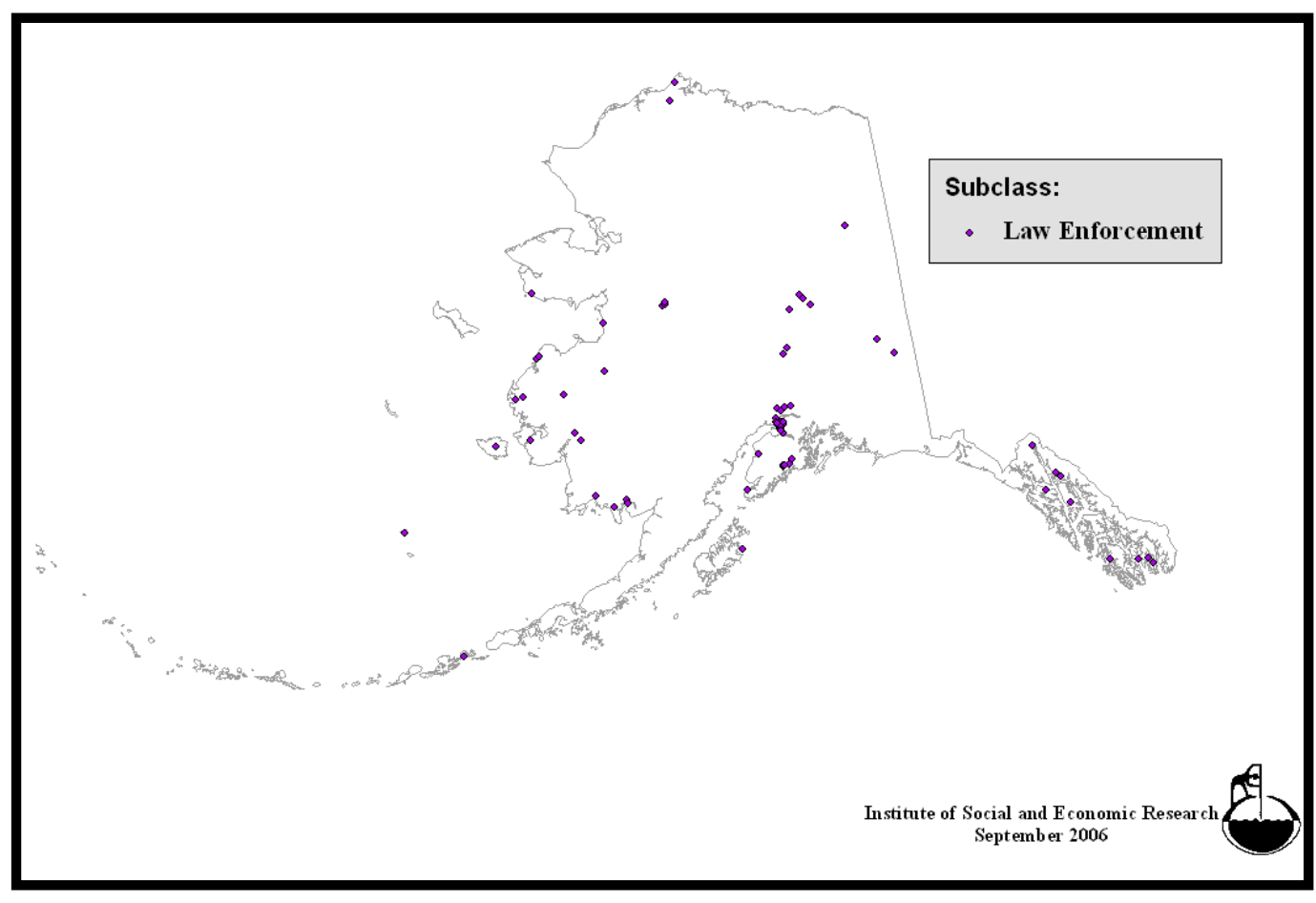

Figure IV-6. Location of Public Health Infrastructure in Alaska

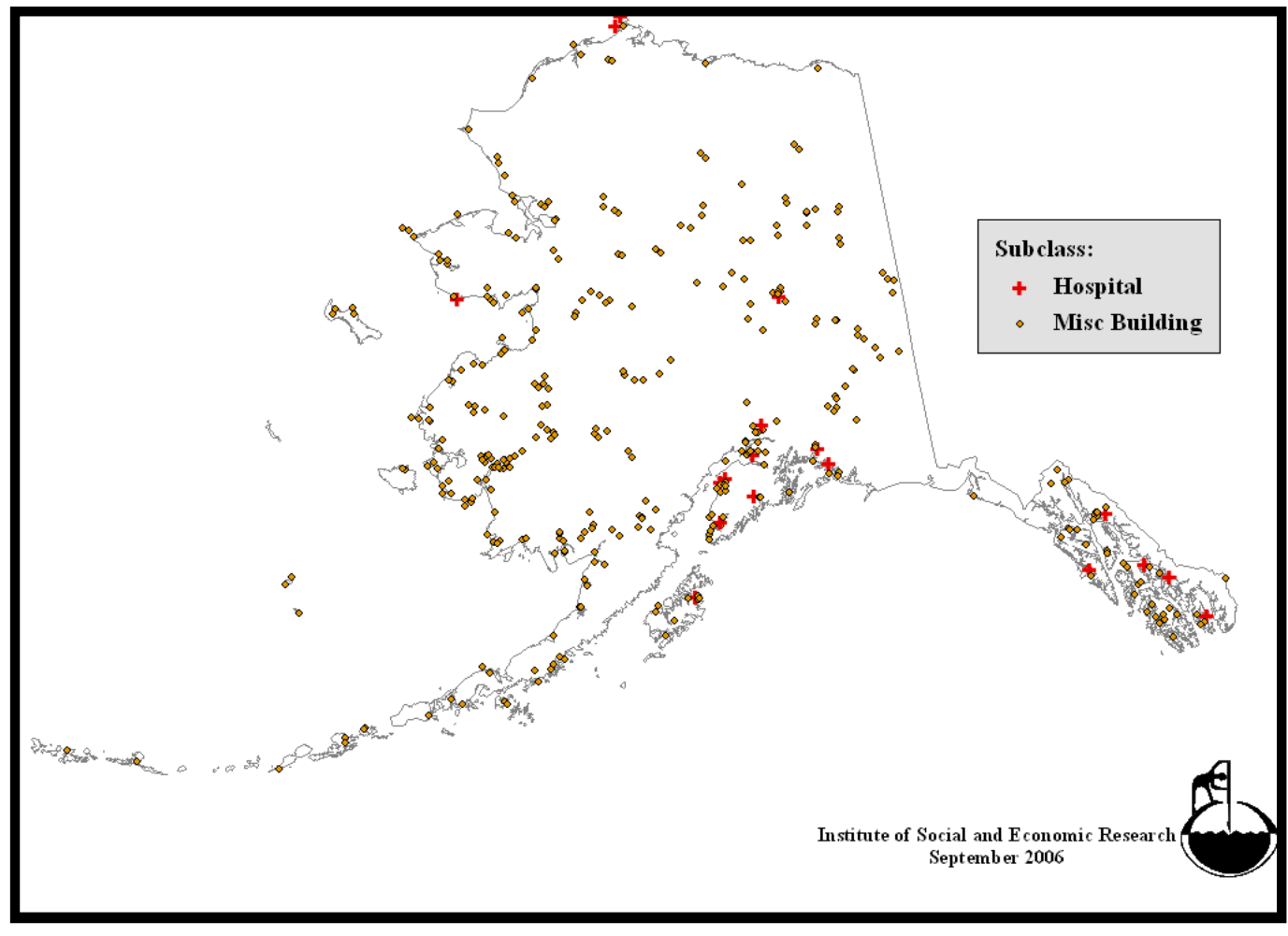


Figure IV-7. Location of Public Utilities Infrastructure in Alaska

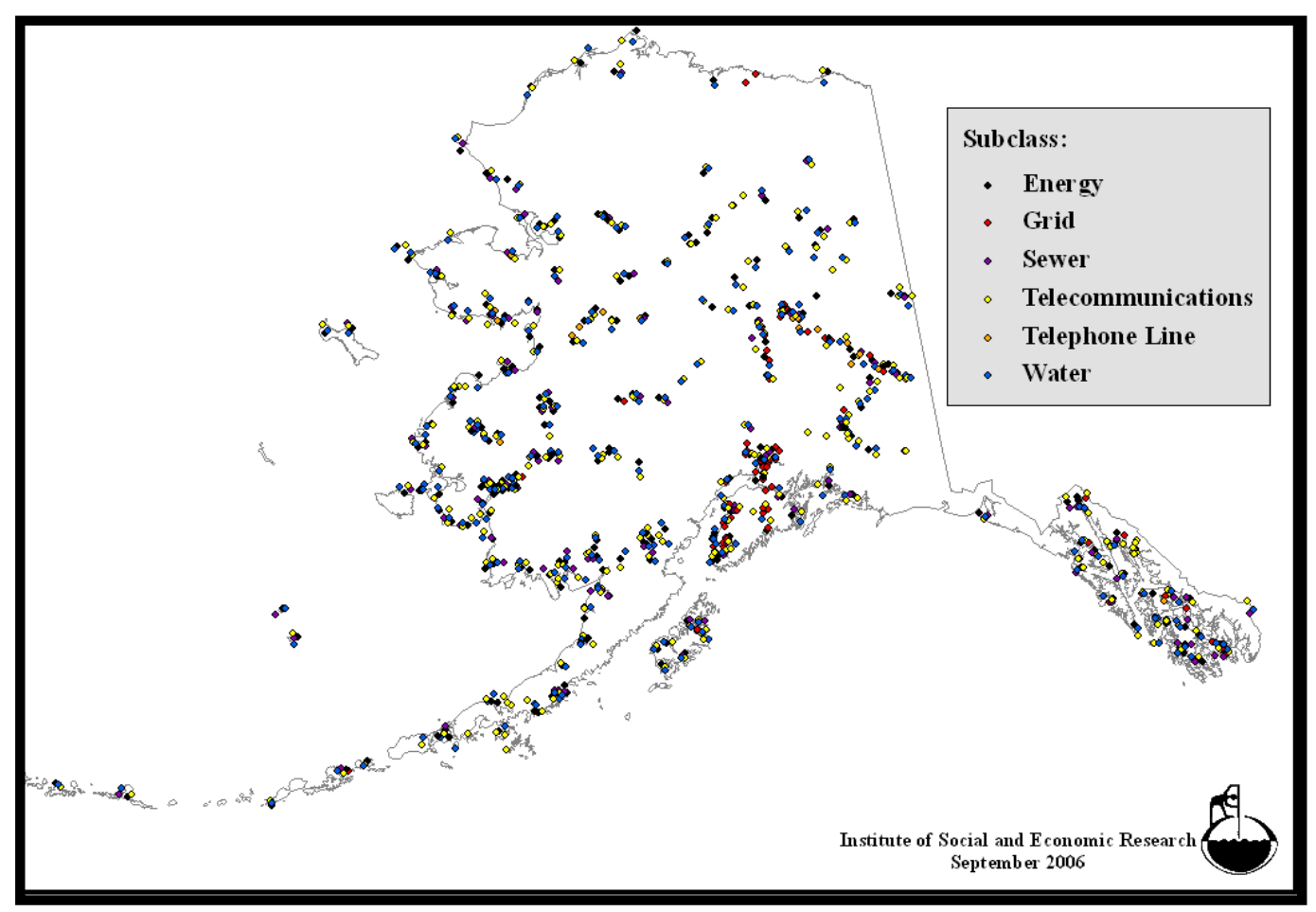

Figure IV-8. Location of Transportation Infrastructure in Alaska

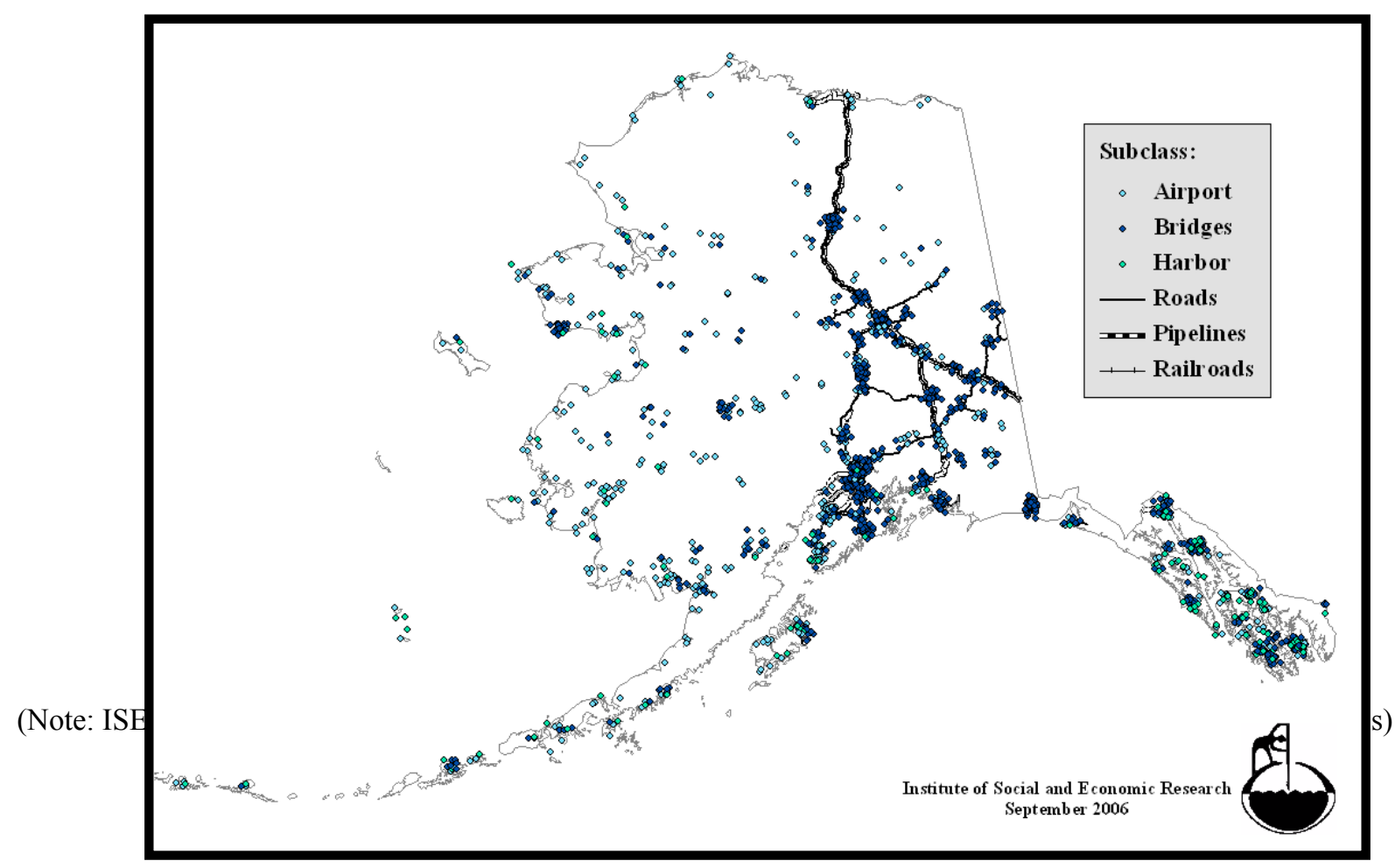




\section{ICICLE MODEL DESCRIPTION}

We combined the output from the climate models with the infrastructure database in a life-cycle cost model - the ISER Comprehensive Infrastructure Climate Life-Cycle Estimator (ICICLE). This model allows us to calculate the net present value cost of infrastructure at risk due to climate change, driven by changes in temperature and precipitation. That choice fits Professor Samuelson's definition of "True Economic Depreciation (TED)," as Rayner and Malone discuss in the context of the costs of inundation from sea-level rise (Samuelson, 1964; Rayner and Malone, 1998).

True economic depreciation, modeled to start at some fixed time prior to [sea-level] inundation and to finish just when inundation would occur, is an appropriate representation of the maximally efficient market response to (known) risk of future sea-level rise. TED is, by definition, a representation of how the value of an asset declines over time as it moves toward its retirement from service. (Rayner and Malone, 1998)

\section{Basic Model Structure}

The basis for the model is the calculation of the net present value of infrastructure replacement over time, under different conditions. For example, the average life span of a road might be 20 years. Therefore, if we know the current age of a particular road, we can estimate the number of times that road will have to be replaced in a given period. Calculating the base case replacement costs is simply a matter of taking the present value of the annualized replacement costs and aggregating them.

Figure V-1 shows the value timeline of a hypothetical piece of infrastructure that would need to be replaced three times between 2006 and 2080, under our base case scenario-which assumes no climate change and therefore provides the benchmark for estimating effects of climate change. 


\section{Figure V-1. Replacement Timeline for a Hypothetical Road (Base Case, Assuming Static Climate)}

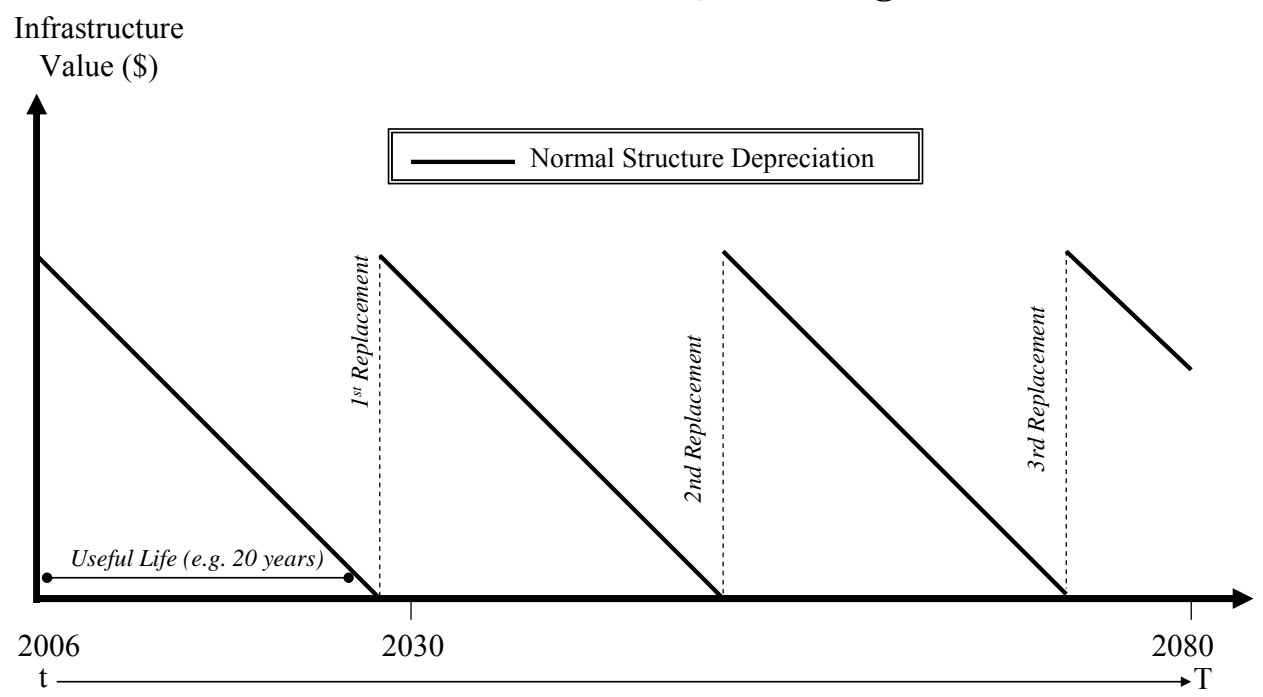

Assuming the road was built in 2006, with a useful life of 20 years, it would need to be replaced in 2026, 2046, and 2066. The total cost would be the sum of the cost of replacement in 2026, 2046 and 2066. The net present value would be those costs discounted to the present, at an appropriate discount rate.

Again using the base case scenario, and summing across all existing Alaska public infrastructure, we estimate it would cost $\$ 32$ billion (in net present value) to maintain and replace existing infrastructure through 2030 and $\$ 56$ billion through 2080. Those estimates do not take into account climate change: they represent the costs of ordinary wear and tear on Alaska infrastructure. Net present value is a standard way of summarizing costs over long periods. It represents the total amount that would need to put in a bank today, earning interest, to pay the costs of maintaining existing public infrastructure through 2030 and through $2080 .^{13,14}$

Our model assumes climate change will reduce the useful life of infrastructure, so that it has to be replaced sooner - and that costs will then be higher. (It is also possible, under some circumstances, that climate change could actually increase the life of some infrastructure. In this initial work, we haven't identified any such exceptions.)

\footnotetext{
${ }^{13}$ The real discount rate in this example is $2.85 \%$ /year.

${ }^{14}$ This estimate is used only as a basis for comparing additional costs resulting from climate change. The base case estimate does not necessarily reflect the amount of money the legislature or federal agencies need to save today to maintain our current level of infrastructure.
} 
Figure V-2 illustrates hypothetically how the same piece of infrastructure we assumed would need replacement once every 20 years might need to be replaced every 16 years, because of climate change. ${ }^{15}$ For a planning horizon to 2080 , the total cost in this example is the sum of five replacements at 16 year intervals.

Figure V-2. Replacement Timeline of Infrastructure (Climate Change Scenario)

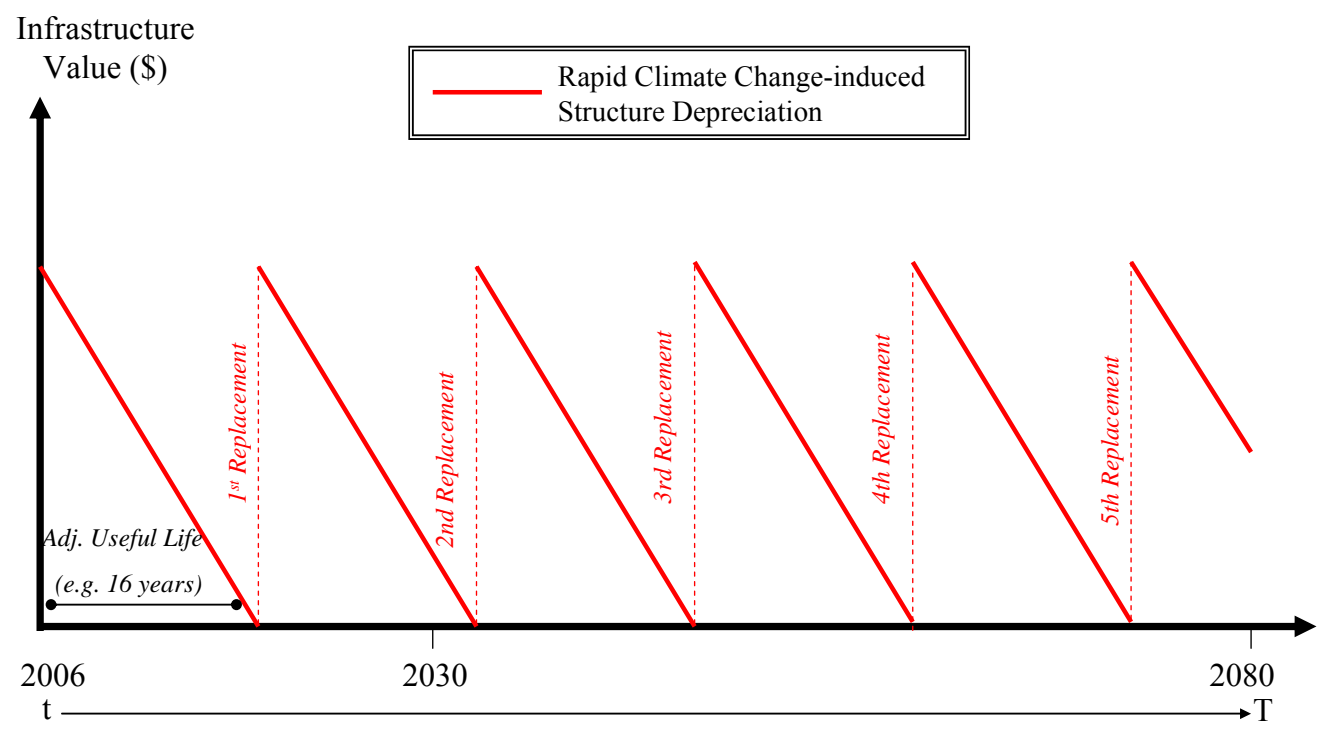

The net present value of infrastructure at risk from climate change is the difference in lifecycle cost of maintaining the public infrastructure in Alaska in the absence of climate change (base case scenario) and the cost with climate change (climate change scenario).

Figure V-3 illustrates our model assumption. Climate change shortens the interval between replacements and thus increases the costs over a given period. That difference in costs will also increase as the time horizon increases.

\footnotetext{
${ }^{15}$ This is an extreme assumption, merely to illustrate the concept.
} 
Figure V-3. The ICICLE Model

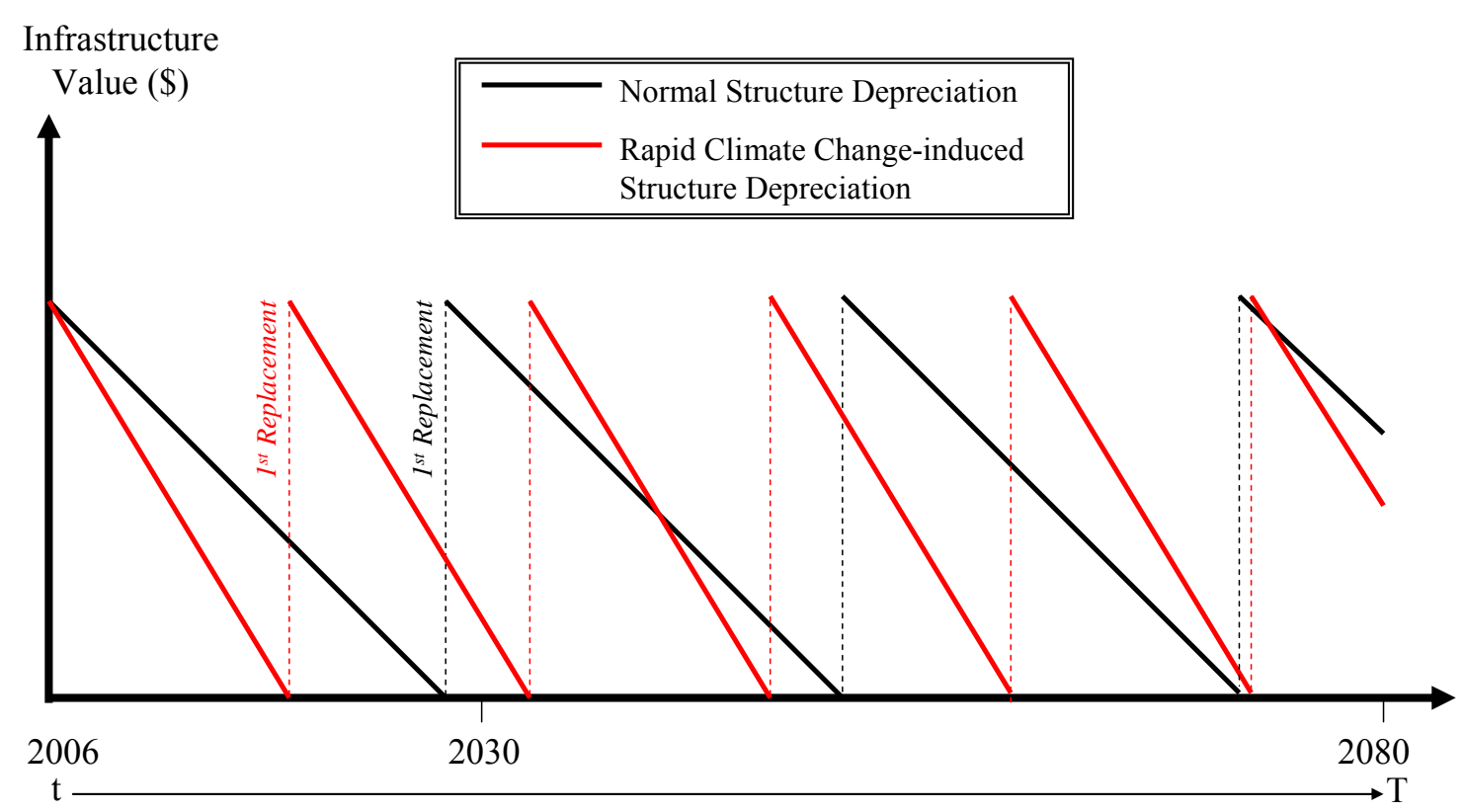

The formal calculation is shown in Figure V-4. The cost of each scenario is the present value of the annual replacement costs, aggregated across all categories of infrastructure. We calculate the replacement cost for each unit of infrastructure on an annual basis as the total cost of its replacement divided by its useful life. 
Figure V-4. ICICLE Model Functional Form

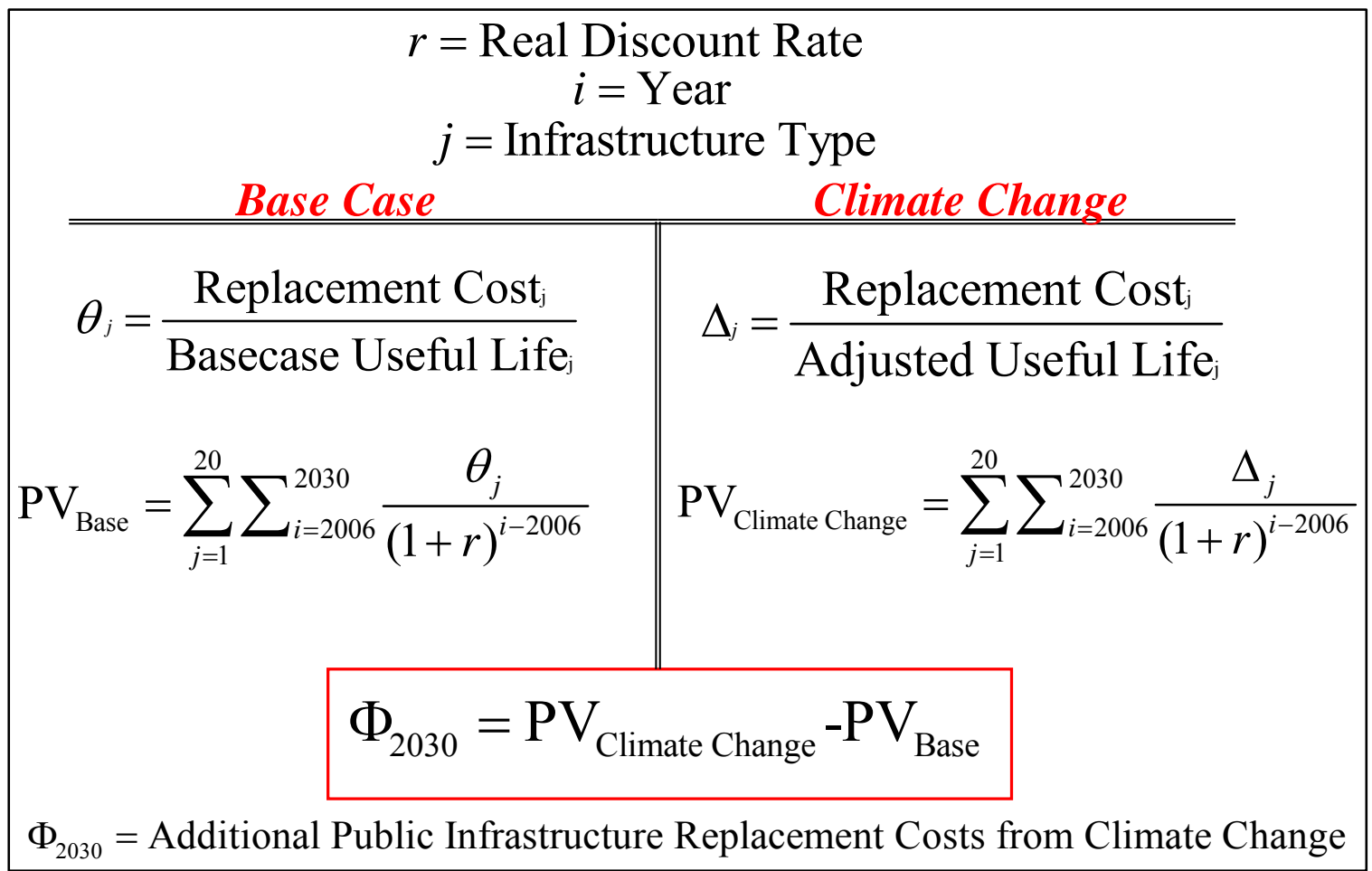

\section{Useful Life Adjustment Coefficients}

Warming air temperatures, increased precipitation, and storms result in environmental changes such as coastal erosion. Some examples of how climate change can harm infrastructure, as well as possible responses in the face of climate change, are listed in Table V-1 below. The link between temperature and precipitation and secondary changes is complex and not easily characterized. For example, although sea level rise is monitored, global projections for the rise vary widely and the effect will depend on local conditions such as, in Alaska, tectonic upheaval.

Furthermore, the responses required to maintain the quality of the infrastructure will depend on local site and infrastructure characteristics. Degradation may result in increasing costs for ordinary maintenance, for complete replacement of the facility at a different site, or for alternative responses. Buildings may require extraordinary maintenance and repairs to roofs, siding, windows and doors, plumbing, mechanical and electrical equipment, or other features due to deterioration of materials associated with freeze-thaw cycles. The most expensive damage will occur when a building's permafrost foundation thaws and settles. Buildings on the open coast may also experience more flooding and wave attack, because receding sea-ice cover allows more 
wave generation and coastal storm surge during increasingly frequent storms. Foundations of coastal and shoreline buildings erode faster during these storms, without the protection of shorefast ice that was typical in previous decades. Buildings on riverbanks may experience more flooding from increased runoff or from ice jams induced by increased mid-winter thawing spells.

All these expenses, from increases in maintenance costs to costs for complete replacement at safer locations, are estimated here by the reduced useful life of the structure. Future enhancements of this work may distinguish more specific types of deterioration and more specific maintenance costs.

Both natural variability (weather) and systematic climate change affect the rate at which different classes of infrastructure depreciate (i.e., lose their useful value) over time. For example, increased flooding may undermine the foundation under a bridge, thus shortening the useful life span of the bridge from 50 years to 40 years or less. Excessive coastal erosion caused by intense storms can wash away roads, and warmer temperatures can cause permafrost layers to melt, cracking building foundations. Climate-change effects are qualitatively discussed in the Arctic Climate Impact Assessment (Instanes et al 2005). Quantitative predictions of effects on infrastructure are, however, rare (e.g., Soo Hoo et al., 2005).

\begin{tabular}{|l|l|l|}
\hline \multicolumn{3}{|c|}{ Table V-1. Examples of How Increased Temperatures and Precipitation } \\
Can Harm Infrastructure \\
\hline Change in site conditions & Impact on infrastructure & Range of response actions \\
\hline Thawing permafrost & Settlement of foundations & $\begin{array}{l}\text { Repair, relocation, complete } \\
\text { replacement at new site }\end{array}$ \\
\hline Sea-level rise & $\begin{array}{l}\text { Inundation of low-lying } \\
\text { coastal property }\end{array}$ & $\begin{array}{l}\text { Repair, build flood control } \\
\text { works relocation, complete } \\
\text { replacement at new site }\end{array}$ \\
\hline Sea-level rise & Coastal erosion & $\begin{array}{l}\text { Repair, build erosion } \\
\text { control works, relocation, } \\
\text { complete replacement at } \\
\text { new site }\end{array}$ \\
\hline Increased runoff & Flooding along rivers & $\begin{array}{l}\text { Repair, build flood control } \\
\text { works relocation, complete } \\
\text { replacement at new site }\end{array}$ \\
\hline Increased runoff & Stream bank erosion & $\begin{array}{l}\text { Repair, build erosion } \\
\text { control works, relocation, } \\
\text { complete replacement at } \\
\text { new site }\end{array}$ \\
\hline
\end{tabular}


We recognize and incorporate into our modeling the fact that the additional costs for infrastructure resulting from climate change depend on the presence of permafrost and the location of the infrastructure in relation to the coast or floodplains.

\section{Presence of Permafrost}

Widespread thawing of permafrost is the most worrisome potential effect of climate warming on Alaska infrastructure (Nelson et al 2003). Thawing across the region surrounding a building or a pipeline with a permafrost foundation will render ineffective thermopiles or other means of protecting the frozen ground from warming by the structure itself. Dramatic settlement will occur if the frozen ground has high ice content and fine soil grains. This type of soil is generally classified as "frost-susceptible" soil. Non-frost-susceptible soil has coarse grains of sand and gravel and does not lose as much bearing capacity when ice thaws in the pores.

In this analysis we consider two types of building response to thawing permafrost foundations: (1) dramatic settlement and complete loss of the facility that will occur for buildings over permafrost composed of frost-susceptible soil; and (2) moderate settlement requiring substantial repairs that will occur for buildings over permafrost composed of non-frostsusceptible soil. Structures not located on permafrost are not anticipated to experience settlement attributable to climate change. Buildings or other structures that require relocation are assumed to be moved to sites without risk of thaw settlement and thus regain their full useful life. Warming and precipitation effects on building materials — roofs and windows, for example — are not considered in this analysis.

Infrastructure's useful life consequently depends on its location in relation to permafrost and on temperature. Table V-2 shows our assumptions about thaw settlement for infrastructure on the four basic categories of permafrost mapped in Figure IV-1 (on page 30). In future work, we hope to do case studies to learn more. 
Table V-2. Assumptions About Thaw Settlement of Facilities on Permafrost Facilities on Continuous Permafrost

- 95 percent of infrastructure is on permafrost $(p f=0.95)$

- 5 percent of infrastructure is not on permafrost and will not settle ( $n p f=0.05$ and loss $=0.0)$

- 50 percent probability that soil is frost susceptible $(f s=0.5$ and $n f s=0.5)$

- No permafrost thaws until average annual temperature exceeds $32^{\circ} \mathrm{F}\left(0^{\circ} \mathrm{C}\right)$

- 20 percent increase in chance of consequences occurring with each $1^{\circ} \mathrm{F}$ rise above $32^{\circ} \mathrm{F}(c f=0.2)$

- Infrastructure age ranges uniformly from new to the last year of its normal useful life $($ age $=0.5)$

- Dramatic thaw settlement occurs in frost susceptible soil that renders infrastructure unusable and its full value is lost (loss $=1.0)$

- Moderate thaw settlement occurs in non-frost-susceptible (NFS) soil, requiring repairs equivalent in cost to 10 percent reduction in remaining useful life (loss $=0.1)$

Facilities on Discontinuous Permafrost

- 70 percent of infrastructure is on permafrost $(p f=0.7)$

- 30 percent of infrastructure is not on permafrost and will not settle $(n p f=0.3)$

- 50 percent probability that soil is frost susceptible $(f s=0.5$ and $n f s=0.5)$

- No permafrost thaws until average annual temperature exceeds $32^{\circ} \mathrm{F}\left(0^{\circ} \mathrm{C}\right)$

- 10 percent increase in chance of consequences occurring with each $1^{\circ} \mathrm{F}$ rise above $32^{\circ} \mathrm{F}(c f=0.1)$

- Infrastructure age ranges uniformly from new to the last year of its normal useful life $($ age $=0.5)$

- Dramatic thaw settlement occurs in frost susceptible soil that renders infrastructure unusable and its full value is lost (loss $=1.0)$

- Moderate thaw settlement occurs in non-frost-susceptible (NFS) soil, requiring repairs equivalent in cost to 10 percent reduction in remaining useful life (loss $=0.1)$

\section{Facilities on Sporadic Permafrost}

- 30 percent of infrastructure is on permafrost $(p f=0.3)$

- 70 percent of infrastructure is not on permafrost and will not settle $(n p f=0.05)$

- 50 percent probability that soil is frost susceptible $(f s=0.5$ and $n f s=0.5)$

- 10 percent increase in chance of consequences occurring with each $1^{\circ} \mathrm{F}$ rise above $32^{\circ} \mathrm{F}(c f=0.1)$

- Infrastructure age ranges uniformly from new to the last year of its normal useful life $($ age $=0.5)$

- Dramatic thaw settlement occurs in frost susceptible soil that renders infrastructure unusable and its full value is lost (loss $=1.0)$

- Moderate thaw settlement occurs in non-frost-susceptible (NFS) soil, requiring repairs equivalent in cost to 10 percent reduction in remaining useful life (loss $=0.1)$

Facilities on Isolated Patches of Permafrost

- Assume this area experiences no significant impacts on buildings from climate change-related thawing of permafrost 
An example of the calculation of the relationship between mean temperature and infrastructure useful life, based on these assumptions, is shown below, and the summary for all four categories of permafrost location is presented in Table V-3.

Weighted average by area for buildings on continuous permafrost:

$$
\begin{aligned}
& \frac{n p f(\text { loss })+p f(f s)[\text { age }(\text { loss })(c f)]+p f(n f s)[\text { age }(\text { loss })(c f)]}{1.00}= \\
& \frac{0.05(0)+0.95(0.50)[0.5(1.0)(0.2)]+0.95(0.50)[0.5(0.1)(0.2)]}{1.00}=0.005
\end{aligned}
$$

\begin{tabular}{|l|c|}
\hline \multicolumn{2}{|c|}{$\begin{array}{c}\text { Table V-3. Summary of Reduction in Useful Life of } \\
\text { Infrastructure Due to Thawing Permafrost }\end{array}$} \\
\hline Basic permafrost condition & $\begin{array}{l}\text { Reduction in years of life (\%) } \\
\text { per degree Fahrenheit }\end{array}$ \\
\hline Continuous permafrost & $0.5 \%$ \\
\hline Discontinuous permafrost & $0.2 \%$ \\
\hline Sporadic permafrost & $0.1 \%$ \\
\hline Isolated patches & $0.0 \%$ \\
\hline
\end{tabular}

\section{Location of Infrastructure in Relation to Coast or Floodplain}

ISER's public infrastructure database notes coastal and riverside infrastructure and also categorizes some sites as "exposed," "protected," "interior," or "floodplain." Coastal and riverside infrastructure is particularly vulnerable to flooding and erosion induced by climate change. When climate-change-induced effects on coastal and riverside infrastructure are objectively quantified in future studies and distinguished from the many other causes for problems at coastal locations, we'll have a basis for refining our approach. Table V-4 shows the authors' judgments about reductions in life span of infrastructure with coastal exposure. 


\begin{tabular}{|l|c|}
\hline \multicolumn{2}{|c|}{$\begin{array}{c}\text { Table V-4. Summary of Reduction in Useful Life of Infrastructure } \\
\text { Due to Coastal Exposure }\end{array}$} \\
\hline Coastal Location & Reduction of life (\%) per degree F \\
\hline Exposed & $7.5 \%$ \\
\hline Protected & $1.0 \%$ \\
\hline Interior & $0.0 \%$ \\
\hline
\end{tabular}

Table V-5 shows our assumptions about reductions in the life of infrastructure in floodplains, which we treated separately from reductions due to permafrost or coastal location.

\begin{tabular}{|c|c|}
\hline \multirow{2}{*}{\multicolumn{2}{|c|}{$\begin{array}{l}\text { Table V-5. Summary of Reduction in Useful Life of Infrastructure } \\
\text { Due to Floodplain Location }\end{array}$}} \\
\hline & \\
\hline & $\begin{array}{l}\text { Reduction of life (\%) per inch increase } \\
\text { in precipitation }\end{array}$ \\
\hline Coastal & $2.0 \%$ \\
\hline River & $7.5 \%$ \\
\hline
\end{tabular}

In this formulation of the model, the functional relationship between temperature precipitation and reduction in useful life is linear, ${ }^{16}$ except at the "tipping point" where average annual temperature becomes greater than 32 degrees Fahrenheit. That implies the cost of climate change could increase without bound for longer planning horizons. This approximation is sufficient for small changes over modest planning horizons. For the longer period to 2080, we de-coupled the "useful life adjustment coefficients" from the equations and held the values constant at the 2030 values. This approximation, in which the effects of climate change move northward across the state over time, is analogous to northward shifts in the southern limit of the expanse of continuous permafrost.

\footnotetext{
${ }^{16}$ It is highly likely that the relationship between climate drivers, including temperature and precipitation, and changes in a structure's useful life, are not of a linear functional form. Additional research by the engineering community is needed to study these complex relationships by type of structure and local topography. "On the ground" case studies that monitor slight changes in the useful life of structures over time would give us valuable insights about a more appropriate shape for our damage function assumptions.
} 


\section{Extreme Events}

Flooding, severe storms, and other extreme events will also influence the schedule of infrastructure replacement, but in a more discontinuous fashion. For example, floods undermine bridge foundations, and droughts (i.e., warmer than average temperatures with lower than normal rainfall) provide ideal conditions for wildfires that damage structures.

We assume an extreme event occurs when the temperature and precipitation are both in either the $1^{\text {st }}$ or $99^{\text {th }}$ percentile of the historical variance. In that event we use a scalar to accelerate the depreciation (or appreciation) by an additional $10 \%$.

\section{Discount Rate}

We used a $7.25 \%$ nominal, or $2.85 \%$ real, discount rate in this analysis. We paid particular attention to the selection of a defensible discount rate, based on recent critiques of Stern (2006). Specifically, we calculated our real discount rate by subtracting the 30-year average Producer's Price Index (PPI) from the 30-year average of the Natural Resources Conservation Service's nominal discount rate for water resources projects (BLS, 2007; USDA, 2007). The Alaska branch of the U.S. Army Corps of Engineers consistently uses the NRCS discount rates for its assessments of possible relocation projects, including its estimates of relocation costs for the communities of Shishmaref, Kivalina, and Newtok in western Alaska. We chose a market-based discount rate following the lead of the Corps of Engineers and after carefully considering the context of evaluating the costs of building public structures with public funds. There may be implicit benefits to society from building these structures, but this analysis narrowly focuses on the additional construction costs due to rapid climate change.

\section{Accounting for Uncertainty}

The most recent academic literature reporting on the intersection of policy analysis and climate change focuses on the issue of conveying uncertainty when making projections of climatic events that are yet to happen. Mastrandrea and Schneider (2004) and other authors they cite persuasively write that: 
Policy analysis regarding climate change necessarily requires decisionmaking under uncertainty. Without explicit efforts to quantify the likelihood of future events, users of scientific results (including policy makers) will undoubtedly make their own assumptions about the probability of different outcomes, possibly in ways that the original authors did not intend. . . . we believe that such probabilistic methods are more valuable for communicating an accurate view of current scientific knowledge to those seeking information for decision-making than assessments that do not attempt to present results in probabilistic frameworks. (Mastrandrea and Schneider, 2004)

The ICICLE model takes uncertainty into account partly by using projections from three climate models, but it also runs a Monte-Carlo (MC) simulation for each of those model projections, to capture a portion of the inherent variability around the mean projections of future conditions. ${ }^{17}$ Consequently, the estimate of the costs of infrastructure at risk is represented by a probability distribution of costs. The resulting range of estimates does not represent the complete range of possible outcomes, given the inherent uncertainty in other variables that we held constant. The Monte-Carlo simulation only takes into account variability around the projected climate change values that can be attributed to measured natural variability represented by temperature and precipitation. The other model assumptions (the discount rate, for example) are held constant across simulations, due to current constraints on computing capacity.

The method by which we capture the uncertainty associated with the climate projections is only the first step toward a more comprehensive approach to capturing theoretical uncertainty (i.e., likelihood of future events), as suggested by probability theory and recent academic literature (Forest et al, 2002 and others). The Euler diagram (Figure V-5) is a simple way of understanding the complex relationships among the many uncertainties we face in trying to estimate how climate change may affect future infrastructure replacement costs. The level of uncertainty (or bandwidth around our estimated costs) is used to convey the likelihood of potential costs given all the unknowns in this integrated model. Simply put, if all of these uncertainties are properly accounted for from both a theoretical and applied standpoint, we could

17 Harrod et al (in prep) used a Monte-Carlo simulation to show the probability of U.S. GDP changing with variation in weather. For a few related examples of others describing Monte-Carlo numerical simulations, see Mastrandrea and Schneider (2004), Stern (2006, 2007), and Greene (2003). 
say with perfect confidence that the projected economic cost would fall within our specified probability distribution of potential future costs.

Specifically within the diagram, the circle that depicts the AOGCM uncertainty represents all the unknowns when modelers project future climate using these complex models of oceanic and atmospheric processes. AOGCM uncertainties include whether each model can replicate historical local climate as well as project future climate based on a wide range of future scenarios. The circle that depicts the uncertainties attributed to observed natural variability represents the idea that any year in the future, natural variability in temperature or precipitation may cause costs to be higher (lower) than an average amount. The intersection of the two circles, which is presently unknown to us, represents the relationship (or intersection) of how observed natural variability affects the biases and errors implicit in the climate models (i.e., "white noise").

The circle detailing the economic and engineering uncertainties represents all the possible errors we could make when projecting the future economic state of Alaska. Those could include selecting incorrect discount rates, unrealistic adaptation decisions, and excessive depreciation factors for the public structures. Unlike the previous two circles, the uncertainties coming from the economics/engineering component of the model have no effect on the natural variability or climate modeling biases and errors so there is no intersection with the other two circles.

The area outside the three circles, but still within the rectangle, represents the unobservable climate record dating back millennia, which some scientists argue is difficult or impossible to measure accurately.

Finally, although it's not shown in Figure V-5, a rectangle called the universal set is often drawn around the Euler diagram, to show the space of all possible types of uncertainties present in this projection of future costs. 
Figure V-5. Conveying Theoretical Model Uncertainty

\section{Euler Diagram of}

\section{Theoretical Climate-Economic-Engineering Uncertainties}

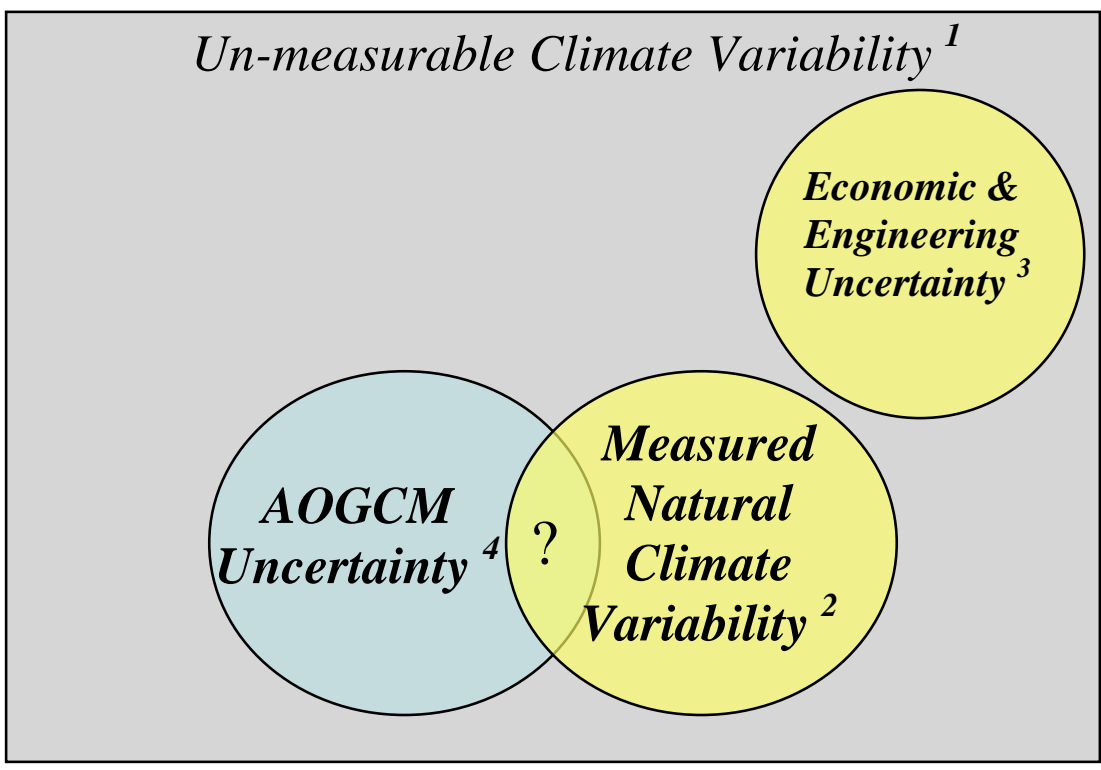

${ }^{1}$ Beyond recorded history ("long memory")

${ }^{2}$ In Alaska, measured climatological recordings date back approximately 50-75 years.

${ }^{3}$ Includes uncertainties relating to future discount rates, replacement/maintenance costs, population growth, structure depreciation rates, adaptation response, etc.

${ }^{4}$ Uncertainties include Atmosphere-Ocean General Circulation Model (AOGCM) ability to replicate historical local climate and project future climate based on a wide range of future scenarios. 


\section{Adaptive Climate Response Cost Models}

Agencies like the Alaska Department of Transportation and Public Facilities, as well as private companies, have historically designed and adapted structures for Alaska conditions, including underlying permafrost. They are likely to increase their efforts as the effects of climate change become more evident. In this section we discuss adaptation to climate change rather than building for current climatic conditions.

A big example of how private industry has built for Alaska conditions is the trans-Alaska oil pipeline, constructed in the 1970s. Over much of the 800-mile pipeline route, Alyeska Pipeline Service Company installed thermosyphons (i.e., pipes that remove heat from the permafrost) near the vertical support members (VSMs), to dissipate heat away from the foundation of the pipeline. Of the nearly 80,000 VSMs, 61,000 were equipped with pairs of thermosyphons in 2003. In 2001, the Joint State-Federal Pipeline Office indicated that at least 22,000 VSMs might be having problems caused by climate change along the pipeline route (USARC, 2003; JPO, 2001). ${ }^{18}$

McBeath (2003) points out that there is no formal criterion for evaluating the long-term consequences of climate change on the Alaska transportation system. However, he does note that the agencies responsible for Alaska's roads, railroad, airports, and ferry systems do consider the effects of climate change on the permafrost layer and other factors when building and maintaining structures.

For all types of public infrastructure, the responsible agencies have to balance (1) the potential for climate change to affect the types of structure built in Alaska with (2) the potential to undertake incremental adaptations to changing weather patterns. If increasing effects of climate change are accepted as a given, then alternative structures or building codes could be adopted that reflect more temperate climates. But if incremental change is the accepted response, then adaptation is a preferred method of continuously updating building codes to meet the ongoing effects of climate change.

At this time, there is no correct answer to this balancing question. The adaptation model we present in this section provides one potential answer, based on historical responses. However, it is important to note that additional factors, such as the question of new facility

\footnotetext{
${ }^{18}$ The oil pipeline is private infrastructure not included in this analysis. We talk about it only as an illustration of current designs for Alaska conditions.
} 
investment versus repair of an existing facility, are also issues that would affect final investment decisions. The model represented here presents one tool for analyzing one component of the adaptation issue.

\section{Historical Background}

Natural disasters occur throughout the United States. Earthquakes are a regular occurrence in the West, hurricanes are regular events in the Southeast, and floods make annual appearances in the Midwest. Although these natural events are not directly analogous to climate change, the local, regional, and federal government responses that have been documented over the last several decades provide foundational models from which to anticipate the adaptation response that may occur in the case of climate change in Alaska. These responses are helpful for the climate-change scenario, because they illustrate that people learn from natural events and adapt to them over time.

Adaptive learning provides the opportunity to offset some of the effects and costs of natural events. This type of adaptation is appropriate for things like public infrastructure, which have long useful lives. In contrast, areas such as high technology focus on adapting for obsolescence. With that shorter frame of reference, technology companies focus on improving disposable products to make existing products obsolete. From an economic perspective this is logical, since technology improvements result in new entities with short anticipated life spans. But for infrastructure, improvements that lengthen its expected life make economic sense.

This section discusses the historical responses that have occurred after natural disasters and then extrapolates these foundational models into an adaptive response model that incorporates learning to respond to Alaska climate change. The cost models presented here represent a first step toward anticipating the costs associated with climate change. Limitations exist in terms of aging inventory and adoption cycles. However, the models represent the opportunities that exist to reduce the effects of climate change through adaptation.

\section{Hurricanes-Phased Adaptation}

The study of natural disaster response has been a priority for agencies such as the Federal Emergency Management Agency (FEMA), as they try to improve both recovery response and resilience of structures to natural events. Leaders in these studies have been the states of Florida 
and South Carolina, where hurricanes introduce a continuously evolving set of requirements and recommendations for improving structure resilience. Since Hurricane Hugo in 1989 and Hurricane Andrew in 1992, Florida and South Carolina have aggressively focused on improving the resilience of structures to major storms. Clemson University (Clemson, 1999) and the State of Florida (Florida, 1996; Florida, 2002) have generated major studies about the costs of adaptation and the adoption of proposed solutions.

These studies have significantly improved the technology associated with infrastructure and private structures. Individual advances in areas such as window construction, roof attachments, and structural connections have resulted in significantly enhanced structural resilience and increased useful life expectancies. Unique to this form of adaptation has been the role of private industry in developing responses. Since the adaptations are focused on a single item such as a window pane, private manufacturers have taken a leading role in developing them. However, these advances have sometimes taken a long time to be fully adopted, because local building authorities have to first test, evaluate, and document their effectiveness.

\section{Earthquakes—Rapid and Continuous Adaptation}

California and other states where earthquakes occur frequently have also attempted to quantify the risks associated with adapting structures to resist earthquake damage. These efforts have attempted to balance the cost of adaptation with the potential loss associated with earthquake damage (FEMA, 1995; FEMA 1998). The difficulty is balancing the cost of adaptation with the risk of earthquake exposure (Stein and Tomasello 2004). As outlined in research efforts, the question of earthquake frequency and exposure needs to be balanced with regulations that require forced adaptation through building codes. Additionally, the need for research and development through publicly funded centers is an essential element of earthquake adaptation, as research facilities for earthquake simulation are limited to large research institutions.

In contrast to the incremental improvements developed by private manufacturers for hurricane resiliency, efforts to improve earthquake resilience have focused on incremental building code modifications. In these regular code modifications, results from research are translated into structural enhancements intended to improve earthquake resistance. In this 
manner, earthquake adaptation emphasizes a regulatory approach rather than a market development approach.

\section{Floods-Forced Adaptation (Event Driven)}

The final adaptation response effort that seems a relevant model for climate change is the response to floods that occur regularly in the U.S. Midwest (Aglan, Wendt, and Livengood, 2004). This model differs from the previous two models in that flood response is primarily an event-driven model. In this form of model, adaptive responses are not put into place until there is a flood that significantly reduces the useful life of infrastructure. Local authorities determine when that threshold has been crossed. If they decide a specific flood didn't reach that threshold, then they don't take any action, with the understanding that this event is part of the natural cycle. New structures are constructed with the same specifications as existing ones, since they are still considered the standard. By contrast, if there is a flood that exceeds what is considered part of the natural cycle, then a rapid adaptation response is put into place, resulting in a change of building codes that requires a stair-step increase in building costs. This response is seen as indirectly based on the rate at which states report and classify floods and the resulting responses to those reports (Pielke, Downton, and Miller 2002)

Similar to the response to earthquakes, the response model for floods is code-based. Rather than the private market driving structural changes, flood response results in regulatory changes. The regulatory changes are codified through building code updates. However, since the code is only updated after a significant event, the regularity of the updates does not follow the pattern seen with earthquakes. The result is an expense that occurs less frequently but tends to have a greater effect when it does occur.

\section{Adaptation Scenarios}

The adaptations documented through the study of hurricanes, earthquakes, and floods can be translated into three specific adaptation scenarios or cost models. These models reflect the cycle of adaptation that occurs in relation to the specific type of natural disaster. The types of scenario can be divided into three foundational classes. 
1. Rapid and Continuous Adaptation. The first scenario is based on experience with earthquakes in California. In this model, the engineering and design communities make a focused effort to respond to and anticipate changes due to climate change. The focused effort results in a mandatory set of changes that are implemented in all designs, with a regular updating of the regulatory building codes. Typically, this update occurs every five years in locations where change is greatest. This updating results in a gradual cost increase, but retains the life expectancy of the structures. However, continued research into the effects of the scenario continue to change the building requirements and thus continue to escalate the costs each generation. It has been found that after the first set of adaptation codes are developed, the cost increases slow down, as code generation changes to code adjustment.

2. Phased Adaptation - The second scenario is based on experience with natural disasters in locations such as Florida, where hurricanes occur regularly but not necessarily in the same locations. Those events create awareness of the need for change, but not a focused interest in adaptation for all structures. In this case, adaptation occurs over a series of generations, with succeeding generations adopting enhanced technology that not only maintains the life expectancy of infrastructure but also provides an opportunity to increase life expectancy. Costs rise slowly at first and then significantly during the second generation, when all structures adopt the new technologies. However, as adaptation continues to evolve, costs decrease as the adaptations become standard practice and competition influences the adaptation market.

3. Forced Adaptation - The third scenario represents the event-driven rather than a code-driven approach to infrastructure adaptation. In this model, adaptations occur only after infrastructure has been significantly damaged. This scenario is often seen in areas where floods or fires are prevalent, and the local government does not adapt until a failure in the system occurs. When failure occurs, there are significant costs to enhance the infrastructure and retain life expectancy. However, these adaptations are often only sufficient to adapt to current conditions and the cycle has to be repeated when the next significant incident occurs.

These three models represent the kinds of responses that may occur in the face of climate change in Alaska and the economic effects that may result from climate change. 


\section{Alaska Climate Change Event-Driven Adaptive Model}

We considered how the various kinds of responses to different natural disasters might apply to analyzing the effects of climate change on public infrastructure costs. We decided that the event-driven model, which incorporates some of the features of both the continuous adaptation and the phased adaptation models, was probably the most realistic fit for Alaska.

The concept of the event-driven model is that adaptation research is being conducted, but no action is taken for a particular structure until damage reduces the life span enough to reach some critical threshold. Until that point, it is assumed additional repair money could maintain a reasonable useful life span. The threshold used in this model is $20 \%$. We adopted that percentage based on a rule of thumb in planning - that once a building loses $20 \%$ of its useful life, economically it becomes more feasible to rebuild than repair. However, this number should be considered an estimated value for this model and not an absolute for every scenario.

In this model, the life span of the structure is affected by the impact template, based on precipitation and temperature increases. For example, a hospital with a 40-year life span that is affected by both temperature and precipitation increases will have its life span shortened, based on the appropriate database entries. In the current database scenario, the worst case is a hospital losing about $5 \%$ of its life span for each 1 degree of temperature increase and each 1-inch increase in precipitation. Given that the average model shows a temperature increase of 2.1 degrees by 2030 and a $4.3 \%$ increase in precipitation (.688 inches in Anchorage), that results in a total life span reduction of $15 \%$, with $11.5 \%$ for temperature and $3.5 \%$ for precipitation.

In the event-driven model, the first generation of the 40 -year hospital is reduced by $15 \%$, or six years, resulting in a useful life of 34 years. At this point, the event-driven model determines if the useful life reduction threshold has been met. If the threshold has not been reached, then a new structure is built with a reduced life span expectancy. In this case it would be 34 years to start with, rather than the original 40 years. If the threshold has been reached, then a cost increase of $5 \%$ is absorbed and the structure is built with the original life span.

The effect of the event-driven model becomes increasingly apparent as the potential useful life of the structure becomes shorter. For example, in the case of a water treatment facility with a 20 -year life span, the difference becomes apparent in only three generations. In this example, the first generation is affected by climate change that reduces the facility life span by $14.3 \%$, or 3.5 years. Since this loss is below the $20 \%$ threshold, the same structure is built with 
no climate-change-adjusted costs, but with an expected useful life of only 16.5 years. This results in the second generation structure lasting only 14.3 years, since it started with an anticipated useful life of only 16.5 years. However, at this point the useful life reduction now exceeds the $20 \%$ reduction threshold. Thus, the third generation structure incorporates a $5 \%$ cost increase to return to the original 20-year life expectancy.

The following sections introduce the application of the event-driven adaptation scenario to ISER's ICICLE model. We'll discuss the difference between no-adaptation and event-driven adaptation, as well as the base case, which acts as a benchmark and assumes no climate change.

\section{Event-Driven Cost Adaptation Model Application}

To illustrate the effect of adaptation on the climate change application, we ran three cases through the adaptation cost model for each infrastructure component: a base case assuming no climate change, a no-adaptation case, and an event-driven case.

No Climate Change. This first case is the benchmark, or base case, assuming climate change has no effect on the useful life of infrastructure. Each infrastructure element lasts for the predetermined useful life and then is replaced with the same useful life, but at a cost that is discounted by the predetermined discount rate.

No-Adaptation Case. The second case models the effect of climate change on infrastructure, assuming that agencies simply react as conditions change. They continue to design and construct infrastructure taking local conditions into account and finding new methods of dealing with problems as they develop. But they don't act strategicallythat is, they don't anticipate and plan for continuing trends in climate change and future vulnerabilities of infrastructure. In this case, the effect of climate change is calculated each year on each infrastructure component. That effect reduces the lifespan each year, resulting in a final useful life that is less than what was anticipated. Compounding this problem is the lack of strategic planning, so the next generation of structure begins with an anticipated useful life equal to the ending useful life of the previous structure. Over several generations, the useful life continues to be reduced, creating a scenario under which additional generations of structures are required for each infrastructure component, thus increasing total costs over time. We don't believe that agencies would in fact react 
this passively in the face of climate change. Still, this no-adaptation case provides a benchmark for measuring the efficacy of adaptation measures and gives agencies an idea of how big a problem they could face, in an environment of continuing change.

Event-Driven (or Adaptation) Case. The final case implements the event-driven model described previously. It assumes agencies look ahead and act strategically to minimize both present and future costs of infrastructure, recognizing that climate change will be ongoing. In this case, structures are once again affected by climate change on a yearly basis, which results in lower actual life spans. The key to this scenario is how much useful life has been lost, compared with the anticipated useful life for a structure. If the lost life span is less than $20 \%$, then a new structure is built with no adaptation, since the event threshold has not been met. Although this new structure carries no additional costs associated with climate change, it follows the no-adaptation case by applying a starting useful life that is only equal to the reduced useful life at the end of the previous generation. However, if the lost life span is greater than $20 \%$, then the event threshold is achieved and the new structure is built with a full useful life value, with an additional $5 \%$ cost associated with climate-change adaptation.

The effect of these three cases is evident when the life span and the effects of climate change are altered for different types of infrastructure components and for differences in effects of climate change by area. The examples below illustrates those differences.

\section{Two Example Scenarios}

\section{Government Health Building with Multiple Climate Change Exposure}

In this example, a government health services building with an anticipated 30-year useful life is modeled in the system. The building is exposed to flooding and permafrost melting. The base cost of the building is $\$ 1,631,781$ per structure. The effect of climate change on that building is illustrated in the following four graphs.

Figures VI-1 and VI-2 illustrate the effect of climate change on remaining life span. Figure VI-1 presents the actual lifecycle of a structure as it experiences a drop in remaining life, from the time it is built until no useful life remains. Figure VI-2 presents the starting useful life of a structure, if it was built in any year from 2006 through 2080. As illustrated in the graphs, 
the base case, without climate change, requires three generations of buildings — one built in 2006, one in 2036, and one 30 years later, in 2066.

When climate change is factored into the scenario, the building loses useful life. However, the no-adaptation case and the event-driven case address the next generation of the structure differently. The no-adaptation case follows the reasoning that no strategic planning has occurred, thus the new building is built each time with an initial useful life equal to what it was at the end of the life of the previous structure-25.5 years in 2032, 17.2 years in 2050, 12.7 years in 2064, and 10 years in 2075. The no-adaptation case requires two extra generations of building - a total of five - to be constructed in the same period, compared with the no-climatechange base case.

The event-driven model requires four generations of building through 2080 - one more than the base case but one less than the no-adaptation case - and planning improves the performance of the generations. The focus of event-adaptation is illustrated in the second and third generations of the building. The reduction in useful life due to climate change does not meet the required threshold at the end of the first generation. So the second generation is constructed the same way as in the no-adaptation case, with an initial useful life of 25.5 years. However, the reduction in useful life at the end of the second generation does meet the threshold level, so an adaptation occurs, resulting in the useful life at the start of the third generation returning to the original design expectation of 30 years. This same adaptation repeats at the beginning of the fourth generation, in 2070.

Examining this same example scenario from the perspective of cumulative cost per structure, Figures VI-3 and VI-4 provide an illustration of the costs associated with climate change. Figure VI-3 presents the cumulative costs for an individual structure over the period until 2080, including discounting. Figure VI-4 shows the cost to build a structure at any time until 2080, without discounting. Once again, the base case with no climate change would require the building of three generations of the same building, each lasting 30 years. Bringing a discount factor into the scenario, the total cost of the three generations of the building for the base case is $\$ 2.6$ million.

The addition of climate change alters this base cost. The no-adaptation case requires two additional generations of the structure to be built at increasingly shorter time spans, due to the cumulative climate change effects. However, since this case does not require an adaptation 
investment, the cost varies only with the extra expense of early rebuilding. The result is that the five generations have a cost of $\$ 3.5$ million. The event-driven case requires four generations of the structure, and there is an investment in adaptation. The four generations of building, plus the adaptation cost, result in a total of $\$ 3.2$ million for this case - more than for the base case, but less than for the no-adaptation case.

Putting this scenario in terms of the total number of structures that have to be replaced in this category of exposure, we can see the cumulative effects of lifespan reduction. If nine structures of this type need to be replaced in Alaska, the resulting cost, without climate change, is $\$ 15.5$ million, under a $2.85 \%$ discount rate. As illustrated in Table VI-1, climate change increases the cost of this replacement. However, the event-driven adaptation results in a lower overall cost than the no-adaptation. 
Figure VI-1. Effect of Climate Change on the Remaining Life of a Building (30 year life)

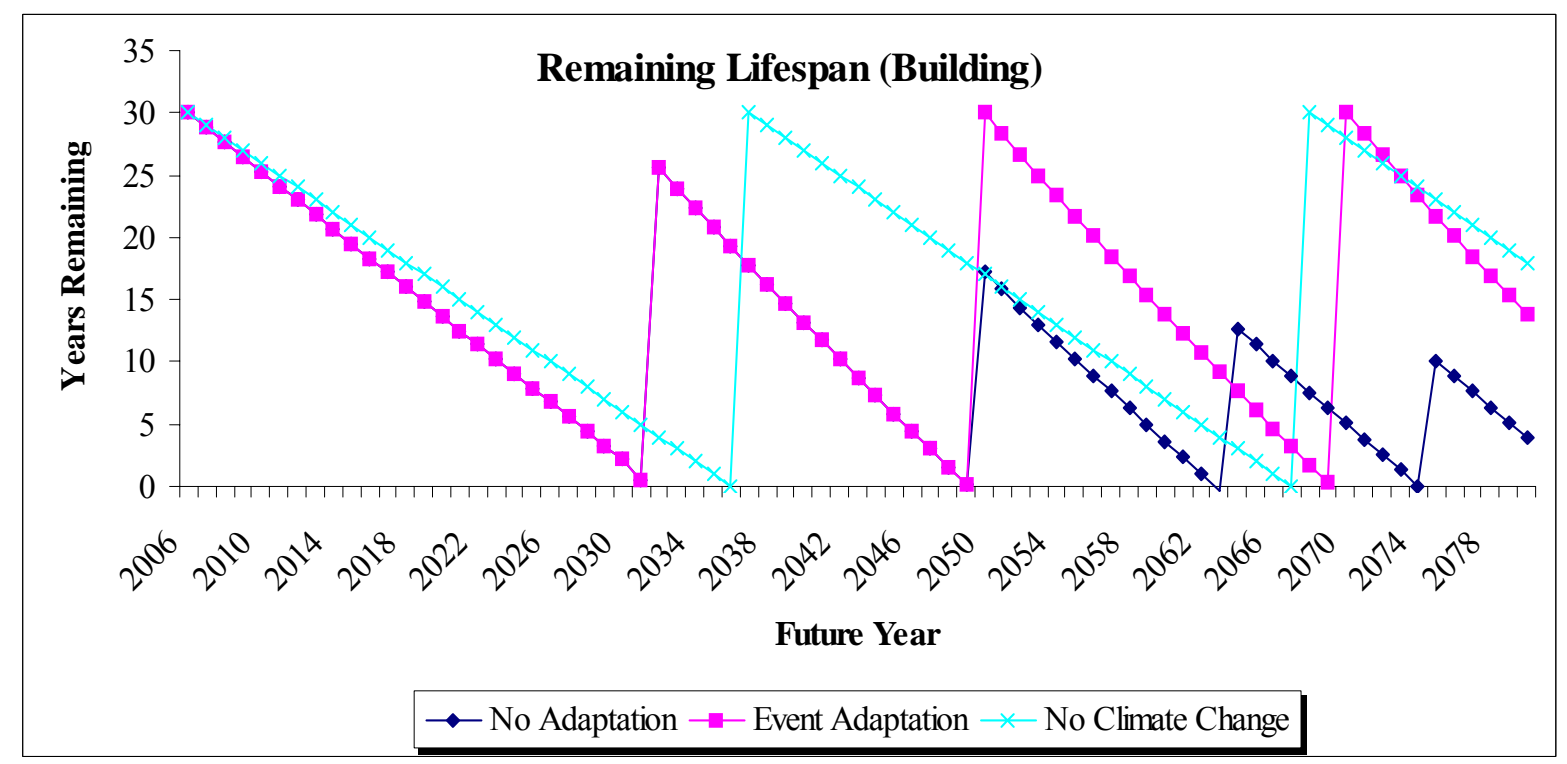

Figure VI-2: Effect of Climate Change on the Useful Life of a Building (30 year life)

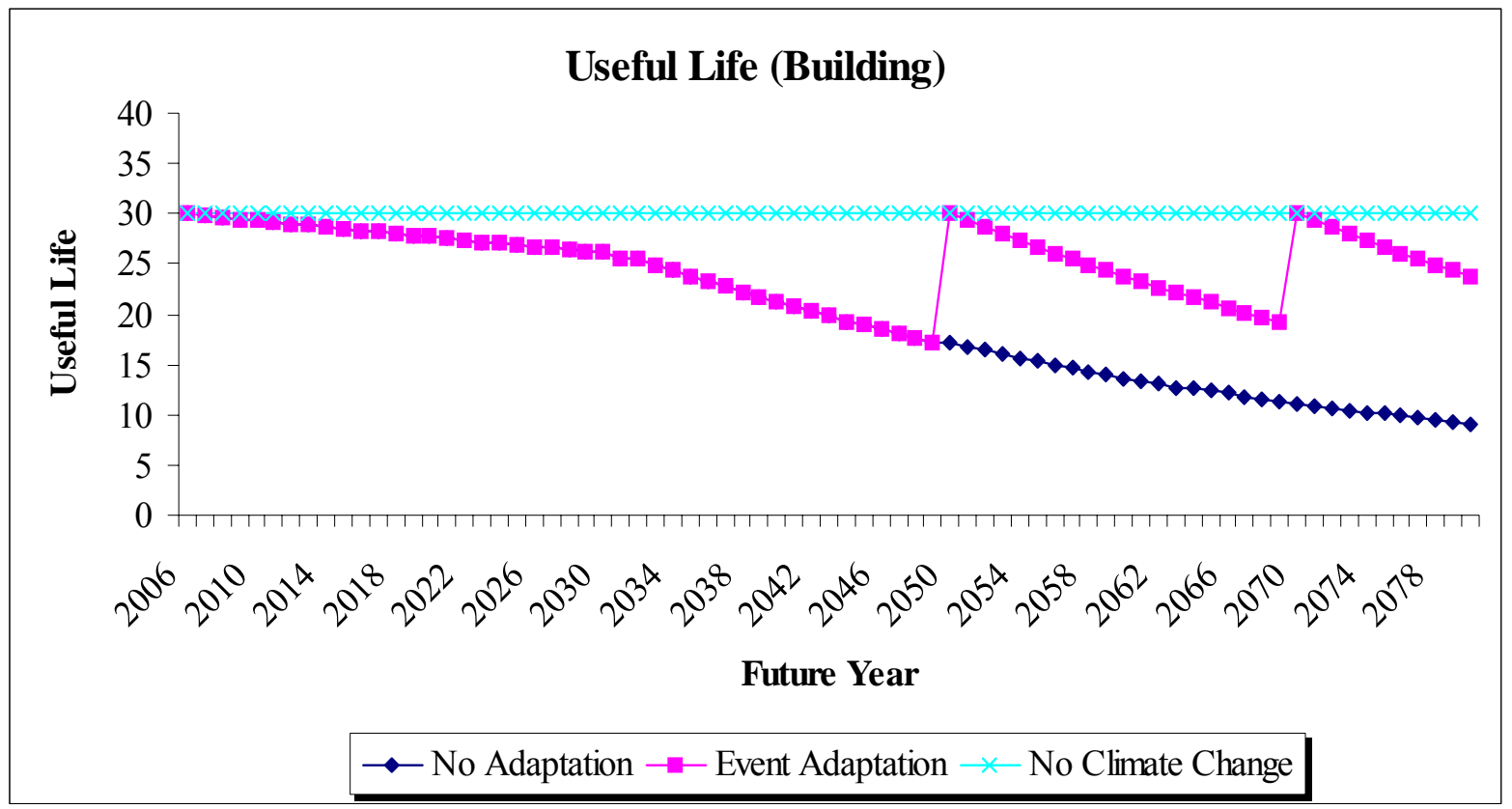


Figure VI-3. Effect of Climate Change on the Cumulative Cost of a 30-Year Building (One Structure, With Discounting)

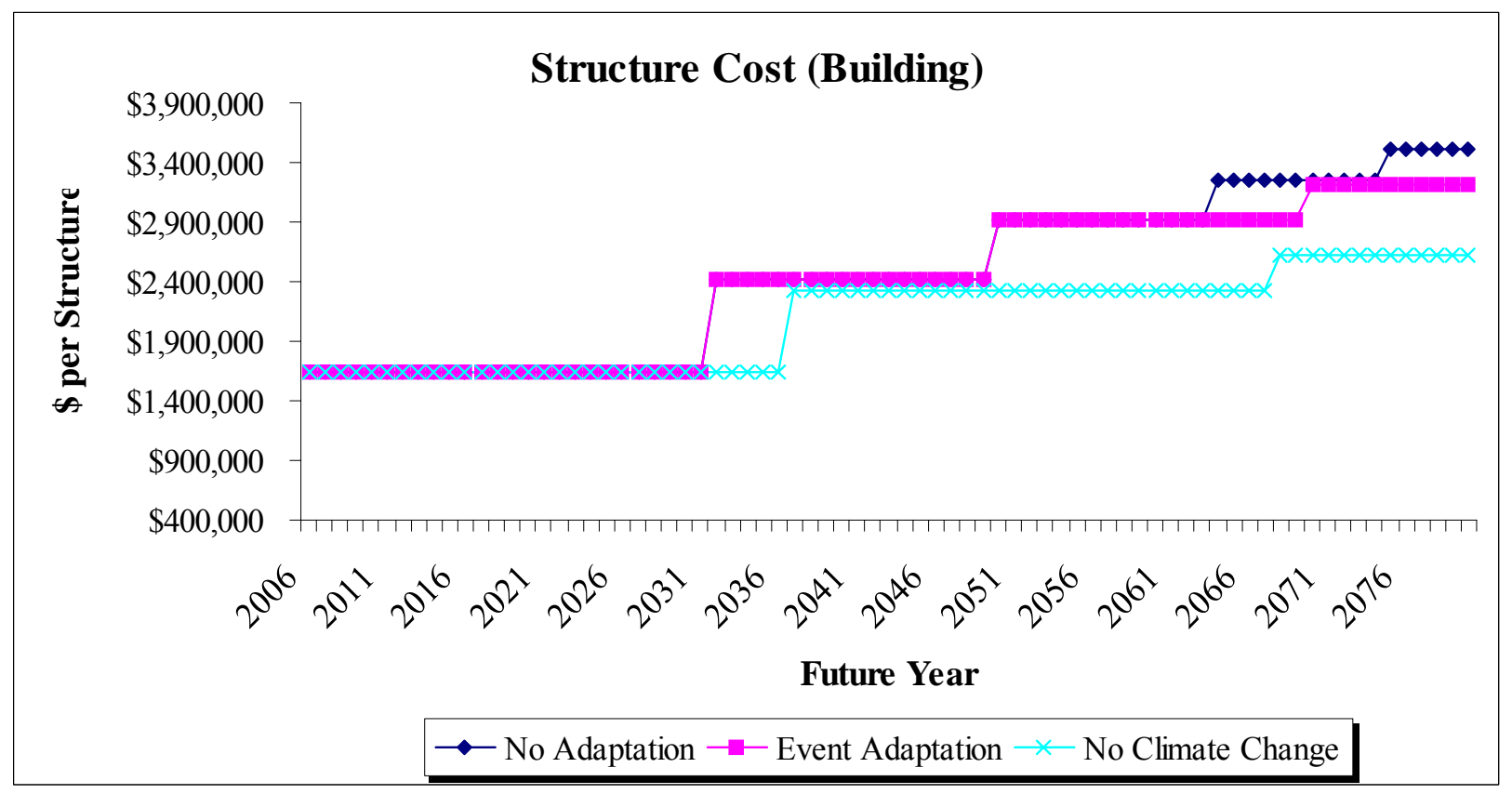

Figure VI-4. Effect of Climate Change on the Initial Cost of a 30-Year Building (One Structure, Not Discounted)

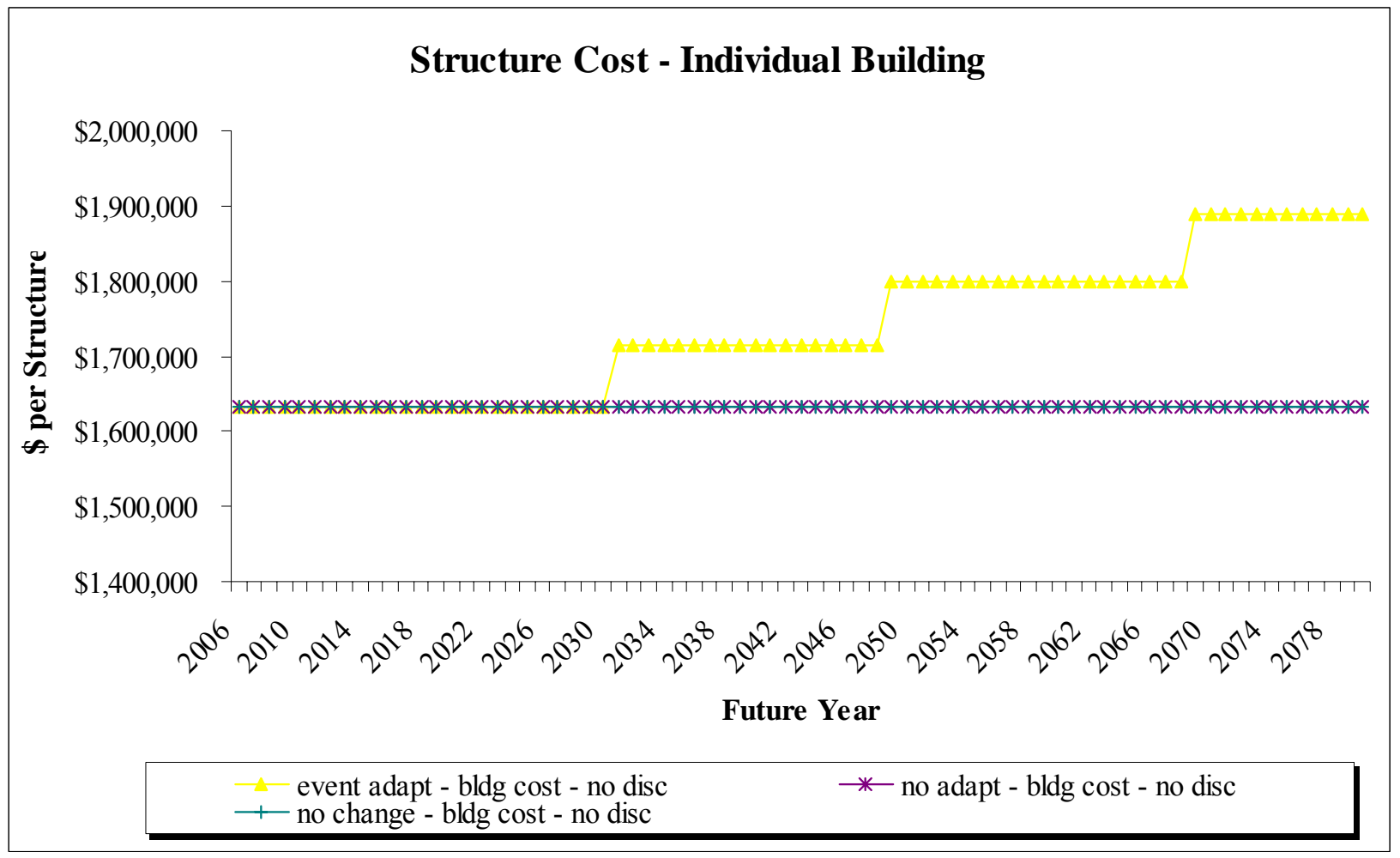




\begin{tabular}{|c|c|c|}
\hline \multicolumn{3}{|c|}{$\begin{array}{c}\text { Table VI-1. Example of Adaptation Model for Public Health } \\
\text { Buildings (Nine Structures) }\end{array}$} \\
\hline & Cost (Million \$) & $\begin{array}{l}\% \text { of } \\
\text { Base }\end{array}$ \\
\hline Base Case: No Climate Change & $\$ 15.52$ & \\
\hline PLUS: Climate Change Induced Costs & $\$ 5.28$ & $34 \%$ \\
\hline EQUALS: Total Cost without Adaptation & $\$ 20.80$ & \\
\hline MINUS: Net Adaptation Savings & $\$ 1.76$ & \\
\hline Adaptation Cost & $\$ 0.18$ & \\
\hline Gross Adaptation Savings & $\$ 1.94$ & $22 \%$ \\
\hline EQUALS: Final Cost with Adaptation & $\$ 19.04$ & \\
\hline ITEM: Net Cost of Climate Change with Adaptation & $\$ 3.45$ & \\
\hline Adaptation Cost & $\$ 0.18$ & \\
\hline Direct Cost to Infrastructure & $\$ 3.27$ & \\
\hline Assumptions: & & \\
\hline infrastructure type $=$ public health building & & \\
\hline structures $=9$ & & \\
\hline useful life $=30 \mathrm{yrs}$ & & \\
\hline unit cost $=\$ 1.632$ million & & \\
\hline permafrost exposure $=$ yes & & \\
\hline coastal exposure $=$ yes & & \\
\hline
\end{tabular}




\section{Water Treatment Services with Single Climate Change Exposure}

In this second example, we model a water treatment plant with an anticipated 20-year useful life, to illustrate a structure with a shorter life span and a single climate exposure. The building is exposed to coastal flooding and minimum permafrost thawing. The base cost of the plant is $\$ 5$ million per structure.

Figures VI-5 and VI-6 show the effect of climate change on remaining and useful lifespan. The base case, without climate change, requires four generations of structures to be built through 2080 — one in 2006 and then one every 20 years after that. When climate change is factored into the scenario, the structure once again loses useful life. The no-adaptation and eventdriven cases show the same reduction in life span through 2040. However, that changes as the scenario is taken further out, and in later generations the event threshold is met. In this example, the no-adaptation case results in seven generations of the structure being built, with the last generation having a useful life of only 6.4 years when it is built. However, the event-driven case deviates from this pattern, as the useful life threshold is met in 2040 and the structure is returned to its original useful life in this and later generations.

Figures VI-7 and VI-8 examine the cumulative cost per structure in this example. Once again, the base case, with no climate change, requires the building of four generations of the same structure, each lasting 20 years. Bringing a discount factor into the scenario, the total cost of the four generations of the structure for the base case is $\$ 10.3$ million.

The addition of climate change once again changes this base cost. The no-adaptation case requires three additional generations of the structure, for a total of seven. There is no investment in adaptation. The result of those extra generations is a cumulative cost of $\$ 14.8$ million.

In the event-driven case, there are additional costs for adaptation, but the overall cost is less than under the no-adaptation case. With an investment in adaptation, five instead of seven generations of the structure have to be built, with an overall cost of $\$ 12.3$ million.

Putting this example in terms of the total number of structures that have to be replaced, we can see the cumulative effects of life span reduction. As illustrated in Table VI-2, if 11 structures of this type need to be replaced in Alaska, the resulting cost without climate change is $\$ 87.18$ million with a $2.85 \%$ discount rate. Climate change increases the cost of this replacement with the no- adaptation case resulting in a $44 \%$ increase and the event-driven case resulting in a $20 \%$ increase. 
Figure VI-5. Effect of Climate Change on Remaining Life of a 20-year Water Facility

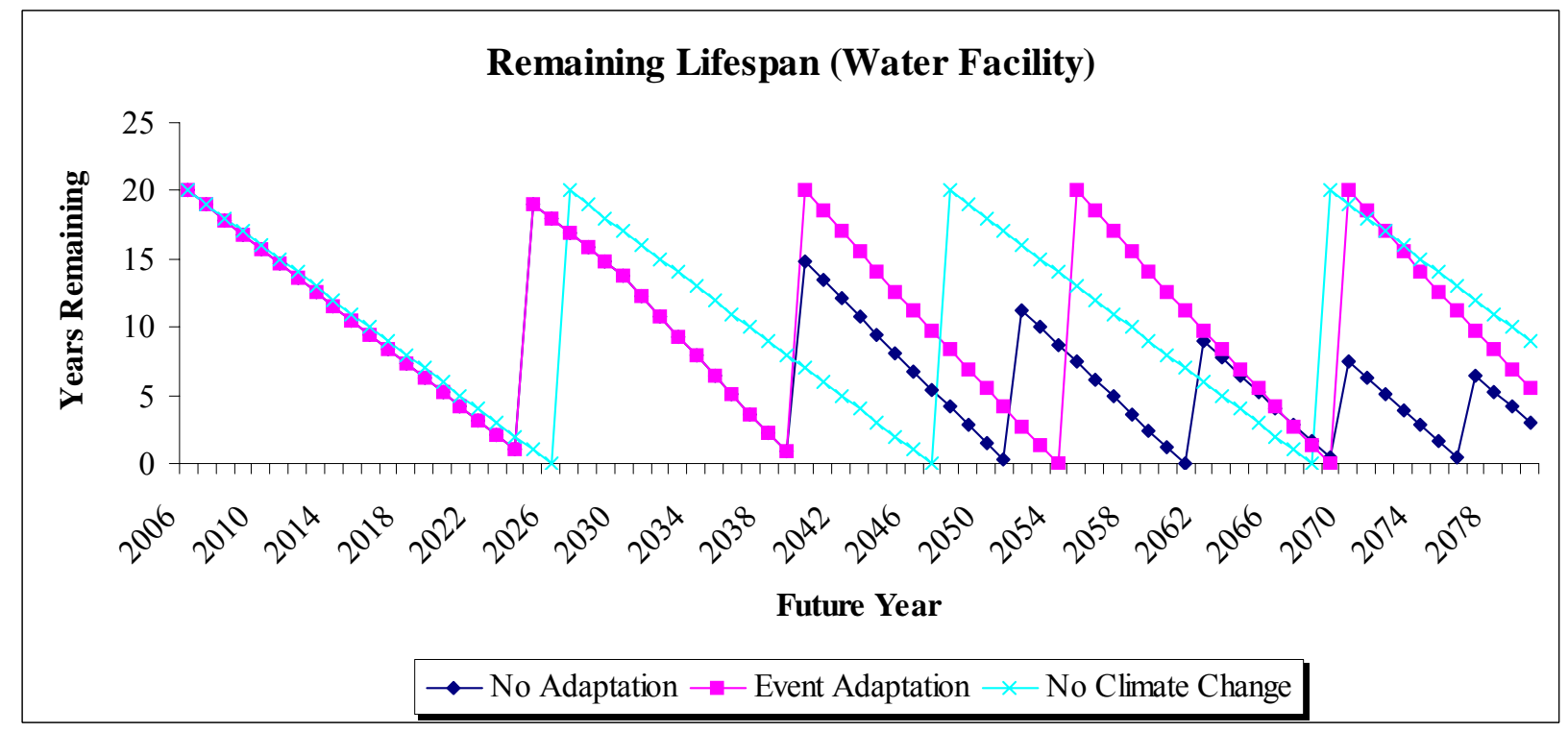

Figure VI-6. Effect of Climate Change on the Useful Life of a 20-Year Water Facility

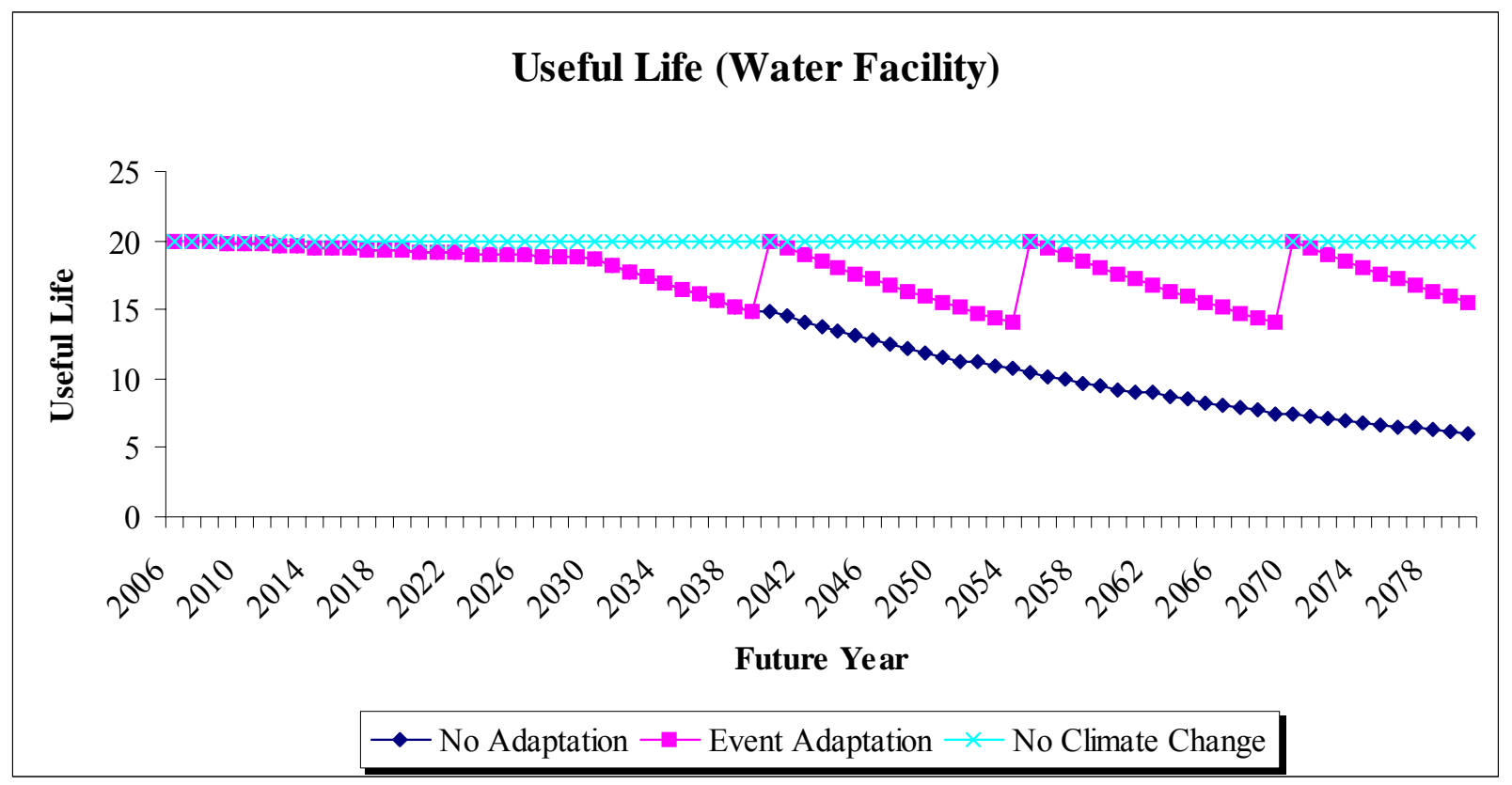


Figure VI-7. Effect of Climate Change on the Cumulative Cost of a 20-Year Water Facility (With Discounting)

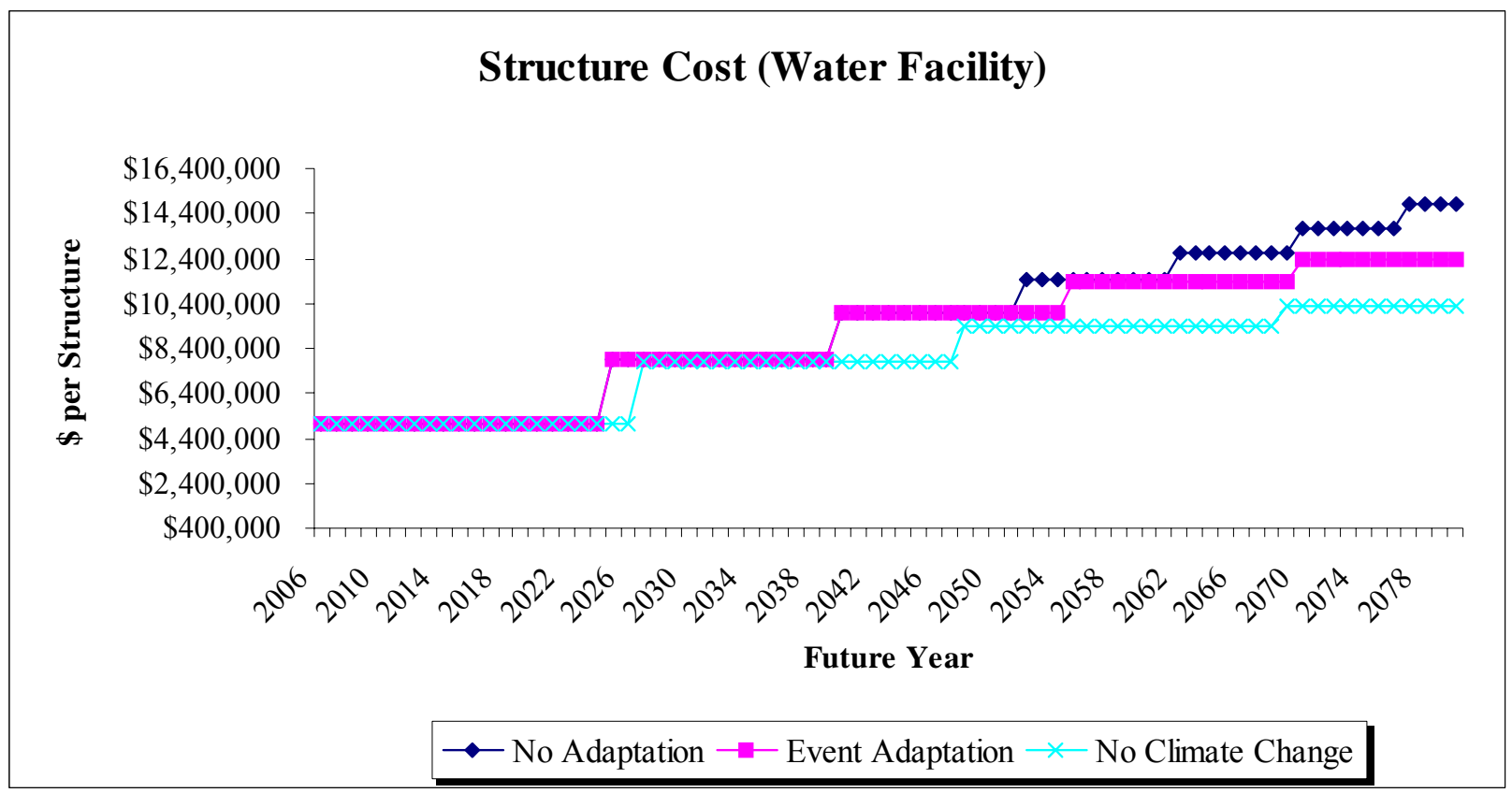

Figure VI-8. Effect of Climate Change on the Initial Cost of a 20-Year Water Facility (One Structure, Not Discounted)

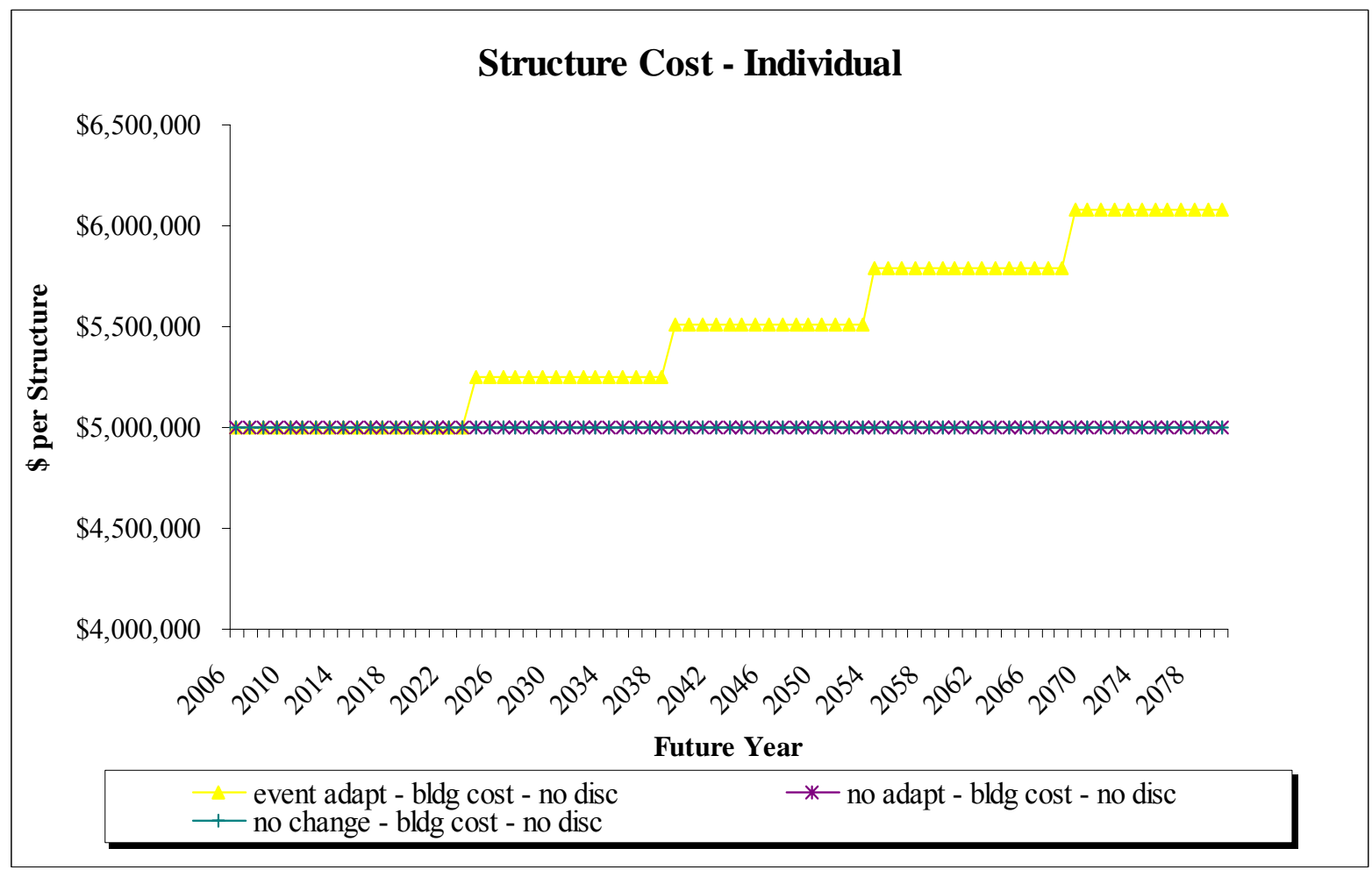




\begin{tabular}{|c|c|c|}
\hline \multicolumn{3}{|c|}{ Table VI-2. Example of Adaptation Model for 11 Water Systems } \\
\hline & Cost (Million \$) & $\begin{array}{l}\% \text { of } \\
\text { Base }\end{array}$ \\
\hline Base Case: No Climate Change & $\$ 87.18$ & \\
\hline PLUS: Climate Change Induced Costs & $\$ 38.36$ & $44 \%$ \\
\hline EQUALS: Total Cost without Adaptation & $\$ 125.54$ & \\
\hline MINUS: Net Adaptation Savings & $\$ 21.05$ & \\
\hline Adaptation Cost & $\$ 1.86$ & \\
\hline Gross Adaptation Savings & $\$ 22.91$ & $20 \%$ \\
\hline \multirow[t]{2}{*}{ EQUALS: Final Cost with Adaptation } & $\$ 133.24$ & \\
\hline & $\$ 1.86$ & \\
\hline ITEM: Net Cost of Climate Change with Adaptation & $\$ 17.14$ & \\
\hline \multicolumn{3}{|l|}{ Adaptation Cost } \\
\hline Direct Cost to Infrastructure & $\$ 15.29$ & \\
\hline \multicolumn{3}{|l|}{ Assumptions: } \\
\hline \multicolumn{3}{|l|}{ infrastructure type $=$ water } \\
\hline \multicolumn{3}{|l|}{ structures $=11$} \\
\hline \multicolumn{3}{|l|}{ useful life $=20 \mathrm{yrs}$} \\
\hline \multicolumn{3}{|l|}{ unit cost $=\$ 5$ million } \\
\hline \multicolumn{3}{|l|}{ permafrost exposure $=$ no } \\
\hline coastal exposure $=$ yes & & \\
\hline
\end{tabular}




\section{Total Infrastructure Replacement Cost with Adaptation}

We analyzed all 19 categories of infrastructure identified for the Alaska climate change model, resulting in the adaptation parameters shown in Table VI-3. ${ }^{19}$ The table shows the cost savings from active adaptation to climate change. It shows, for example, that adapting airports to climate change, under the warmest climate projections, would cost just $85 \%$ as much as it would if there were no adaptations. Alternatively, we can say that adapting airports to climate change could save an estimated $15 \%$ over the next few decades.

\begin{tabular}{|c|c|c|c|c|c|c|}
\hline \multicolumn{7}{|c|}{$\begin{array}{c}\text { Table VI-3. Ratio of Total Cost of Infrastructure Replacement With } \\
\text { and Without Climate Change Adaptation }\end{array}$} \\
\hline & \multicolumn{3}{|c|}{$2006-2030$} & \multicolumn{3}{|c|}{$2006-2080$} \\
\hline & Warm & Warmer & Warmest & Warm & Warmer & Warmest \\
\hline Airport & 1.00 & 0.99 & 0.85 & 0.88 & 0.69 & 0.51 \\
\hline Bridge & 1.00 & 0.98 & 0.88 & 0.91 & 0.74 & 0.60 \\
\hline Courts & 1.00 & 1.00 & 1.00 & 0.99 & 0.82 & 0.67 \\
\hline Defense & 1.00 & 1.00 & 1.00 & 0.99 & 0.85 & 0.69 \\
\hline $\begin{array}{l}\text { Emergency } \\
\text { Services }\end{array}$ & 1.00 & 1.00 & 1.00 & 1.00 & 0.86 & $\mathbf{0 . 7 0}$ \\
\hline Energy & 1.00 & 1.00 & 1.00 & 0.99 & 0.85 & 0.68 \\
\hline Grid & 1.00 & 0.99 & 0.90 & 0.93 & 0.81 & 0.65 \\
\hline Harbor & 1.00 & 0.97 & 0.84 & 0.84 & 0.65 & 0.48 \\
\hline Hospital & 1.00 & 1.00 & 1.00 & 0.99 & 0.78 & 0.62 \\
\hline Law Enforcement & 1.00 & 1.00 & 1.00 & 0.99 & 0.84 & 0.68 \\
\hline $\begin{array}{l}\text { Misc. } \\
\text { Building_Govt }\end{array}$ & 1.00 & 1.00 & 1.00 & 0.99 & 0.85 & 0.70 \\
\hline $\begin{array}{l}\text { Misc.Building } \\
\text { Health }\end{array}$ & 1.00 & 1.00 & 1.00 & 1.00 & 0.85 & 0.69 \\
\hline Railroad & 1.00 & 0.99 & 0.90 & 0.94 & 0.81 & 0.62 \\
\hline Roads & 1.00 & 0.98 & 0.89 & 0.92 & 0.75 & 0.60 \\
\hline School & 1.00 & 1.00 & 1.00 & 1.00 & 0.87 & 0.72 \\
\hline Sewer & 1.00 & 0.98 & 0.84 & 0.87 & 0.68 & 0.49 \\
\hline $\begin{array}{l}\text { Tele- } \\
\text { communications }\end{array}$ & 1.00 & 0.99 & 0.85 & 0.88 & 0.69 & 0.50 \\
\hline Telephone Line & 1.00 & 0.95 & 0.87 & 0.92 & 0.78 & 0.57 \\
\hline Water & 1.00 & 0.98 & 0.84 & 0.87 & 0.69 & 0.50 \\
\hline
\end{tabular}

\footnotetext{
${ }^{19}$ Anticipated ICICLE model enhancements will include incorporation of the adaptation scenario into the model. Currently it was applied ex post in the aggregate to each infrastructure category.
} 


\section{Model Results}

The model allows us to generate estimates of the present value of the cost of public infrastructure replacement under a range of conditions. Here we present a base case scenario, assuming continued replacement of the current public infrastructure but with no climate change, and then report the results of three exploratory scenarios of climate change, each modeled with and without adaptation to climate change.

Each climate-change scenario is the result of a Monte Carlo analysis in which the output of the climate model - average annual temperature and precipitation — is allowed to vary based on probability distributions derived from historical data. These climate-change scenarios first assume no adaptation in response to increased costs for infrastructure construction and maintenance resulting from climate change. The difference between the no-adaptation scenarios and the base case scenario is an estimate of the cost of infrastructure at risk from climate change for the planning interval between 2006 and 2030 or 2080.

Next we present incremental cost estimates that take into account adaptations government agencies might be expected to make over time, as the effects of climate change on infrastructure become more evident. These adaptations reduce some of the costs estimated in each climate change scenario. The difference between the climate-change scenarios with adaptations and the base case represent the best current estimate of the potential additional costs for Alaska public infrastructure from climate change. The model allows us to calculate results by infrastructure type and region and also to map the location of costs, but here we present only summary results.

Before discussing the model results under each case, we first summarize the big picture in Figure VII-1. It shows our preliminary estimates of the likely range of additional infrastructure costs resulting from climate change. These estimates are in net present value. We hope to refine them over time, as more information becomes available. That figure shows that public infrastructure costs in Alaska could be an estimated \$32 billion between now and 2030 and $\$ 56$ billion through 2080, even without climate change - that is, ordinary wear and tear on public infrastructure in Alaska would cost that much over time. Climate change would add an estimated $\$ 3.6$ to $\$ 6.1$ billion through 2030 and $\$ 5.6$ to $\$ 7.6$ billion through 2080, under different levels of climate change and assuming government agencies actively adapt to that change. Much of the extra cost through 2030 would be for damage to roads and other transportation infrastructure. 


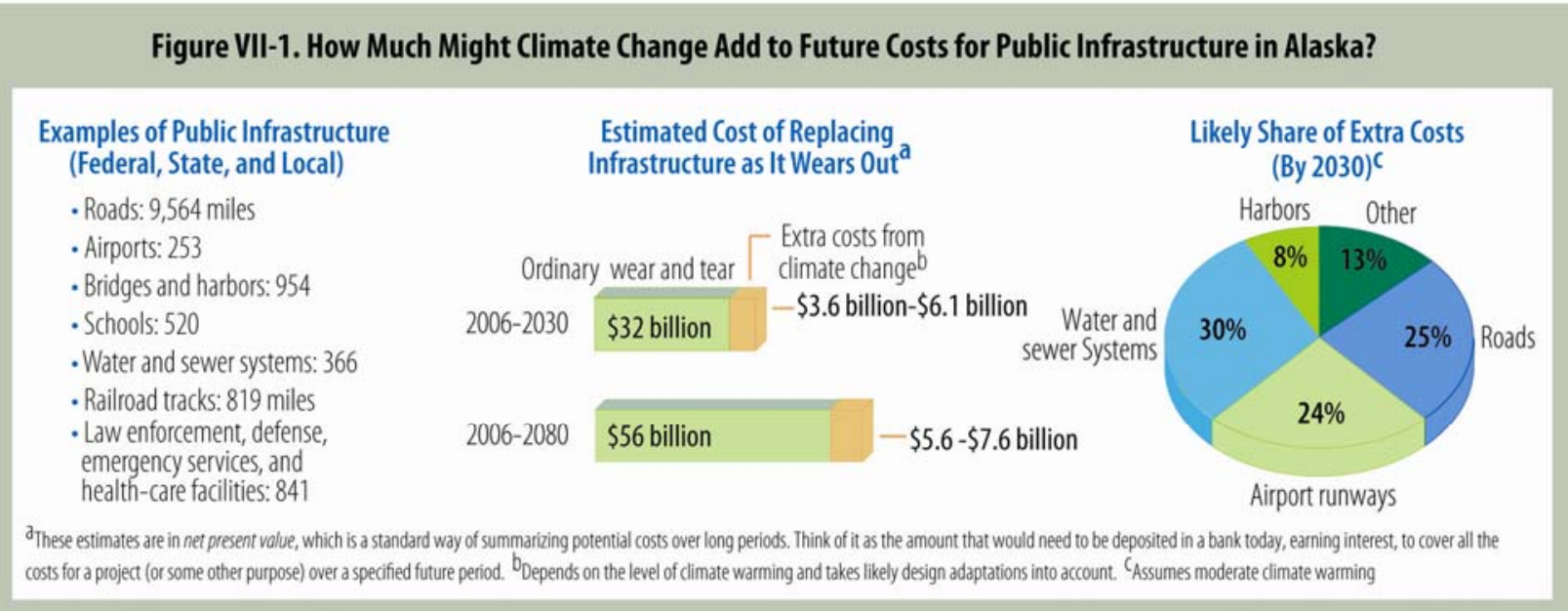

\section{Base Case}

We estimate the net present value cost of maintaining and replacing the existing public infrastructure in Alaska to be $\$ 32$ billion for the next 25 years, to 2030, and $\$ 56$ billion for the next 75 years, to 2080. These figures are the present value of all future construction costs associated with replacing the current infrastructure as is wears out under normal conditions. Roads and airports account for a large share of the total. Table VII-1 shows base case costs by type of infrastructure, through 2030 and through 2080. 
Table VII-1. Base Case (Assumes No Climate Change)

Public Infrastructure Replacement Cost, Net Present Value (In Millions of Dollars)

\begin{tabular}{|l|c|c|}
\hline Public Infrastructure Type & $\mathbf{2 0 0 6 - 2 0 3 0}$ & $\mathbf{2 0 0 6 - 2 0 8 0}$ \\
\hline Airport & $\$ 4,590$ & $\$ 7,989$ \\
\hline Bridges & $\$ 754$ & $\$ 1,312$ \\
\hline Courts & $\$ 309$ & $\$ 538$ \\
\hline Defense & $\$ 25$ & $\$ 43$ \\
\hline Emergency Services & $\$ 99$ & $\$ 172$ \\
\hline Energy & $\$ 4$ & $\$ 8$ \\
\hline Grid & $\$ 93$ & $\$ 162$ \\
\hline Harbor & $\$ 789$ & $\$ 1,374$ \\
\hline Hospital & $\$ 367$ & $\$ 639$ \\
\hline Law Enforcement & $\$ 157$ & $\$ 273$ \\
\hline MiscBuilding_govt & $\$ 982$ & $\$ 1,709$ \\
\hline MiscBuilding_health & $\$ 342$ & $\$ 595$ \\
\hline Railroad & $\$ 1,390$ & $\$ 2,419$ \\
\hline Roads & $\$ 17,022$ & $\$ 29,630$ \\
\hline School & $\$ 587$ & $\$ 1,023$ \\
\hline Sewer & $\$ 3,360$ & $\$ 5,849$ \\
\hline Telecommunications & $\$ 149$ & $\$ 260$ \\
\hline Telephone Line & $\$ 114$ & $\$ 24$ \\
\hline Water & $\$ 1,093$ & $\$ 1,902$ \\
\hline TOTAL & $\$ \mathbf{3 2 , 1 2 6}$ & $\$$ \\
\hline
\end{tabular}




\section{Potential Additional Costs, No Adaptation}

The base case cost estimate provides the benchmark against which we estimate potential additional costs from climate change. Tables VII-2 and VII-3 show estimated additional costs under the three climate projections - from the warm, warmer, and warmest models - assuming no adaptations, through 2030 and 2080. The estimated extra costs between 2006 and 2030 range from about $\$ 3.6$ billion to $\$ 7.0$ billion and between 2006 and 2080 the estimates range from $\$ 6.2$ to $\$ 12.3$ billion.

Table VII-2. Climate Scenarios, Incremental Public Infrastructure Replacement Costs to 2030, Without Adaptation, Net Present Value in Millions of Dollars

\begin{tabular}{|l|c|c|c|}
\hline Public Infrastructure Type & Warm Model & Warmer Model & Warmest Model \\
\hline Airport & $\$ 761$ & $\$ 1,467$ & $\$ 1,634$ \\
\hline Bridges & $\$ 88$ & $\$ 143$ & $\$ 216$ \\
\hline Courts & $\$ 56$ & $\$ 64$ & $\$ 105$ \\
\hline Defense & $\$ 4$ & $\$ 4$ & $\$ 7$ \\
\hline Emergency Services & $\$ 8$ & $\$ 13$ & $\$ 14$ \\
\hline Energy & $\$ 1$ & $\$ 1$ & $\$ 1$ \\
\hline Grid & $\$ 8$ & $\$ 10$ & $\$ 14$ \\
\hline Harbor & $\$ 252$ & $\$ 474$ & $\$ 579$ \\
\hline Hospital & $\$ 54$ & $\$ 70$ & $\$ 115$ \\
\hline Law Enforcement & $\$ 22$ & $\$ 23$ & $\$ 32$ \\
\hline MiscBuilding_govt & $\$ 103$ & $\$ 121$ & $\$ 165$ \\
\hline MiscBuilding health & $\$ 53$ & $\$ 68$ & $\$ 88$ \\
\hline Railroad & $\$ 126$ & $\$ 123$ & $\$ 276$ \\
\hline Roads & $\$ 1,044$ & $\$ 1,522$ & $\$ 1,638$ \\
\hline School & $\$ 84$ & $\$ 116$ & $\$ 137$ \\
\hline Sewer & $\$ 675$ & $\$ 1,419$ & $\$ 1,547$ \\
\hline Telecommunications & $\$ 29$ & $\$ 22$ & $\$ 32$ \\
\hline Telephone Line & $\$ 4$ & $\$ 3$ & $\$ 3$ \\
\hline Water & $\$ 200$ & $\$ 402$ & $\$ 435$ \\
\hline Total & $\$ 3,572$ & $\$ 6,066$ & $\$ 7,038$ \\
\hline
\end{tabular}


Table VII-3. Climate Scenarios, Incremental Public Infrastructure Replacement Costs to 2080, Without Adaptation, Net Present Value in Millions of Dollars

\begin{tabular}{|l|r|r|r|}
\hline Public Infrastructure Type & Warm Model & Warmer Model & Warmest Model \\
\hline Airport & $\$ 1,325$ & $\$ 2,554$ & $\$ 2,844$ \\
\hline Bridges & $\$ 154$ & $\$ 249$ & $\$ 376$ \\
\hline Courts & $\$ 97$ & $\$ 111$ & $\$ 183$ \\
\hline Defense & $\$ 13$ & $\$ 8$ & $\$ 11$ \\
\hline Emergency Services & $\$ 1$ & $\$ 22$ & $\$ 24$ \\
\hline Energy & $\$ 14$ & $\$ 1$ & $\$ 2$ \\
\hline Grid & $\$ 439$ & $\$ 17$ & $\$ 24$ \\
\hline Harbor & $\$ 94$ & $\$ 825$ & $\$ 1,008$ \\
\hline Hospital & $\$ 38$ & $\$ 122$ & $\$ 201$ \\
\hline Law Enforcement & $\$ 180$ & $\$ 41$ & $\$ 56$ \\
\hline MiscBuilding_govt & $\$ 93$ & $\$ 211$ & $\$ 288$ \\
\hline MiscBuilding_health & $\$ 220$ & $\$ 118$ & $\$ 154$ \\
\hline Railroad & $\$ 1,818$ & $\$ 214$ & $\$ 480$ \\
\hline Roads & $\$ 146$ & $\$ 2,650$ & $\$ 2,852$ \\
\hline School & $\$ 1,174$ & $\$ 202$ & $\$ 239$ \\
\hline Sewer & $\$ 50$ & $\$ 2,471$ & $\$ 2,692$ \\
\hline Telecommunications & $\$ 7$ & $\$ 39$ & $\$ 55$ \\
\hline Telephone Line & $\$ 347$ & $\$ 5$ & $\$ 758$ \\
\hline Water & $\$ 6,217$ & $\$ 10,558$ & $\$ 12,251$ \\
\hline Total & & & \\
\hline
\end{tabular}




\section{Infrastructure at Risk, Adjusted for Adaptation}

With event-based adaptation, the potential extra costs resulting from climate change are reduced. For the period 2006-2030 the estimated additional costs range from $\$ 3.6$ to $\$ 6.1$ billion, under the three climate projections. For the longer period, to 2080, extra costs could range from $\$ 5.6$ to $\$ 7.6$ billion. Tables VII-4 and VII-5 shows those estimates, which are in net present value, by type of infrastructure.

Table VII-4. Climate Scenarios With Adaptation, Incremental Public Infrastructure Replacement Costs to 2030, Net Present Value in Millions of Dollars

\begin{tabular}{|l|c|c|c|}
\hline Public Infrastructure Type & Warm Model & Warmer Model & Warmest Model \\
\hline Airport & $\$ 761$ & $\$ 1,453$ & $\$ 1,389$ \\
\hline Bridges & $\$ 88$ & $\$ 140$ & $\$ 190$ \\
\hline Courts & $\$ 56$ & $\$ 64$ & $\$ 105$ \\
\hline Defense & $\$ 4$ & $\$ 4$ & $\$ 7$ \\
\hline Emergency Services & $\$ 8$ & $\$ 13$ & $\$ 14$ \\
\hline Energy & $\$ 1$ & $\$ 1$ & $\$ 1$ \\
\hline Grid & $\$ 8$ & $\$ 9$ & $\$ 12$ \\
\hline Harbor & $\$ 252$ & $\$ 460$ & $\$ 487$ \\
\hline Hospital & $\$ 54$ & $\$ 70$ & $\$ 115$ \\
\hline Law Enforcement & $\$ 22$ & $\$ 23$ & $\$ 32$ \\
\hline MiscBuilding_govt & $\$ 103$ & $\$ 121$ & $\$ 165$ \\
\hline MiscBuilding_health & $\$ 53$ & $\$ 68$ & $\$ 88$ \\
\hline Railroad & $\$ 126$ & $\$ 122$ & $\$ 248$ \\
\hline Roads & $\$ 1,044$ & $\$ 1,492$ & $\$ 1,458$ \\
\hline School & $\$ 84$ & $\$ 116$ & $\$ 137$ \\
\hline Sewer & $\$ 675$ & $\$ 1,391$ & $\$ 1,299$ \\
\hline Telecommunications & $\$ 29$ & $\$ 22$ & $\$ 27$ \\
\hline Telephone Line & $\$ 4$ & $\$ 3$ & $\$ 3$ \\
\hline Water & $\$ 200$ & $\$ 394$ & $\$ 366$ \\
\hline Total & $\$ 3,572$ & $\$ 5,965$ & $\$ 6,143$ \\
\hline
\end{tabular}


Table VII-5. Climate Scenarios, With Adaptation, Incremental Public Infrastructure Replacement Costs to 2080, Net Present Value in Millions of Dollars

\begin{tabular}{|l|c|c|c|}
\hline Public Infrastructure Type & Warm Model & Warmer Model & Warmest Model \\
\hline Airport & $\$ 1,166$ & $\$ 1,762$ & $\$ 1,450$ \\
\hline Bridges & $\$ 140$ & $\$ 185$ & $\$ 225$ \\
\hline Courts & $\$ 96$ & $\$ 91$ & $\$ 123$ \\
\hline Defense & $\$ 7$ & $\$ 7$ & $\$ 8$ \\
\hline Emergency Services & $\$ 13$ & $\$ 19$ & $\$ 17$ \\
\hline Energy & $\$ 1$ & $\$ 1$ & $\$ 1$ \\
\hline Grid & $\$ 13$ & $\$ 14$ & $\$ 15$ \\
\hline Harbor & $\$ 368$ & $\$ 536$ & $\$ 484$ \\
\hline Hospital & $\$ 93$ & $\$ 95$ & $\$ 125$ \\
\hline Law Enforcement & $\$ 38$ & $\$ 34$ & $\$ 38$ \\
\hline MiscBuilding govt & $\$ 178$ & $\$ 179$ & $\$ 201$ \\
\hline MiscBuilding health & $\$ 93$ & $\$ 101$ & $\$ 106$ \\
\hline Railroad & $\$ 207$ & $\$ 173$ & $\$ 297$ \\
\hline Roads & $\$ 1,672$ & $\$ 1,987$ & $\$ 1,711$ \\
\hline School & $\$ 146$ & $\$ 176$ & $\$ 172$ \\
\hline Sewer & $\$ 1,022$ & $\$ 1,680$ & $\$ 1,319$ \\
\hline Telecommunications & $\$ 44$ & $\$ 27$ & $\$ 28$ \\
\hline Telephone Line & $\$ 7$ & $\$ 4$ & $\$ 3$ \\
\hline Water & $\$ 302$ & $\$ 482$ & $\$ 379$ \\
\hline Total & $\$ 5,606$ & $\$ 7,553$ & $\$ 6,703$ \\
\hline
\end{tabular}

Tables VII-6 and VII-7 summarize our estimates of additional costs, under all three climate models, with and without adaptation, by 2030 and by 2080. The potential savings from adaptations are modest at first, but become much more substantial over the long run - as much as $45 \%$ below costs in the no-adaptation case - since agencies have more time to plan and adapt over time.

\begin{tabular}{|l|r|r|r|}
\hline \multicolumn{4}{|l|}{ Table VII-6. Incremental Infrastructure Replacement Cost, 2006-2030, } \\
With and Without Adaptation, Net Present Value, Millions of Dollars \\
\hline & \multicolumn{1}{|c|}{ Warm Model } & \multicolumn{1}{|c|}{ Warmer Model } & Warmest Model \\
\hline $\begin{array}{l}\text { Total with } \\
\text { adaptation }\end{array}$ & $\$ 3,572$ & $\$ 5,965$ & $\$ 6,143$ \\
\hline $\begin{array}{l}\text { Total without } \\
\text { adaptation }\end{array}$ & $\$ 3,572$ & $\$ 6,066$ & $\$ 7,038$ \\
\hline Adaptation Savings & $\mathbf{0 \%}$ & $\mathbf{2 \%}$ & $\mathbf{1 3 \%}$ \\
\hline
\end{tabular}




\begin{tabular}{|l|r|r|r|}
\hline \multicolumn{4}{|l|}{$\begin{array}{l}\text { Table VII-7. Incremental Infrastructure Replacement Cost, 2006-2080, } \\
\text { With and Without Adaptation, Net Present Value, Millions of Dollars }\end{array}$} \\
\hline & \multicolumn{1}{|c|}{ Warm Model } & \multicolumn{1}{|c|}{ Warmer Model } & \multicolumn{1}{c|}{ Warmest Model } \\
\hline $\begin{array}{l}\text { Total with } \\
\text { adaptation }\end{array}$ & $\$ 5,606$ & $\$ 7,553$ & $\$ 6,703$ \\
\hline $\begin{array}{l}\text { Total without } \\
\text { adaptation }\end{array}$ & $\$ 6,217$ & $\$ 10,558$ & $\$ 12,251$ \\
\hline Adaptation Savings & $\mathbf{1 0 \%}$ & $\mathbf{2 8 \%}$ & $\mathbf{4 5 \%}$ \\
\hline
\end{tabular}

The estimates we've just presented are averages, and the extra costs are most likely to fall close to the averages. But climate change projections involve uncertainty, and our model takes that uncertainty into account by estimating a probability distribution of total replacement cost outcomes for each climate-change scenario. In estimating the probability distribution, we took natural year-to-year variability in temperature and precipitation into account, based on historical observations.

Figures VII-2 and VII-3 show the probability distributions for extra costs, under the warm, warmer, and warmest projections, through 2030 and through 2080.

\section{About Shishmaref, Kivalina, and Newtok}

As we noted earlier, the U.S. Army Corps of Engineers has concluded that increasing erosion along the Bering Sea Coast means the villages of Shishmaref, Kivalina, and Newtok will need to be moved in the next 10 to 15 years, at an estimated cost of as much as $\$ 455$ million. We have not included that estimate in our cost projections, because it includes a very wide range of costs associated with relocating entire communities. The corps did not report what share of the total moving costs was specifically for public infrastructure. 
Figure VII-2. Range of Additional Public Infrastructure Costs, 2006-2030, Adaptation Case (In Billions of Dollars, Net Present Value)

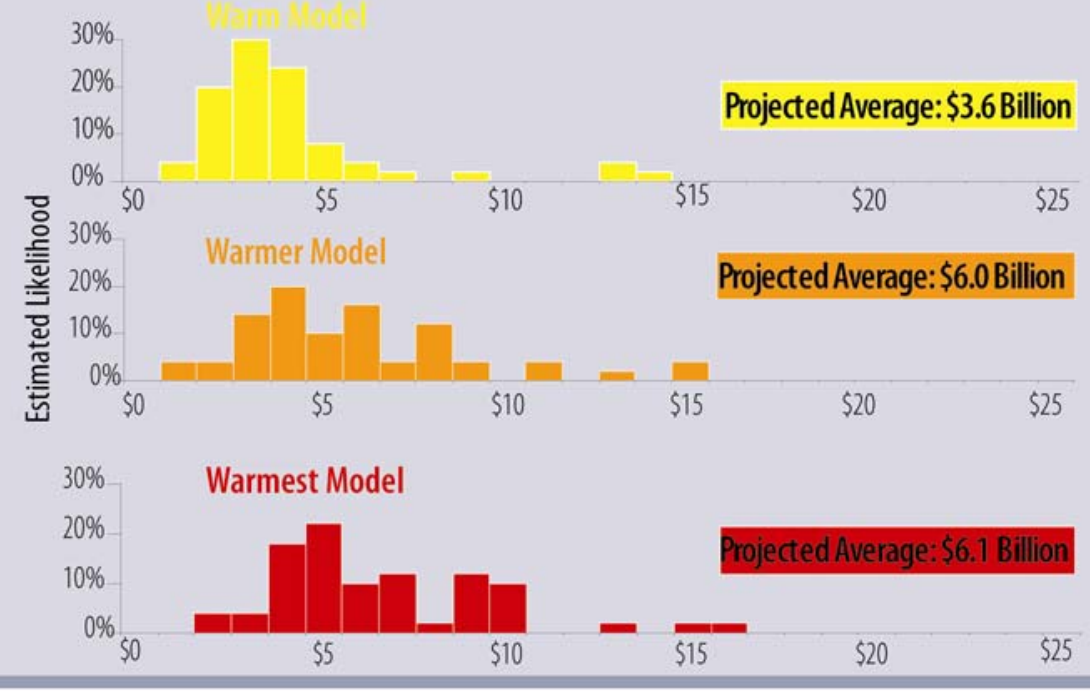

Figure VII-3. Range of Additional Public Infrastructure Costs, 2006-2080, Adaptation Case (In Billions of Dollars, Net Present Value)

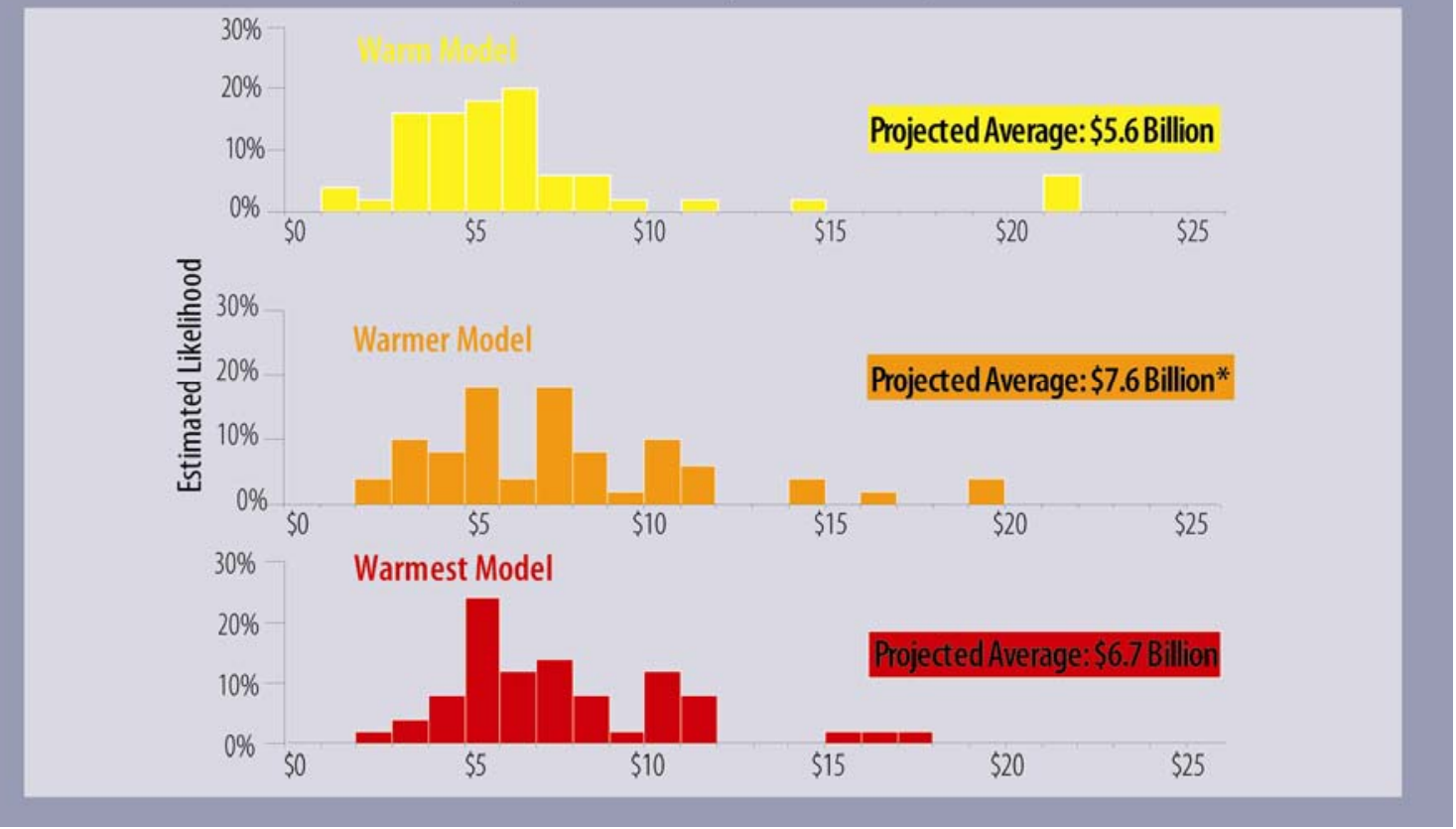




\section{FUTURE DIRECTIONS OF RESEARCH Updates of Climate Projections}

Our technical advisors have indicated that the IPCC climate projections presented in this paper have a useful life of about two to five years. Therefore, if this model proves useful, it will be important to obtain updates of the climate projections.

Also, it might prove useful to study the effects of variations in the level of greenhouse gas emissions controls as they relate to the climate change scenarios. The ISER model was run on climate projections using the IPCC's A1B scenario. Therefore, if climate projections are updated or rerun with different underlying regulatory scenarios (i.e., more stringent regulation of $\mathrm{CO}_{2}$ and methane,) we would be able to test the potential savings for Alaska public infrastructure from different levels of emissions control. For example, if there were to be federal legislation limiting $\mathrm{CO}_{2}$ to year 2000 levels, the model could assess the effect on the cost of public infrastructure in Alaska given the adjusted climate projections (i.e., projected future temperature changes under new emission controls).

If the uncertainty built into the climate projections were available, we could directly incorporate that information into the model, instead of basing the estimates of variability in temperature and precipitation on simple interpretation of historical data.

When more detailed spatial and temporal climate projections become available, we can expand our model to incorporate that information.

\section{Infrastructure Database Refinements}

Agencies like the Denali Commission and the Alaska Department of Commerce, Community, and Economic Development keep fairly comprehensive databases online of the capital investment projects being undertaken across the state. It is important to collaborate with these agencies to get the most up-to-date infrastructure information being collected on the ground. ISER's public infrastructure database needs to be refined with more detailed and current information on the type and location of individual types of infrastructure as well as their replacement cost and age. We are certain there is some under-counting (and probably also overcounting) of infrastructure in the database at this time. 


\section{Refine Rules of Thumb Linking Climate Change to Deterioration}

Much additional work needs to be done refining the links between climate change, environmental conditions, and infrastructure costs. Our rules of thumb use changes in useful life as a proxy for all the effects of climate change on infrastructure. These rules of thumb need to be studied and amplified and the parameter values further investigated.

\section{Refine Adaptation Projections}

Much additional work also needs to be done to investigate the present and potential future adaptation mechanisms that could reduce the infrastructure costs associated with climate change. The initial model work shows that such measures can substantially reduce those costs.

\section{Computer Hardware Upgrade}

The results presented in this paper represent output from a series of SAS programs that are able to estimate the dollar effect on public infrastructure from climate change with probabilities. ${ }^{20}$ Specifically, there are three SAS programs that, when run sequentially, are able to produce the results presented in this paper in about 24 hours. Further enhancements in the models to incorporate more detail or more uncertainty will require additional computer hardware capacity.

\footnotetext{
${ }^{20} \mathrm{SAS}$ is a set of statistical programming software tools that allow social scientists to import data and run sophisticated modeling techniques to produce results and output like you see in this paper.
} 


\section{CONCLUSION}

In this paper, we have presented the preliminary results of a new model for estimating future public infrastructure costs associated with projected climate change in Alaska. The model quantifies the degree to which the public infrastructure is vulnerable, and we hope it can be useful to policymakers considering mitigation and adaptation measures.

We first developed a comprehensive database of Alaska public infrastructure by type and location and estimated the future costs of replacing that infrastructure as it naturally deteriorated. We developed a set of rules of thumb relating changing climate conditions to changing rates at which the infrastructure deteriorated. Then, using climate projections developed by climate researchers, we estimated the effects of temperature and precipitation changes on the rates at which the infrastructure deteriorated and required replacement. The cost of the more frequent replacement due to climate change was the basis for the estimates of public infrastructure at risk. We adjusted these estimates, recognizing that agencies would adapt infrastructure in the face of climate change and try to minimize the costs associated with it.

Our preliminary estimate using these models is that the public infrastructure at risk, or vulnerable, after accounting for likely adaptations, is in the range of $\$ 3.6$ to $\$ 6.1$ billion for the period 2006 to 2030 and from $\$ 5.6$ to $\$ 6.7$ billion, for the longer planning horizon to 2080 . Without adaptations, the long-run costs could be billions of dollars higher.

To put these numbers in perspective, we estimated that without climate change the cost of maintaining and replacing public infrastructure (in net present value) would be $\$ 32$ billion through 2030 and $\$ 56$ billion through 2080. Given the assumptions in our initial model runs, we conclude that projected climate change several decades in the future could increase infrastructure costs roughly $10 \%$ above the costs of normal wear and tear.

In May 2006, the Alaska Legislature passed HCR 30 with unanimous votes in both the House and Senate. That bill created an Alaska Climate Impact Assessment Commission to assess the effects and costs of climate change in Alaska, as well as to develop recommendations for adaptive measures Alaska communities could use. Policymakers need objective analysis of the effects of climate change on the state's critical infrastructure. The work we've described here, while preliminary, does begin to quantify the potential magnitude of the problem in Alaska-and can help Alaskans start thinking about solutions. 


\section{APPENDiX:}

\section{ICICLE ASSUMPTIONS FOR “I-1” MODELING SCENARIO}

\begin{tabular}{|c|c|}
\hline Model Component & Assumption \\
\hline Functional Form: & Probabilistic Lifecycle Analysis \\
\hline Discount Rate: & $2.85 \% /$ year (real) \\
\hline Base Year: & 2006 \\
\hline Projected Years: & 2030,2080 \\
\hline Public Infrastructure Count: & 15,665 Pieces \\
\hline Public Infrastructure Value: & \$39.4 Billion $(\$ 2006)$ \\
\hline Infrastructure Base Costs (per unit): & See Table IV-1 \\
\hline Infrastructure Useful Life by Type: & See Table IV-1 \\
\hline Depreciation Matrix Version: & January 31,2007 \\
\hline Climate Projection Regions: & $\begin{array}{c}5.6^{\circ} \times 5.6^{\circ} \text { Grid Box Centered at Anchorage, Barrow, } \\
\text { Bethel, Juneau, Fairbanks, and Nome }\end{array}$ \\
\hline IPCC SRES Scenario: & A1B \\
\hline Preferred Climate Models: & $\begin{array}{l}\text { CSIRO-Mk3.0 (Australia), MIROC3.2.(HIRES) (Japan), } \\
\text { and NOAA.GFDL-CM2.0 (U.S.) }\end{array}$ \\
\hline Climate Model Base Years: & 1980-1999 \\
\hline Observed Climate Variability Data Source: & University of Alaska Fairbanks Geophysical Institute \\
\hline $\begin{array}{l}\text { Distribution Shape for Observed Regional } \\
\text { Climate: }\end{array}$ & Gaussian \\
\hline Extreme Climate Events Probability: & $\begin{array}{c}\text { Less than } 1^{\text {st }} \text { Percentile, Greater than } 99^{\text {th }} \text { Percentile (for } \\
\text { observed range of climate) }\end{array}$ \\
\hline Extreme Climate Events Scalar: & $+10 \%$ Increase in Impact to Useful Life \\
\hline Natural Variability Forward in Time & Static at Observed Regional Annual Variances \\
\hline TAPS Included in Results: & No 2 \\
\hline Event-based Adaptation: & Yes \\
\hline Infrastructure Growth Forward in Time: & Static at 2006 Count (i.e. 15,653 ) \\
\hline Permafrost State Forward in Time: & Static at 1965 Location (USGS) \\
\hline Impacts from Changes in Relative Sea-level: & Implicit, but not locally projected \\
\hline Software System: & SAS 9.1 TS Level 1M3, XP PRO Platform \\
\hline Hardware System: & $\begin{array}{c}\text { Dell Dimension } 8300 \text { (Intel Pentium } 3.06 \mathrm{GHz} ; 500 \mathrm{~GB} \\
\text { Hard Drive) }\end{array}$ \\
\hline
\end{tabular}




\section{REFERENCES}

Aglan, H., Wendt, R., and Livengood, S. (2004). Field Testing on Energy-Efficient FloodDamage-Resistant Residential Envelope Systems, Oak Ridge National Laboratory, Oak Ridge, Tennessee, June 2004.

Alaska Mapper (Alaska Department of Natural Resources). 2006. State of Alaska Land Records. http://mapper.landrecords.info/. Accessed May 2006.

ANTHC (Alaska Native Tribal Health Consortium) (2005) Infrastructure and Climate Change: Potential Indirect Impacts to Human Health. Prepared for the Sustainable Utilities Work Group, November.

ACIA (2005). Arctic Climate Impact Assessment. Cambridge University Press, Cambridge.

Baillie, R.T. (1996) Long memory processes and fractional integration in econometrics. Journal of Econometrics 73:5-59

Brown, J., M. T. Jorgenson, O.P. Smith, and W. Lee (2003) Long-term rates of coastal erosion and carbon input, Elson Lagoon, Barrow, Alaska. In proceedings of the Eighth International Conference on Permafrost (M. Philips, S.M. Springman, and L.U. Arenson, Ed.). A.A. Balkema, Lisse, p. 101-106.

Bruce C. Douglas and W. Richard Peltier (2002). The Puzzle of Global Sea-Level Rise. Physics Today 55 (3): 35-41. The Puzzle of Global Sea-Level Rise. Physics Today.

Carter, R., C. R. de Freitas, I. M. Goklany, D. Holland, and R. S. Lindzen (2006) The Stern Review: A Dual Critique. Part I: The Science. World Economics, 7(4), October-December.

CEC (Committee on Energy and Commerce) (2002) "The U.S. National Climate Change Assessment: Do the Climate Models Project A Useful Picture of Regional Climate?" Hearing Before the Subcommittee on Oversight and Investigations of the Committee on Energy and Commerce, U.S. House of Representatives, July.

Chapman,W.L. and J.E.Walsh (2003) Observed climate change in the Arctic, updated from Chapman and Walsh, 1993: Recent variations of sea ice and air temperatures in high latitudes. Bulletin of the American Meteorological Society, 74(1):33-47.

Accessed at: http://arctic.atmos.uiuc.edu/

Clemson (1999). What Can Homeowners Do Now, Clemson University Wind Load Test Facility Report, Clemson University.

Cohen, S.J. (ed.), (1997) Mackenzie Basin Impact Study (MBIS) Final Report: Summary Results. Environment Canada, Toronto, ON, Canada, 20 pp. 
Cohen, S., W. Soo Hoo, and M. Sumitani (2005) Climate Change Will Impact the Seattle Department of Transportation. Office of City Auditor, Seattle, Washington. August.

Cole, H., V. Colonell, and D. Esch (1999) "The Economic Impact and Consequences of Global Climate Change on Alaska's Infrastructure" in Assessing the Consequences of Climate Change for Alaska and the Bering Sea Region. Workshop proceedings summarized for the U. S. Global Change Research Program, University of Alaska Fairbanks, pp 43-56.

Curtis, J., G. Wendler, R. Stone, and E. Dutton (1998): Precipitation Decrease in the Western Arctic, with Special Emphasis on Barrow and Barter Island, Alaska. International Journal of Climatology, 18: 1687-1707

ESRI (Environmental Systems Research Institute) (2006). ESRI Support. www.esri.com Accessed September 2006.

FEMA (1995). Seismic Considerations for Communities at Risk, Federal Emergency Management Agency, FEMA 83, September 1995.

FEMA (1998). Promoting the Adoption and Enforcement of Seismic Building Codes, Federal Emergency Management Agency, FEMA 313, September 1998.

Florida (1996). Assessment of Damage to Homes Caused by Hurricane Opal, Florida State Homebuilders Association, January 1996.

Florida (2002). Florida Building Code Cost and Loss Reduction Benefit Comparison Study, Florida Department of Community Affairs, January 2002.

Forest, C. et al (2002) Quantifying Uncertainties in Climate System Properties with the Use of Recent Climate Observations. Science 295, 113.

GAO (United States General Accounting Office) (2004) Alaska Native Villages: Villages Affected by Flooding and Erosion Have Difficulty Qualifying for Federal Assistance. Statement of Robert A. Robinson, Managing Director Natural Resources and Environment. June.

Greene, William (2003), Econometric Analysis, Fifth Edition. Prentice Hall. pp 919-946.

Hamlen, S. (2004) United Utilities Memo to Kate Giard Requesting a UUI Supplementary Funding Request, September.

Harrod M., P. Larsen, J. Lazo, and D. Waldman (2007) Sensitivity of U.S. Economic Sectors to Weather Variability. Submitted to the American Economic Review. Boulder, April.

Hayes (2005) Infrastructure: A Field Guide to the Industrial Landscape. Published by W.W. Norton and Company. New York City, New York. 
Houghton, J. T., Y. Ding, D. J. Griggs, M. Noguer, P. J. van der Linden, D. Xiaosu, and K. Maskell (eds.) (2001). Climate Change 2001: The Scientific Basis. New York: Cambridge University Press.

Instanes, A., Anisimov, O., Brigham, L., Goering, D., Khrustalev, L., Ladanyi, B., and J. Larsen (2005), "Infrastructure: Buildings, Support Systems, and Industrial Facilities," Ch. 16, Arctic Climate Impact Assessment, Cambridge University Press.

IPCC (2001): Climate Change 2001: The Scientific Basis. Contribution of Working Group I to the Third Assessment Report of the Intergovernmental Panel on Climate Change [Houghton, J.T.,Y. Ding, D.J. Griggs, M. Noguer, P.J. van der Linden, X. Dai, K.

Maskell, and C.A. Johnson (eds.)]. Cambridge University Press, Cambridge, United Kingdom and New York, NY, USA, 881pp.

Jollands, N., M. Ruth, C. Bernier, N. Golubiewski, R. Andrew, and V. Forgie (2005), “Climate's Long-term Impacts on New Zealand Infrastructure: Hamilton City Case Study." New Zealand Centre for Ecological Economics, July.

Jorgenson, D., R. Goettle, B. Hurd, and J. Smith (2004), “U.S. Market Consequences of Global Climate Change" Prepared for the Pew Center on Global Climate Change, April.

JPO (Joint Pipeline Office) (2001) A look at Alyeska Pipeline Service Company's operation of the Trans-Alaska Pipeline System 1999/2000. Alyeska Pipeline Service Company.

Kirshen, P., W. Anderson, M. Ruth, and T. Lakshmanan (2004): Infrastructure Systems, Services and Climate Change: Integrated Impacts and Response Strategies for the Boston Metropolitan Area. EPA Grant Number: R.827450-01. August.

Lavallee, D. and H. Beltrami (2004) Stochastic modeling of climatic variability in dendrochronology. Geophysical Research Letters, 31, L15202 doi:10.1029/2004GL020263, 2004.

London Climate Change Partnership (2002). London's Warming: The Impacts of Climate Change on London, Technical Report.

Lonergan, S., R. Difrancesco, and M. Woo (1993), "Climate change and Transportation in Northern Canada: An Integrated Impact Assessment”, Climatic Change, V24, 331-351, August.

Mandelbrot, B. and R. Hudson (2004) The (Mis)Behavior of Markets: A Fractal View of Risk, Ruin, and Reward. Perseus Books Group, New York.

Mastrandrea, M.D. and S. H. Schneider (2004) "Probabilistic Integrated Assessment of 'Dangerous' Climate Change.” Science, V304, pp 571-575.

McBeath J. (2003) Institutional Responses to Climate Change: The Case of the Alaska Transportation System. Mitigation and Adaptation Strategies for Global Change, 8, 3-28. 
McGuinness, S. and C. Tebaldi (2006): PCMDI Climate Projections for Alaska. AOGCM output provided with assistance from Lawrence Livermore National Laboratory and National Center for Atmospheric Research. July.

Mendelsohn, R.O., W. Morrison, M.E. Schlesinger, and N.G.Andronova (2000), "Country specific market impacts of climate change", Climatic Change, 45, 553-569.

Moteff, J., C. Copeland, and J. Fischer (2003) Critical Infrastructure: What makes an Infrastructure Critical? Report for Congress Prepared by the Congressional Research ServiceResources, Science and Industry Division, January.

Mount, T. (2006) Personal communication with Peter Larsen regarding underlying distributional shapes of long-run, unmeasurable climate observations. Cornell University's Department of Applied Economics and Management, December.

Nakićenović, N. and Swart, R. (Eds.), (2000) Special Report on Emissions Scenarios, Cambridge University Press, Cambridge, UK.

Nelson, F., Brigham, L., Hinkel, K., Parker, W., Romanovsky, V., Shiklomanov, N., Smith, O., Tucker, W., and Vinson, T., "Climate Change, Permafrost, and Impacts on Civil Infrastructure," Special Report 01-03, US Arctic Research Commission, 2003.

Nordhaus, W.D. and Z.Yang (1996), 'RICE: A Regional Dynamic General Equilibrium Model of Optimal Climate-Change Policy', American Economic Review, 86, (4), 741765.

Nordhaus, William (2006), 'The Stern Review on the Economics of Climate Change', http://nordhaus.econ.yale.edu/SternReviewD2.pdf

Nordhaus, W. D. and J. Boyer (2000) Warming the World: Economic Models of Global Warming. Cambridge, Mass.: MIT Press.

Osterkamp, T.E., D.C. Esch, and V.E. Romanovsky (1998) Permafrost. In Implications of Global Change in Alaska and the Bering Sea Region: Proceedings of a Workshop (G. Weller and P.A. Anderson, Ed.). Center for Global Change and Arctic System Research, University of Alaska Fairbanks, p. 115-127.

Overland, J. E. and M. Wang, (2005): The Arctic climate paradox: The recent decrease of the Arctic Oscillation - art. no. L06701, Geophys. Res. Lett., 32, 6701.

Rayner, S. and E. Malone (eds) (1998) Human choice and climate change: The tools for policy analysis. Battelle Press, Volume 3. p. 44. 
Robinson, S.D., R. Couture, M.M. Burgess, and S. Smith, (in prep.) Climate change and infrastructure in northern permafrost-affected communities: potential impacts and adaptations. For submission to Adaptations and Mitigation of Climate Change.

Romanovsky, V., S. Smith, K. Yoshikawa, and J. Brown (2002) Permafrost temperature records: Indicators of climate change. Eos, Transactions, American Geophysical Union, 83(50), 589 and 593-594.

Rosenzweig, C. and W.D. Solecki (Eds.). (2001) "Climate Change and a Global City: The Potential Consequences of Climate Variability and Change - Metro East Coast (MEC)." Report for the U.S. Global Change Research Program, National Assessment of the Potential Consequences of Climate Variability and Change for the United States, Columbia Earth Institute, New York. 224 pp.

Samuelson, P.A. (1964) Tax deductibility of economic depreciation to insure invariant valuations. Journal of Political Economy 72(4), 604-606

SAS (Statistical Analysis System) (2007) SAS V9.1 PROC IML Language Reference Document. Chapter 20. SAS Institute. Cary, NC.

Schar, C., P. L. Vidale, D. L"uthi, C. Frei, C. H“aberli, M. A. Liniger, and C. Appenzeller (2004). The role of increasing temperature variability in European summer heatwaves. Nature 427 (322), 332-336. doi:10.1038/nature02300.

Smith, J.B., H.-J. Schellnhuber, M.M.Q. Mirza, S. Fankhauser, R. Leemans, E. Lin, L. Ogallo, B. Pittock, R.G. Richels, C. Rosenzweig, R.S.J. Tol, J.P. Weyant and G.W. Yohe (2001), 'Vulnerability to Climate Change and Reasons for Concern: A Synthesis', Chapter 19, pp. 913-967, in J.J. McCarthy, O.F. Canziani, N.A. Leary, D.J. Dokken and K.S. White (eds.), Climate Change 2001: Impacts, Adaptation, and Vulnerability, Cambridge University Press, Cambridge.

Smith, J.B. and C. Wagner. (2006) Scenarios for the National Commission on Energy Policy. Memorandum to Peter Larsen from Stratus Consulting Inc., Boulder, CO. August.

Snowchange (2005) "Stories of the Raven: An International Workshop on Indigenous Observations of Ecological and Climate Change," Anchorage, Alaska.

Soo Hoo, W., Sumitani, M., Cohen, S. (2005), “Climate Change Will Impact the Seattle Department of Transportation," Office of City Auditor, Seattle.

State of Alaska Department of Transportation and Public Facilities, Bridge Section. (2005). 2005 Bridge Inventory Report. Accessed July 2006. (http://www.dot.state.ak.us/stwddes/desbridge/assets/pdf/2003bridgeinventory.pdf).

Stein, Seth and Tomasello, Joseph (2004). "When Safety Costs Too Much," The New York Times, January 10, 2004. 
Stern, N., S.Peters, V.Bakhshi, A.Bowen, C.Cameron, S.Catovsky, D.Crane, S.Cruickshank, S.Dietz, N.Edmonson, S.-L.Garbett, L.Hamid, G.Hoffman, D.Ingram, B.Jones, N.Patmore, H.Radcliffe, R.Sathiyarajah, M.Stock, C.Taylor, T.Vernon, H.Wanjie, and D.Zenghelis (2006), Stern Review: The Economics of Climate Change, HM Treasury, London.

Stern, N. (2007) The Stern Review: The Economics of Climate Change. Cambridge University Press, January.

Tebaldi, C., R. Smith, D. Nychka, and L. Mearns (2005): Quantifying Uncertainty in Projections of Regional Climate Change: A Bayesian Approach to the Analysis of Multimodel Ensembles. Journal of Climate, V18. pp 1524-1540.

Tebaldi, C., L. Mearns, D. Nychka, and R. Smith (2004): Regional probabilities of precipitation change: A Bayesian analysis of multimodel simulations. Geophysical Research Letters, V31. L24123.

Tol, R.S.J. and S. Fankhauser (1998), 'On the Representation of Impact in Integrated Assessment Models of Climate Change', Environmental Modelling and Assessment, 3, 63-74.

Tol, R.S.J., and G. Yohe (2006), 'A Review of the Stern Review', World Economics, 7 (4), October-December.

Tol, R.S.J. (2006), "The Stern Review of the Economics of Climate Change: A Comment" Economic and Social Research Institute, October.

Toman, M. (1998) Research Frontiers in the Economics of Climate Change. Resources for the Future Discussion Paper 98-32. April.

UAFGI (University of Alaska Fairbanks Geophysical Institute) (2006) Monthly Time-Series Data of Temperature and Precipitation for Alaska. Accessed at: http://climate.gi.alaska.edu/Climate/Location/TimeSeries/index.html, August.

UCAR (University Corporation for Atmospheric Research) (2007) Most of Arctic's Near-Surface Permafrost May Thaw by 2100. Press Release. Accessed at: http://www.ucar.edu/news/releases/2005/permafrost.shtml, January.

USARC (United States Arctic Research Commission) (2003) Climate Change, Permafrost, and Impacts on Civil Infrastructure. Permafrost Task Force Report, Special Report 01-03, United States Arctic Research Commission, Arlington, Virginia.

United States Army Corps of Engineers (2006) An Examination of Erosion Issues in the Communities of Bethel, Dillingham, Kaktovik, Kivalina, Newtok, Shishmaref, and Unalakleet. Alaska Village Erosion Technical Assistance Program. April. 
USBLS (United States Bureau of Labor Statistics) (2007) Producer's Price Index for Commodities. Accessed at: http://data.bls.gov/PDQ/servlet/SurveyOutputServlet, January.

USDA (United States Department of Agriculture) (2007) Discount Rates for Water Resources Projects. Natural Resources Conservation Service. Accessed at: http://www.economics.nrcs.usda.gov/cost/discountrates.html, January.

U.S. General Accountability Office (2004). Alaska Native Villages: Villages Affected by Flooding and Erosion Have Difficulty Qualifying for Federal Assistance. Statement of Robert A. Robinson, managing director, Natural Resources and Environment. June.

USGS (United State Geological Services). (2006). Permafrost Map of Alaska-Metadata Information. http://agdcftpl.wr.usgs.gov/pub/projects/fhm/permafrost.html Accessed September 2006.

Walsh, J. (2006) Personal communication with Peter Larsen commenting on the conclusions of Kerr et al (2007). Sent by electronic mail on January 10, 2007.

Weller, G., P. Anderson and B.Wang (eds.) (1999) Preparing for a Changing Climate:The Potential Consequences of Climate Change and Variability. A Report of the Alaska Regional Assessment Group for the U. S. Global Change Research Program, University of Alaska Fairbanks, 42p.

Yohe, G., J. Neumann, P. Marshall, H. Amaden (1996). The economic cost of greenhouse gas induced sea-level rise for developed property in the United States. Climatic Change 32(3), 387410 .

Yohe, G. and Tol, R.S.J. (2002): Indicators for social and economic coping capacity-moving toward a working definition of adaptive capacity; Global Environmental Change-Human and Policy Dimensions, v. 12, p. 25-40. 
